\title{
Analysis Of Membrane Transporter Systems Expressed During Symbiotic Nitrogen Fixation In The Model Legume Medicago Truncatula
}

Christina Laureen Wyman

Follow this and additional works at: https://researchrepository.wvu.edu/etd

\section{Recommended Citation}

Wyman, Christina Laureen, "Analysis Of Membrane Transporter Systems Expressed During Symbiotic Nitrogen Fixation In The Model Legume Medicago Truncatula" (2018). Graduate Theses, Dissertations, and Problem Reports. 7280.

https://researchrepository.wvu.edu/etd/7280

This Dissertation is protected by copyright and/or related rights. It has been brought to you by the The Research Repository @ WVU with permission from the rights-holder(s). You are free to use this Dissertation in any way that is permitted by the copyright and related rights legislation that applies to your use. For other uses you must obtain permission from the rights-holder(s) directly, unless additional rights are indicated by a Creative Commons license in the record and/ or on the work itself. This Dissertation has been accepted for inclusion in WVU Graduate Theses, Dissertations, and Problem Reports collection by an authorized administrator of The Research Repository @ WVU.

For more information, please contact researchrepository@mail.wvu.edu. 


\title{
ANALYSIS OF MEMBRANE TRANSPORTER SYSTEMS EXPRESSED DURING SYMBIOTIC NITROGEN FIXATION IN THE MODEL LEGUME MEDICAGO TRUNCATULA
}

\author{
Christina Laureen Wyman \\ Dissertation submitted to \\ Davis College of Agriculture, Natural Resources and Design \\ at West Virginia University \\ in partial fulfilment of the requirements for the degree of
}

\author{
Doctor of Philosophy \\ in \\ Genetics and Developmental Biology
Vagner Benedito, Ph.D., Chair Jonathan Cumming, Ph.D. Daniel Panaccione, Ph.D.
Nicole Waterland, Ph.D. Jianbo Yao, Ph.D. \\ Division of Plant and Soil Sciences
}
Morgantown, West Virginia
2018

Keywords: legume, Medicago truncatula, transporter, amino acid, copper

Copyright 2018 Christina Laureen Wyman 


\section{ABSTRACT}

\section{ANALYSIS OF MEMBRANE TRANSPORTER SYSTEMS EXPRESSED DURING SYMBIOTIC NITROGEN FIXATION IN THE MODEL LEGUME MEDICAGO TRUNCATULA}

\section{Christina Laureen Wyman}

As the second largest crop family, legumes provide a significant component to the human diet as well as livestock nutrition through forage species. Unique from most other plants groups, legumes are able to form a symbiosis with naturally occurring soil rhizobia, diazotrophs, which are able to reduce atmospheric nitrogen to usable forms of nitrogen for the plant. In return for providing reduced nitrogen, differentiated rhizobia are sustained by dicarboxylates, branched chain amino acids, and other nutrients from the plant. In order for the movement of nutrients to be translocated between symbionts and from the cytosol to cell organelles, other cells, and plant tissues, membrane transporters must be present to move substrates across lipid bilayers. Secondary transporters supply the necessary amino acids and additional nutrients to and from the nitrogen fixation zone of nodules to support symbiotic nitrogen fixation. While the biosynthesis pathways of amino acids to feed symbiosis is well understood, the involved transporters, including importers and exporters, of amino acids, as well as transporters of other nutrients to support infected cells are largely unknown and relatively few transporters have been functionally characterized in legumes. In order to assess potential amino acid transporters, I performed a genomic inventory of putative transporters belonging to the Amino Acid Polyamine-Organocation superfamily by compiling a list of transporters classified under the superfamily in the Transporter Classification Database, along with their protein size, transmembrane domains (TMDs), and compared them to characterized members of transporter families to determine confidence of functionality. I also compiled expression data to determine expression patterns to manually annotate candidate nodule specific transporters of interest for further study. Using the model species Medicago truncatula to study symbiotic nitrogen fixation, I genetically characterized the nodule specific membrane transporter, MtAPC1 through in silico analysis of expression patterns, followed by transcriptional analysis of inoculation with rhizobial mutants to determine essential steps of infection necessary for gene expression. Transcriptional activity of MtAPC1 was also fine-tuned to identify cell-type 
within the nodule and the impact of the MtAPC1 knockdown in nodule development during symbiotic nitrogen fixation. I also characterized expression patterns of a copper transporter, MtCOPT1, regarding its transcriptional activity in nodules and its capability of importing copper into the cell cytosol. In addition, I preliminarily analyzed of two putative nodule-specific transporters, MtSEN1 and MtOPT1 for iron and short oligopeptides (3-8 amino acids in length) though in silico analysis with publicly available datasets, as well as determined expression patterns by RT-qPCR of nodulating root inoculated with rhizobial mutants and wild-type rhizobia. 


\section{ACKNOWLEDGEMENTS}

First and foremost, I would like to thank my wonderful doctoral advisor, Dr. Vagner Benedito. For the last eight years, he has dedicated countless hours to helping me grow as a scientist in both lab methods, techniques, and skills, as well as in the fundamental understanding of legume biology and specifically membrane transporters. His enthusiasm for legume biology is contagious and our weekly meetings allowed rich discussion and encouraged me to be the best scientist I could be. His continual support and guidance through this journey has been invaluable. I will be forever grateful to him for the time he has dedicated and the opportunity he has afforded me to grow and develop not only as a scientist, but as a person.

I am also grateful for my graduate committee members - Dr. Nicole Waterland, Dr. Daniel Panaccione, Dr. Jianbo Yao, and Dr. Jonathan Cumming for providing valuable feedback throughout my research project and graduate studies. I particularly appreciate Dr. Nicole Waterland's gracious sharing of lab equipment to enable my research project.

I am thankful for my labmates through-out this process, Drs. Lucas Maia and Lina Yang, with whom I spent many hours discussing lab experiments and conceptual ideas. Lucas was always a happy face to see in the lab and I enjoyed the time we spent in our lab and office, but also the time we spent as friends.

Thank you to Dr. Dana Huebert-Lima who gave me teaching opportunities in biology and mentored and encouraged me these last few years.

Last, but not least, a special thanks to my Mom and Dad for their love, support, and encouragement throughout this entire process. They are my own personal cheerleaders and have provided unconditional love and support at every stage of my life and they mean the world to me. 


\section{TABLE OF CONTENTS}

$\begin{array}{lll}\text { ABSTRACT } & \text { ii }\end{array}$

ACKNOWLEDGEMENTS

TABLE OF CONTENTS $\quad$ v

LIST OF FIGURES Nii

LIST OF TABLES $\quad$ X

CHAPTER 1 - Overview and Objectives 1

References 3

CHAPTER 2 - Symbiotic nitrogen fixation in legume crops are supported by membrane transporters enabling nutritional flux

Abstract

Introduction

References

CHAPTER 3 - Identification of Membrane Transporters of the Amino Acid PolyamineOrganocation (APC) Superfamily in Medicago truncatula Reveals Key Candidates for Amino Acid Transporter in Root Nodules

Abstract

Introduction

Materials and Methods

References

CHAPTER 4 - Functional characterization of the Medicago truncatula nodule-specific amino acid transporter MtAPC1

Abstract

Introduction

Results and Discussion

Conclusion

Materials and Methods

References

CHAPTER 5 - Functional characterization of the Medicago truncatula nodule-specific copper transporter MtCOPT1

Abstract

Introduction

Results and Discussion

83

Conclusion

94

Materials and Methods 
CHAPTER 6 - Introducing additional nodule specific membrane transporters as potential essential participants in symbiotic nitrogen fixation in Medicago truncatula

Abstract

Introduction

108

Results and Discussion

109

Conclusion

120

Materials and Methods

120

References

122

CHAPTER 7 - General Conclusions

126 


\section{LIST OF FIGURES}

Medicago truncatula trifoliate leaf and twenty-one day old plants 5

$\begin{array}{ll}\text { Medicago truncatula cv. 'A17’ nodules } & 10\end{array}$

$\begin{array}{ll}\text { Types of membrane transporters } & 12\end{array}$

Infected nodule cells in the nitrogen fixation zone of Medicago truncatula 15

$\begin{array}{ll}\text { Simplified diagram of an infected nodule cell } & 16\end{array}$

$\begin{array}{lr}\text { Nitrogen assimilation and the nitrogen cycle within nodules } & 29\end{array}$

APC Superfamily evolutionary relationships 31

Expression of APC Superfamily members in organs 36

Expression of APC Superfamily members in nodule zones 37

Phylogenetic analysis of all prokaryotic and eukaryotic CAT subfamily transporters $\quad 40$

$\begin{array}{lr}\text { Nitrogen assimilation cycle in legumes } & 50\end{array}$

Phylogenetic tree of the six Medicago truncatula CAT transporters and gene architecture 54

Map of chromosome 8 with expanded view of MtAPC1 55

Protein alignment of the CAT membrane transporters in Medicago truncatula 56

Membrane topology of MtAPC1 57

Expression profile of the nodule-specific MtAPC1 gene 58

Expression of MtAPC1 by real-time PCR analysis 59

MtAPC1 RNAi nodules and Real-Time qPCR expression profile $\quad 60$

In situ hybridization of mature nodule sections using MtAPC1 probe 61

Epidermal peel of Nicotiana benthamiana leaf after infiltration with MtAPC1 62

$\begin{array}{ll}\text { Amino acid import assay in yeast strain 22 } \Delta 10 \mathrm{AA} & 63\end{array}$

Gene network centered on MtAPC1 64 
Phylogenetic analysis of all members of the Ctr/COPT channel family

Molecular phylogenetic tree of the complete Ctr protein family

Phylogenic tree of the eight Medicago truncatula COPT family members

and gene architecture

Predicted gene architecture and protein sequence of nodule-specific MtCOPT1 88

Membrane topology of MtCOPT1 89

Protein sequencing analysis of MtCOPT1 in the Medicago Protein Compendium 99

Transcriptional profile of the MtCOPT1 gene

RT-qPCR of MtCOPT1 in root systems of Medicago truncatula ecotype 'R108' inoculated with Sm1021 rhizobia

Copper import assays for MtAPC1

Gene network centered on MtCOPT1 gene

MtOPT1 and closely related genes chromosomal location, gene architecture and organ expression

Molecular Phylogenetic analysis of MtOPT and all eukaryotic OPT homologs in TCDB

Molecular Phylogenetic analysis of the complete OPT gene family in Medicago truncatula and Arabidopsis thaliana

Protein alignment of MtOPT1 and two closely related proteins

Membrane topology of MtOPT1

RT-qPCR analysis of MtOPT1 in root systems of Medicago truncatula ecotype 'R108' inoculated with Sm1021 rhizobia

Expression profile of MtSEN1 gene

Gene structure of MtSEN1

Membrane topology of MtSEN1

Molecular Phylogenetic of MtSEN1, Medicago truncatula family members, Arabidopsis, and homologs 
RT-qPCR of MtSEN1 in root systems of Medicago truncatula ecotype 'R108' inoculated with Sm1021 rhizobia 


\section{LIST OF TABLES}

$\begin{array}{ll}\text { Comparison of the three model legume systems } & 7\end{array}$

Functionally characterized membrane transporters in the model legumes 14

The APC family proper subfamilies $\quad 33$

Transporter identification of the Medicago truncatula proteome 34

Functionally characterized CAT transporters in Arabidopsis thaliana 38

Similarity matrix of Medtr8g089320.1, Medtr8g089340.1, and Medtr8g089360.1 protein sequences

Comparative Genomics analysis of APC tandem duplications using CoGe

63 


\section{Chapter 1}

\section{OVERVIEW AND OBJECTIVES}

Membrane transporters are ubiquitous in all biological membranes to translocate substrates essential to cell function. In legumes, during symbiotic nitrogen fixation, the nutritional flux between plant organs and rhizobia are sustained by substrate specific membrane transporters. The biosynthesis pathways of amino acids and other substrates feeding symbiosis are well understood, but the importers and exporters for amino acids, as well as some essential substrates of symbiotic nitrogen remain chiefly unknown. Given the central role of transporting substrates to bacteroids and also the return of nutrients to the plant cytosol, across plasma membranes to other cells, and the export of substrates to the xylem and sink tissues, our current lack of knowedge involving transporters needs to be addressed. Functional characterization of proteins involved in transport is required to fully understand the involved genes and essential components to support the dynamic symbiotic nitrogen fixation process.

The purpose of my dissertation work was to reanalyze putative transporters from the Medicago truncatula proteome and classify confidence levels of functionality based on transporter classification families (TCDB.org; Saier et al., 2016), as well as SwissProt annotation (Boeckmann et al., 2003), Gene Ontology (GO) classification (Ashburner et al., 2000; The Gene Ontology Consortium, 2017), and expected Pfam domains (Finn et al., 2016), as described in Benedito et al. (2010). This reannotation was performed to identify transporters of interest in the study of symbiotic nitrogen fixation and the Amino Acid Polyamine-Organocation (APC) Superfamily of transporters. In addition, this work was carried out to functionally characterize nodule specific transporters involved in the nitrogen fixation process to provide information about expression patterns, transcriptional activity, and impacts of gene knockdown of transporter proteins.

\section{Specific Aim 1 - Genomic inventory of putative transporters belonging to the APC} superfamily. In Chapter 3, I compiled a list of transporters classified under the APC Superfamily in the Transporter Classification Database and compared their protein size and TMDs to characterized members of transporter families to determine confidence of functionality. I also 
compiled expression data to determine expression patterns to manually annotate candidate nodule specific transporters of interest for further study.

Specific Aim 2 - Genetic characterization of the nodule-specific MtAPC1 (Medtr8g089360.1) transporter during symbiotic nitrogen fixation. In Chapter 4, I further characterized a nodule-specific APC transporter by in silico analysis of expression patterns, followed by transcriptional analysis of inoculation with rhizobial mutants to determine essential steps of infection necessary for gene expression. I also fine-tuned the MtAPC1 transcriptional activity to cell-type within the nodule and determined the impact of the MtAPC1 knockdown in nodule development during symbiotic nitrogen fixation.

Specific Aim 3 - Functionally characterization of the nodule-specific MtCOPT1 (Medtr4g019870.1) transporter. In Chapter 5, I characterized expression patterns of a copper transporter regarding its transcriptional activity in nodules and its capability of importing copper into the cell cytosol.

Specific Aim 4 - Objective: Preliminarily analyses of two nodule-specific transporters, MtOPT1 (Medtr7g092230.1) and MtSEN1 (Medtr4g094335.1). In Chapter 6, I carried out analyses of gene expression for two nodule-specific putative transporters for iron and short oligopeptides (3-8 amino acids in length) through in silico analysis with publicly available datasets, as well as determined expression patterns by RT-qPCR of nodulating root inoculated with rhizobial mutants and wild-type rhizobia. This work will serve as a launchpad to further functional characterization of these transporters in order to find their roles to sustain symbiotic nitrogen fixation. 


\section{REFERENCES}

Ashburner M, et al (2000) Gene ontology: tool for the unification of biology. Nature Genetics 25: 25-29

Benedito VA, Li H, Dai X, Wandrey M, He J, Kaundal R, Torres-Jerez I, Gomez SK, Harrison MJ, Tang Y, Zhao PX, Udvardi MK (2010) Genomic inventory and transcriptional analysis of Medicago truncatula transporters. Plant Physiology 152: 1716-1730

Boeckmann B, Bairoch A, Apweiler R, Blatter MC, Estreicher A, Gasteiger E, Martin MJ, Michoud K, O'Donovan C, Phan I, et al (2003) The SWISS-PROT protein knowledgebase and its supplement TrEMBL in 2003. Nucleic Acids Research 31: 365-370

Finn RD, Coggill P, Eberhardt RY, Eddy SR, Mistry J, Mitchell AL, et al (2016) The Pfam protein families database: towards a more sustainable future. Nucleic Acids Research 44: 279-285

The Gene Ontology Consortium (2017) Expansion of the Gene Ontology knowledgebase and resources. Nucleic Acids Research 45: 331-338

Saier MH, Reddy VS, Tsu BV, Ahmed MS, Li C, Moreno-Hagelsieb G (2016) The Transporter Classification Database (TCDB): recent advances. Nucleic Acids Research 44: 372-379 


\title{
Chapter 2
}

\section{Symbiotic nitrogen fixation in legume crops are supported by membrane transporters enabling nutritional flux}

\begin{abstract}
Worldwide, legumes provide a significant component of human diets and are essential to the industrial livestock production. Legumes (Fabaceae) are the second largest crop family, after cereals and the third botanical family, after Asteraceae and Orchidaceae, with over 20,000 species including the common bean, chickpea, soybean, peanuts and forage species. Unique from most other plants, many legume species can utilize atmospheric nitrogen, thus reducing the amount of synthetically-fixed nitrogen fertilizers applied to agricultural systems. The reduction of atmospheric nitrogen into usable forms to the plant is attained through a species-specific symbiosis with naturally occurring soil rhizobia in specialized root structures called nodules. The nutritional flux between rhizobia and plant organs is sustained by membrane transporters with affinity to specific molecules. The transporters that provide movement of nutrients are essential to the symbiotic nitrogen fixation process and the main focus of interest to our lab. In this chapter, I introduce legume biology and the importance of legumes for sustainable agriculture, make a case for using Medicago truncatula as a model system, explain why membrane transporters are central for symbiotic nitrogen fixation in the legume-rhizobial system, and present the outstanding scientific questions in the field.
\end{abstract}




\section{INTRODUCTION}

\section{Importance of legumes and symbiotic nitrogen fixation to agriculture}

Throughout the world, legumes (Fabaceae) encompass an important component of the human diet and account for approximately one third of the world's primary crop production (Smil, 1999; Vance et al., 2003). Legumes are the second largest agricultural family in the world, only behind cereals, providing both oils and protein to humans and animals. One hundred eighty million hectares of legumes are grown yearly, encompassing $12-15 \%$ of the Earth's arable surface (Graham and Vance, 2003; Reeves et al., 2016), which is larger than the total area of Alaska. Some well-known legumes include pulses (edible, dry beans) and other grains, such as common beans, soybean, peas, lentils, and peanuts, as well as important forage species, such as alfalfa, clover, vetch and stylo. In the United States, over 33 million hectares of soybean were grown in 2016, accounting for the area of New Mexico, the fifth largest state (http://www.fao.org/faostat/en/\#data/QC). Indeed, legumes have been called the lynch pin of sustainable agriculture because of their ability to fix nitrogen when in symbiotic association with rhizobial bacteria (Udvardi et al., 2005). Being the third botanical family, with almost 20,000 species, legumes are found natively worldwide and three of them are used as biological models: Medicago truncatula (Figure 1), Lotus japonicus, and soybean (Glycine max).

A

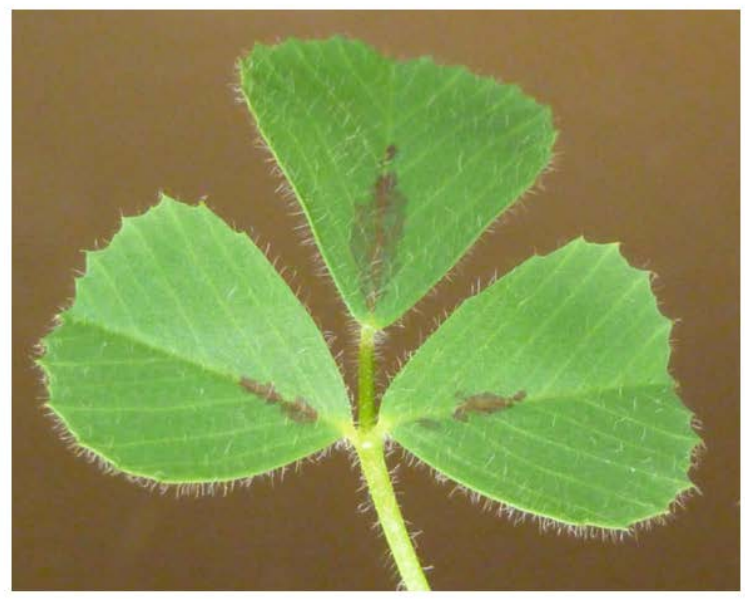

B

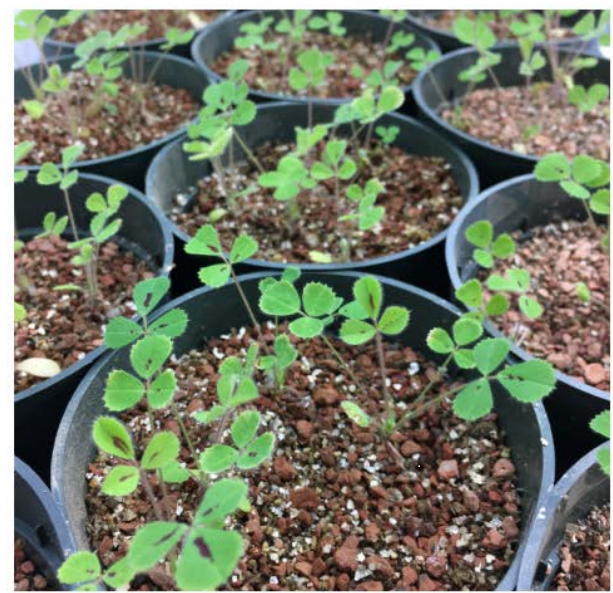

Figure 2.1. Medicago truncatula. (A) Trifoliate leaf. Trichomes are visible on the leaves, petiole, and stem. (B) Twenty one day old plants growing in turface and vermiculite substrate. 
Nitrogen and phosphorous are largely the most limiting mineral nutrients for plant growth in terrestrial ecosystems (Agren et al., 2012). Nitrogen fertilizer is produced for crop cultivation by the Haber-Bosch process, the main industrial process to generate ammonia. This process utilizes high pressure and temperature in order to convert atmospheric nitrogen and hydrogen into ammonia (Erisman et al., 2008). For each ton of ammonia produced in North America for agricultural purposes, 45.5 MJ of energy is used and produces 2.55 tons of carbon dioxide gas (Kool et al., 2012; Bicer et al., 2017). In 2016, whereas the United States used over 12 million tons of nitrogen fertilizer for agricultural use, the country produced less than 9 million tons (http://www.fao.org/faostat/en/\#data/RFN).

The level of profit and sustainability of an agricultural system can increase as the use of applied fertilizers is reduced by relying mostly or exclusively on symbiotically fixed nitrogen. An estimated 40-60 million tons of nitrogen are fixed annually by cultivated legumes (Postgate, 1982; Smil, 1999). This accounts for an annual savings of about $\$ 10$ billion on nitrogen fertilizer produced by the Haber-Bosch process (Graham and Vance, 2003; Herridge et al., 2008). If given all of the necessary tools to foster a symbiotic relationship, this could reduce the necessity of applied fertilizer which averages $77.5 \mathrm{~kg} / \mathrm{hectare}$ of agricultural land (http://www.fao.org/faostat/en/\#data/RFN).

Together, the biological processes of lightening and symbiotic nitrogen fixation account for approximately 60 percent of the Earth's fixed nitrogen (Zahran, 1999). Fixed nitrogen in the biosphere is rapidly turned over and lost to the atmosphere as gaseous dinitrogen $\left(\mathrm{N}_{2}\right)$ due to microbial denitrification, thus requiring reduced nitrogen to frequently be replenished from the atmosphere (Mylona et al., 1995). This process is carried out by prokaryotes expressing a nitrogenase enzymatic system in order to reduce atmospheric nitrogen $\left(\mathrm{N}_{2}\right)$ into ammonia $\left(\mathrm{NH}_{3}\right)$. Through a symbiotic relationship, nitrogen fixation occurs most recurrently in species of the Fabaceae family and it must happen in mutualistic association with the soil bacteria Rhizobia.

However, symbiotic nitrogen fixation with rhizobia is not exclusive to legumes (Trinick, 1979; van Velzen et al., 2018). Species of few orders in the Rosids I clade (namely: Fabales, Fagales, Rosales, and Cucurbitales) establish this endosymbiotic relationship with rhizobial bacteria in unique root structures called nodules (Sprent, 2001; Oldroyd et al., 2011; Limpens et al., 2013). Recent transcriptomic comparisons between the nonlegume, nitrogen-fixing plant species Parasponia andersonii (Cannabaceae, Rosales) and the legume Medicago truncatula 
indicate they may share a single origin for genes essential to nodule development and symbiotic nitrogen fixation. Also, comparison of Parasponia to closely related, nonnodulating species indicated parallel loss of genes essential to nodulation, which challenges the current paradigm of parallel evolution of nodulation in the Rosids I (van Velzen et al., 2018).

\section{Concurrent model legumes and the uniqueness of Medicago truncatula}

The legume family encompasses around 20,000 species recently regrouped into six subfamilies, of which the major clades are Caesalpinioideae (which now includes the mimosoid clade) and the Papilionoideae (Azani et al., 2017). All three established model legumes belong to the latter subfamily: Soybean (Glycine max), Lotus japonicus and Medicago truncatula (Table 1). They have similar generation times ( 3 months, seed-to-seed) and are autogamous. They also had their genome sequenced and are well annotated (Sato et al., 2005; Grant et al., 2010; Young et al., 2011) and have transcriptome data publicly available (Lamblin et al., 2003; Severin et al., 2010; Verdier et al., 2013), in addition to plethora of genetic resources, such as mutant collections (Pislariu et al., 2012; Tsuda et al., 2015; Malolepszy et al., 2016).

Table 2.1. Comparison of the three model legume systems. Medicago truncatula is our model organism of choice due to small genome size, availability of genetic resources and indeterminate nodules (Mergaert et al., 2006).

\begin{tabular}{|l|l|l|l|}
\cline { 2 - 4 } \multicolumn{1}{l|}{} & Medicago truncatula & Lotus japonicus & Glycine max \\
\hline Clade & Hologalegina (IRLC) & Hologalegina & Phaseolid \\
\hline Nodule growth & indeterminate & determinate & determinate \\
\hline $\begin{array}{l}\text { Bacteroid division after } \\
\text { infection }\end{array}$ & Endoreduplication & No endoreduplication & No endoreduplication \\
\hline Form of N exported & amides & amides & ureides \\
\hline Genome size & $390 \mathrm{Mb}$ & $470 \mathrm{Mb}$ & 1.1 Gb \\
\hline Genome ploidy & Diploid $(\mathrm{n}=8)$ & Diploid $(\mathrm{n}=8)$ & Allotetraploid $(\mathrm{n}=20)$ \\
\hline
\end{tabular}

Medicago truncatula is unique among the legume models, in that it develops indeterminate nodules with a persistent meristem, a more primitive trait (Sprent, 2007; Ren, 2018). The Inverted Repeat-Lacking Clade (IRLC) of Hologalegina (galegoids), to which Medicago and most cultivated temperate legume crops belong (e.g., chickpea, fava bean, lentil), is characterized by the loss of a 25-kb inverted repeat region in the plastidial genome. In addition, however, and most 
importantly, this clade (along with the Dalbergioid subfamily) controls bacteroid differentiation by a massive expression of nodule-specific cysteine-rich (NCR) peptides (Czernic et al., 2015; Wang et al., 2017a; Yang et al., 2017). Therefore, understanding nodulation and symbiotic nitrogen fixation in temperate legume crops can only be achieved by studying Medicago truncatula within the available model options.

Medicago truncatula is also closely related to the autotetraploid, perennial crop, alfalfa ( $M$. sativa), the most cultivated forage legume worldwide (Yuegao and Cash, 2009). The alfalfa genome is highly syntenous to that of $M$. truncatula (Li et al., 2014), although its ploidy level and allogamous fertilization system preclude it as a model genetic system.

Medicago truncatula has many specific genetic databases and resources available for research. The Noble Research Institute (formerly, Samuel Roberts Noble Foundation) hosts the Medicago truncatula Gene Expression Atlas (MtGEA) (Benedito et al., 2008; He et al., 2009) that provides Affymetrix GeneChip data and thorough functional genomics tools for data analysis (http://mtgea.noble.org/v3/). The Noble Research Institute is also home to the Medicago truncatula mutant collection (http://medicago-mutant.noble.org/mutant/), which is the largest collection of DNA-insertion mutants of all legumes (Tadege et al., 2008; Pislariu et al., 2012). The tobacco retrotransposon Tnt1 was used to tag insertion events in the Medicago truncatula genome, which are preferentially located in gene-rich regions (Tadege et al., 2008). The mutant database features over 19,000 Tnt1 lines containing 470,000 random insertions in the genome, which covers $\sim 90 \%$ of all genes in the Medicago genome.

\section{The process of nodulation and symbiotic nitrogen fixation}

Due to the advances in genomics methods and significant investment in legume research, the processes of nodule development and symbiotic nitrogen fixation are being unveiled at the molecular genetic level since the last decade (Qin et al., 2012; Collier and Tegeder, 2012; TejadaJiménez et al., 2017; Kryvoruchko et al., 2018; Wang et al., 2017a; Wang et al., 2017b; Yang et al., 2017). Nodulation starts with a chemical communication between Medicago truncatula roots and the free-living soil rhizobia. When the nitrogen in the soil available is low, aromatic compounds known as flavonoids are secreted from $M$. truncatula roots into the rhizosphere, signaling the rhizobia to synthesize and secrete lipochitooligosaccharides called Nod factors 
(Catoira et al., 2000). At the same time, rhizobia are attracted by chemotaxis, attach to the root hair, and become trapped in a curled structure in the tip of the root hair called a shepherd's crook (Esseling et al., 2003). Nod factors are perceived by receptors in the plasma membrane of root hair cells and induce a response in the infection pocket to produce invagination of the plasma membrane in order to form infection threads containing the rhizobia (Veereshlingam et al., 2004; Guan et al., 2013). Rhizobia travel through the infection threads towards the developing nodule primordia that is being concomitantly formed by cell divisions in the root cortex (Oldroyd and Downie, 2008). Upon arriving at the inner cortical tissues, these rhizobia are engulfed by the plasma membrane through endocytosis and differentiate into bacteroids contained within symbiosomes (Veereshlingam et al., 2004; Morieri et al., 2013). Infected root cells develop a new organ called the nodule, which provides the microaerobic environment necessary for nitrogenase activity (Jones et al., 2007). Rhizobia continue to produce Nod factors as the plant develops, allowing a continual perception during infection (Popp and Ott, 2011) and nodulation is produced by the simultaneous epidermal infection from rhizobia and cortical cell division (Guan et al., 2013). Indeterminate nodules, like those formed in M. truncatula (Figure 2.2) and pea roots, have five zones: meristem (I), invasion (II), interzone (II-III), nitrogen fixation (III), and senescence (IV). The meristem zone consists of a primordium-like structure composed of many dividing cells and a quiescent center (Maunoury et al., 2010). Bacteroids differentiate within the invasion and interzones. The nitrogen fixation zone contains mature bacteroids possessing the ability to fix atmospheric nitrogen. The senescence zone involves the proteolysis and degradation of the symbiosome (Van de Velde et al., 2006). Indeterminate nodules are produced through continuous growth from the apical meristem of the nodule (Györgyey et al., 2000), while determinate nodules are developed in species such as soybean and Lotus japonicus. It is worth noting that the interaction between rhizobia and legume species is highly specific. Sinorhizobium meliloti will form symbiosis with Medicago, Melilotus, and Trigonella (in the IRLC clade), while Mesorhizobium loti forms symbioses with Lotus species (Gibson et al., 2008). Efficiency of nitrogen fixation is greatly impacted by the interaction between the various strains of $S$. meliloti and ecotypes of $M$. truncatula (Kazmierczak et al., 2017; Wang et al., 2017a; Yang et al., 2017). For example, the association between the common ecotype 'A17' (the first $M$. truncatula genome sequenced) and R. meliloti strain 2011 leads to suboptimal nitrogen fixation rates for plant development (Moreau et al., 2008). More recently, the role of nodule-specific cystein-rich (NCR) peptides has been 
linked with nitrogen fixation rates through legume-rhizobia interactions (Wang et al., 2017a; Yang et al., 2017).

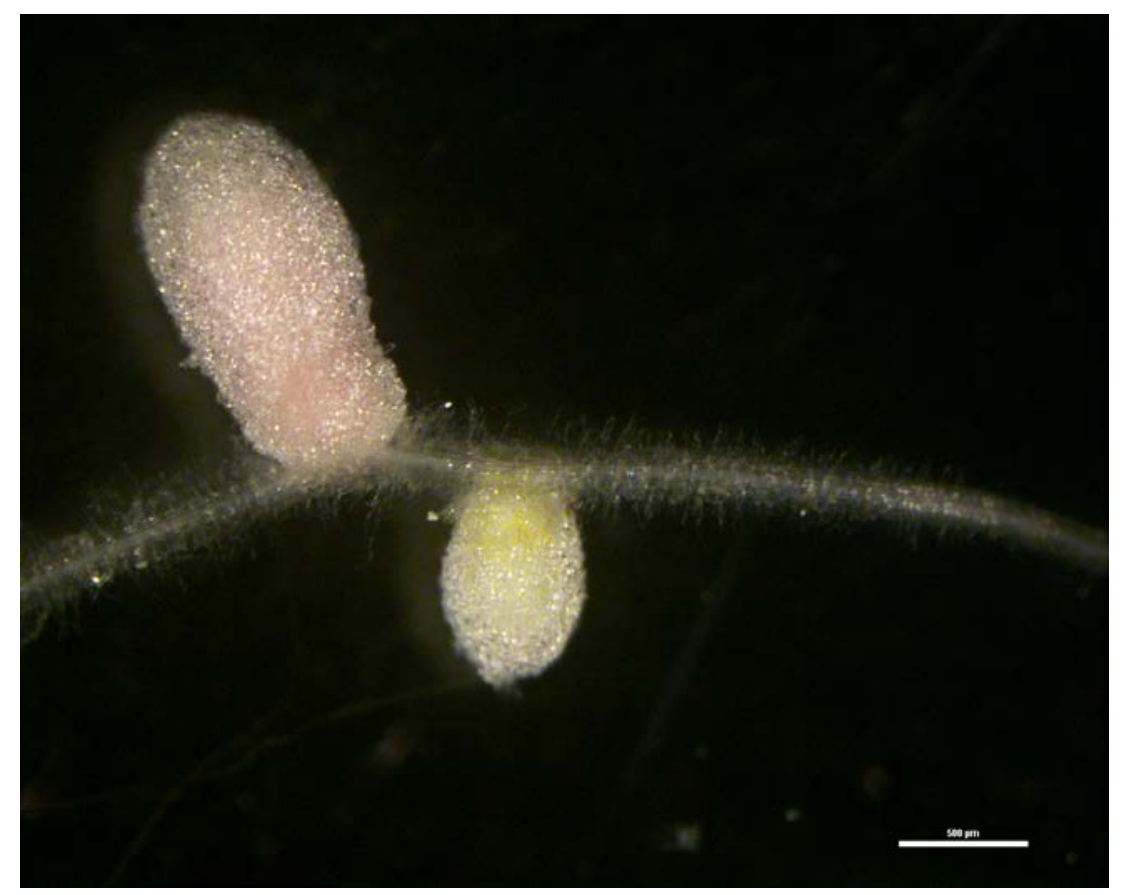

Figure 2.2. Medicago truncatula cv. 'A17' nodules (28 days post inoculation with Sinorhizobium meliloti strain Sm1021-LacZ). The larger nodule is elongated and pink due to leghemoglobin and indicative of nitrogen fixation. The smaller, developing nodule still lacks leghemoglobin. Scale bar: $500 \mu \mathrm{m}$.

\section{Membrane transporters and symbiotic nitrogen fixation in legumes}

Transporters are ubiquitously present in all biological membranes - membrane transporters are a sine qua non for life to exist. Cell membranes are the most basic structure of a cell - they not only delimit the cell from the inorganic surrounding environment and its organelles within the cell, but they also function in signal perception and in establishing electrochemical gradients that allow coordinated transport of substances to occur in a very controlled manner. Some substrates need assistance because they are polar or too large to move across biological membranes by simple diffusion. Indeed, many different types of transporters are embedded in the phospholipid bilayer of the semi-permeable cellular membrane in order to facilitate this process.

Our understanding of the involvement of membrane transporters in integrating the legume physiology with symbiotic nitrogen fixation, as well as within the nodule cells, has been patchy 
(Benedito et al., 2010; Udvardi and Poole, 2013). However, without fully identifying and characterizing membrane transporter genes involved in symbiotic nitrogen fixation, our understanding of the process will remain incomplete.

The several types of membrane transporters are presented in Figure 2.3. Those that require direct metabolic energy are pumps that hydrolyze ATP to move a substrate against the electrochemical gradient (Figure 2.3A). Channels do not utilize energy input directly, but they can only move ions and small molecules downhill (i.e., in favor of the electrochemical gradient) and use a gating system (open or closed states) to regulate their activity. Secondary transporters utilize energy stored as electrochemical gradient often created by a pump to couple the transport of a substrate against the gradient with the movement of another in favor of the gradient.

There are three types of secondary transporters (Figure 2.3B). Uniporters transport a substrate down its concentration gradient. Cotransporters can be divided into symporters and antiporters. Symporters move one molecule against its concentration gradient and is driven by the movement of an ion down the electrochemical gradient with both molecules moving in the same direction of the membrane. Antiporters also move molecules against the concentration gradient driven by a substrate moving down the electrochemical gradient, where the molecules or ions are moving in opposite orientation of each other. 

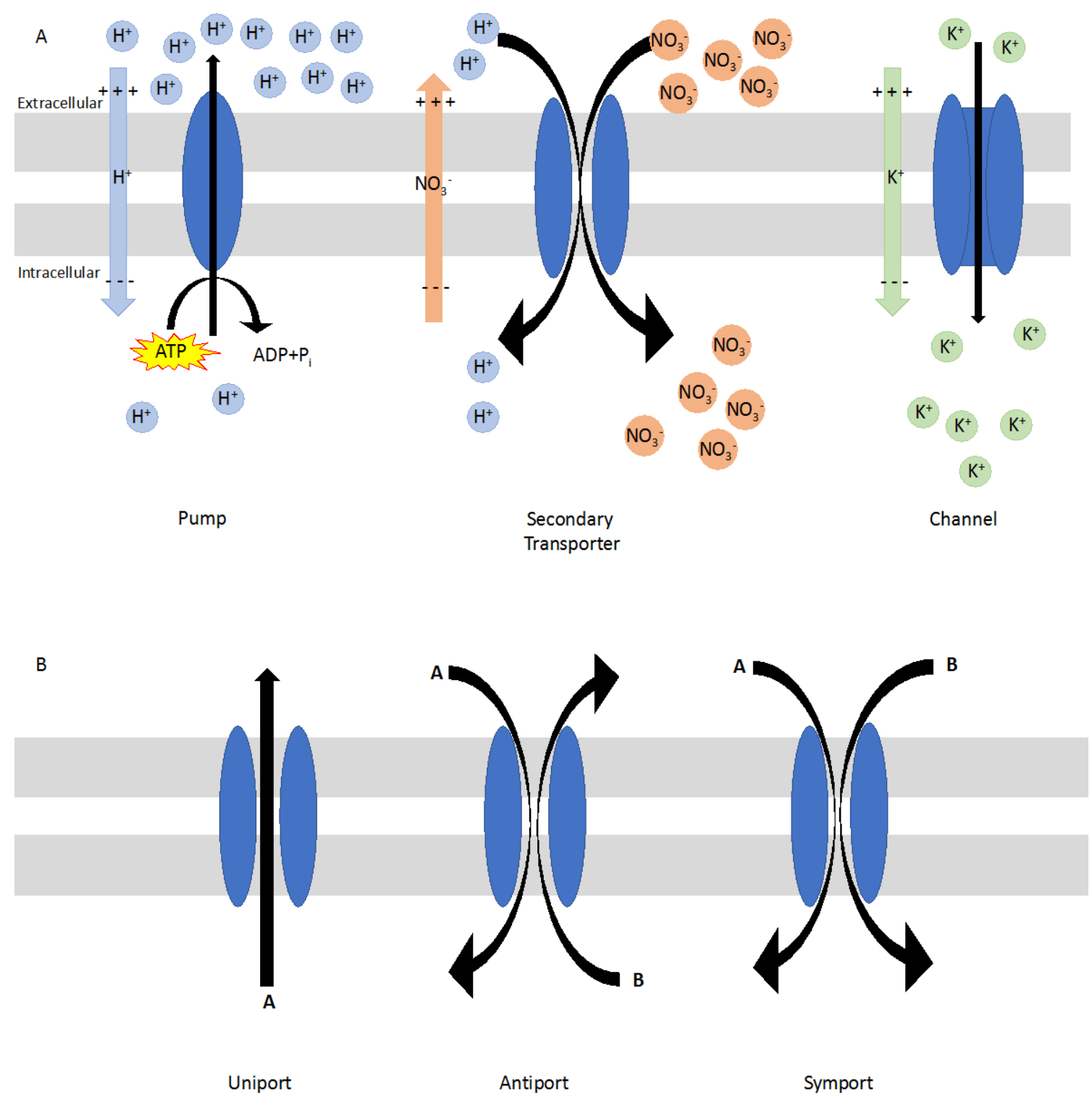

Figure 2.3. Transport of large and polar molecules across lipid bilayers is mediated by specific transmembrane proteins or protein complexes called membrane transporters. (A) Pumps are primary active transporters that require the hydrolysis of ATP to move ions and molecules against the electrochemical gradient. Secondary transporters utilize the electrochemical gradient established by pumps to move molecules against the gradient. Channels allow ions to move across a membrane in favor of the electrical potential (downhill) through facilitated diffusion. (B) There are three types of secondary transporters. Uniporters move substrates in one direction across a membrane, antiporters move substrates in opposite directions, and symporters move substrates in the same direction across a membrane. Antiporters and symporters usually utilize the electrochemical potential established for one substrate to move it downhill while moving the other substrate uphill.

Plasma membrane transporters regulate movement of ions and substances from inside the cell to the extracellular environment and vice versa. Transporters also are ubiquitously present in 
the membranes of subcellular organelles to regulate movement into and out of organelles. Transporters consist of proteins with multiple transmembrane domains encompassing stretches of in-tandem hydrophobic amino acids that span the lipid bilayer, along with hydrophilic amino acid residues that connect the transmembrane domains and may compose the $\mathrm{N}$ - and C-terminal tails.

The infected nodule cell is unique in that they confine the rhizobia within symbiosomes. Symbiosomes are organellar structures formed through endocytosis of bacteria in infected nodule cells, and therefore is of plasma membrane origin (Figure 2.4). They are comprised of the symbiosome membrane, the bacteroid (the nitrogen-fixing form of the endosymbiotic rhizobia), and the symbiosome or peribacteroid space (Catalano et al., 2007). The symbiosome space is highly acidic ( $\mathrm{pH} 4.0$ ), thus providing the electrical potential to enable secondary transport (Pierre et al., 2013). The symbiosome membrane is essential to mediate metabolite exchanges and provides a physical boundary between the symbionts (Catalano et al., 2004). Notwithstanding, only a few of the transporters that mediate these exchanges have been genetically identified and functionally characterized (Table 2.2). 
Table 2.2. Functionally characterized membrane transporters in the model legumes, Medicago truncatula, Lotus japonicus, and Glycine max (soybean).

\begin{tabular}{|c|c|c|c|c|}
\hline Species & Transporter & Gene ID & Substrate & References \\
\hline M. truncatula & COPT1 & Medtr4g019870 & copper & Senovilla et al., 2018 \\
\hline M. truncatula & $\begin{array}{c}\text { LATD/NIP/N } \\
\text { PF1.7 }\end{array}$ & & nitrate & Bagchi et al., 2012 \\
\hline M. truncatula & MATE1 & & $\begin{array}{c}\text { 3'-O- } \\
\text { Glucoside }\end{array}$ & Zhao et al., 2011 \\
\hline M. truncatula & MATE2 & Medtr1g100180 & $\begin{array}{l}\text { flavonoid } \\
\text { glucosides }\end{array}$ & Zhao et al., 2009 \\
\hline M. truncatula & MATE55 & Medtr5g067460 & iron & Wang et al., 2017b \\
\hline M. truncatula & $\begin{array}{l}\text { MATE66, } \\
\text { MATE69 }\end{array}$ & $\begin{array}{l}\text { Medtr2g097900, } \\
\text { Medtr3g029510 }\end{array}$ & citric acid & Wang et al., 2017b \\
\hline M. truncatula & MOT1.3 & Medtr3g464210 & molybdenum & Tejada-Jiménez et al., 2017 \\
\hline M. truncatula & MATE67 & Medtr8g037170 & citrate & Kryvoruchko et al., 2018 \\
\hline M. truncatula & $\begin{array}{c}\text { NPF6.8/NRT } \\
1.3\end{array}$ & & nitrate & Pellizzaro et al., 2014 \\
\hline M. truncatula & $\begin{array}{l}\text { SUT1-1, } \\
\text { SUT4-1 }\end{array}$ & $\begin{array}{l}\text { Medtr1g096910, } \\
\text { Medtr5g067470 }\end{array}$ & sucrose & Doidy et al., 2012 \\
\hline M. truncatula & SWEET11 & Medtr3g098930 & sucrose & Kryvoruchko et al., 2016 \\
\hline M. truncatula & ZIP6 & Medtr4g083570 & zinc & Abreu et al., 2017 \\
\hline G. $\max$ & DMT1 & Glyma17G165200 & iron & Kaiser et al., 2003 \\
\hline G. $\max$ & N70 & Glyma18G018900 & anions & Vincill et al., 2005 \\
\hline G. $\max$ & PT5 & & phosphate & Qin et al., 2012 \\
\hline G. $\max$ & UPS1 & & ureide & Collier and Tegeder, 2012 \\
\hline G. $\max$ & ZIP1 & Glyma20G063100 & zinc & Moreau et al., 2002 \\
\hline L. japonicus & ALMT4 & & dicarboxylates & Takanashi et al., 2016 \\
\hline L. japonicus & AMT2;1 & & ammonium & Simon-Rosin et al., 2003 \\
\hline L. japonicus & KUP & & potassium & Desbrosses et al., 2004 \\
\hline L. japonicus & MATE1 & & citrate & Takanashi et al., 2013 \\
\hline L. japonicus & N70 & & anions & Vincill et al., 2005 \\
\hline L. japonicus & SST1 & & sulfate & Krussel et al., 2005 \\
\hline L. japonicus & SUT4 & & sucrose & Flemetakis et al., 2003 \\
\hline L. japonicus & SWEET3 & & sucrose & Sugiyama et al., 2016 \\
\hline
\end{tabular}




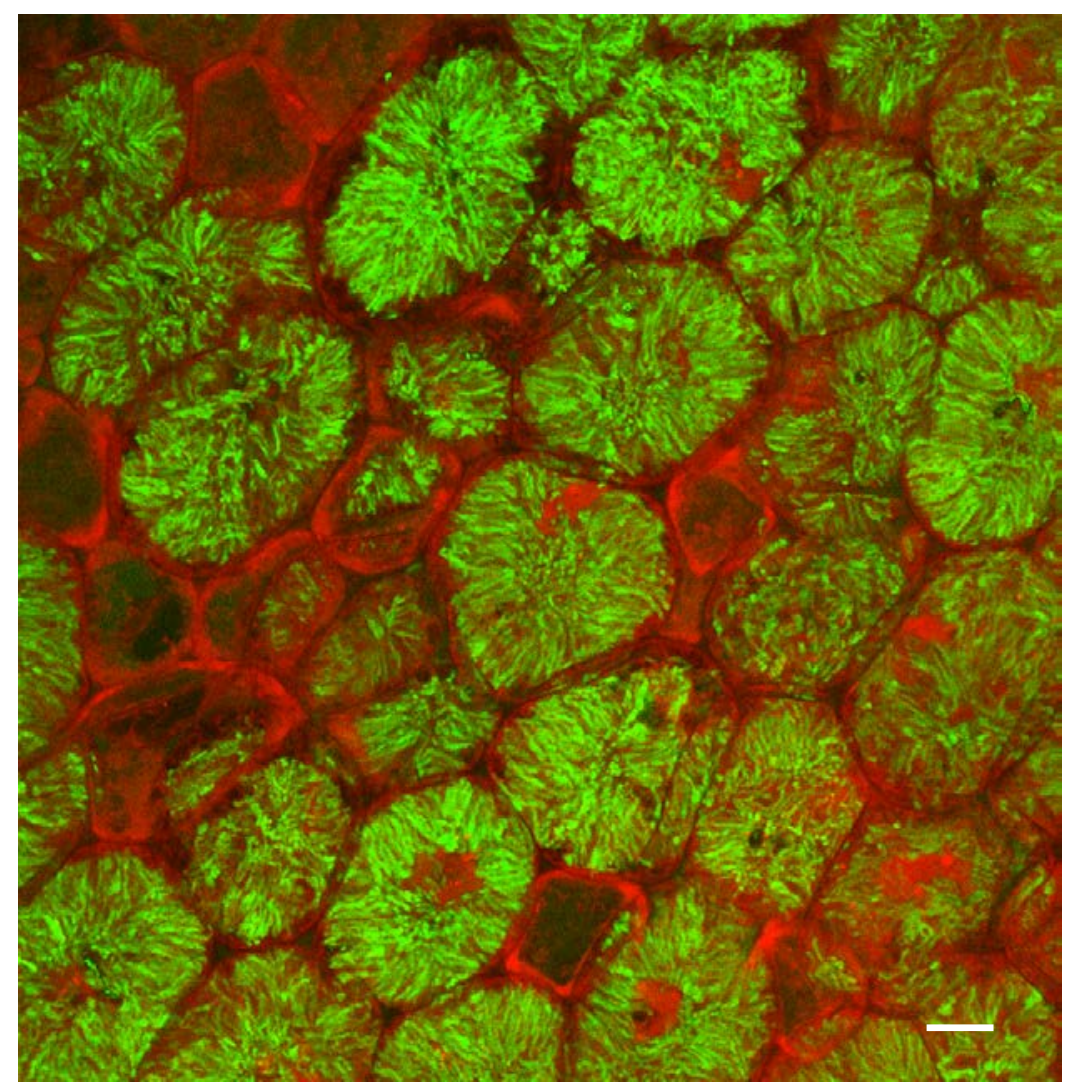

Figure 2.4. Infected nodule cells in the nitrogen fixation zone. Each infected cell encloses numerous bacteroids. Green autofluorescence shows elongated and differentiated bacteroids that are capable of fixing nitrogen. Red signal from DsRed shows the roots transformed with the vector pUBIcGFP that contains the DsRed gene constitutively expressed as visual marker (Kryvoruchko et al., 2016). Scale bar: $10 \mu \mathrm{m}$. Image taken on a Zeiss Violet confocal LSM 510. 


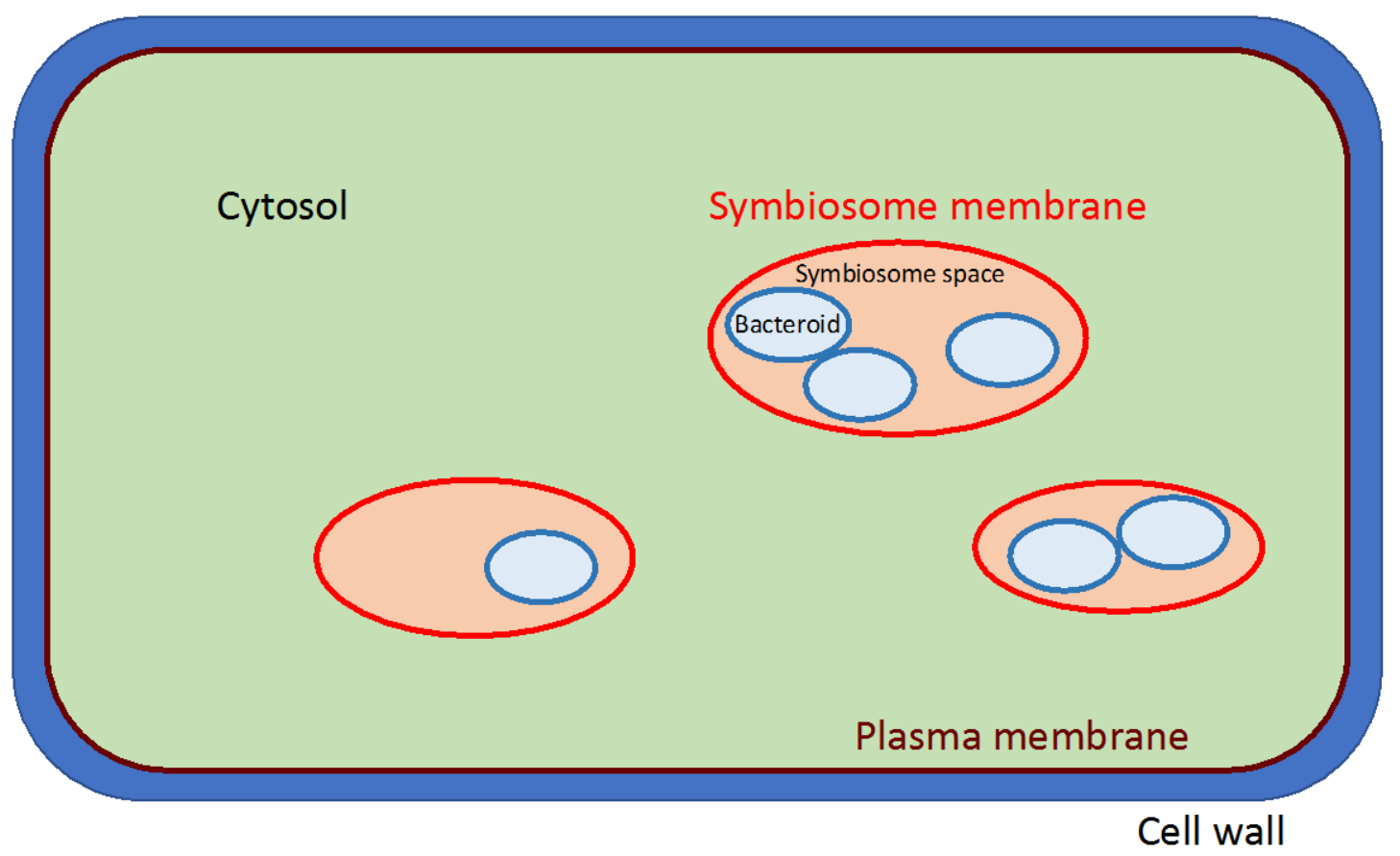

Figure 2.5. Simplified diagram of an infected nodule cell. Infected cells can hold up to 10,000 bacteroids in each cell (Bailey, 1986). In Medicago truncatula, each symbiosome contains a single bacteroid that is terminally differentiated (Mergaert et al., 2006). Membrane transporters are found on the plasma membrane as well as on the symbiosome membrane, vacuole and other membranes and are coded for by the plant genome. Those found on the bacteroid membrane are coded for by the rhizobia. As ammonia moves through the symbiosome space it is protonated into ammonium.

In the nodule, membrane transporters mediate nutrient exchanges during nodule development and symbiotic nitrogen fixation (Udvardi et al., 1988; Benedito et al., 2006, Benedito et al., 2008, Benedito et al., 2010) and are key targets to improve the plants' ability to take up and utilize nutrients (Schroeder et al., 2013) as well as integrate the whole physiology of the plant by directing the translocation of diverse metabolites and signals.

\section{Recent developments and outstanding questions in legume biology, symbiotic nitrogen fixation and membrane transport}

The recent elucidation of mechanisms responsible for compatible and incompatible genotypes of rhizobia and plants, raises the question of other unknown interactions involved in making a successful symbiosis, since plant and rhizobial symbioses are complex and intricate 
interactions which have yet to be fully described (Wang et al., 2017a; Yang et al., 2017). However, our focus on nutritional flux between symbionts also has many unanswered questions. In nodules, the movement of substrates and products created by and consumed by symbiotic nitrogen fixation must be transported between the rhizobia and plant and across membranes including the symbiosome membrane and the plasma membrane. Amino acid transporters, among others, must be involved in symbiosis but have not been molecularly characterized. An aspartate/glutamate shuttle has been proposed 15 years ago, asserting a transporter must be present in the bacteroid membrane to import glutamate into the bacteroid for utilization as a transamination donor during asparagine synthesis and this hypothesis has not yet been confirmed (Lodwig et al., 2003). Another outstanding question involves transporters of branched-chain amino acids (BCAA: leucine, isoleucine, and valine). BCAAs must be supplied to the bacteroids by the plant, as under symbiotic conditions bacteroids become auxotrophic for these three amino acids (Rastogi and Watson, 1991; Lodwig et al., 2003; Prell et al., 2009, 2010). Alanine has also been proposed to be an alternative product of nitrogen fixation in the bacteroid that is exported to the plant cytoplasm, although this hypothesis has not been assessed to date (Day et al., 2001). The transporters at the symbiosome membrane supplying those amino acids have not been functionally characterized so far. Through the functional characterization of legume genes necessary for successful symbiosis, greater understanding of the intricate balance and transport supporting the energy intensive process of nitrogen fixation can be understood and built upon. 


\section{REFERENCES}

Abreu I, Saez A, Castro-Rodríguez R, Escudero V, Rodríguez-Haas B, Senovilla M, Larue C, Grolimund D, Tejada-Jiménez M, Imperial J, et al (2017) Medicago truncatula Zinc-Iron Permease6 provides zinc to rhizobia-infected nodule cells. Plant, Cell \& Environment 40: 27062719

Ågren GI, Wetterstedt JAM, Billberger MFK (2012) Nutrient limitation on terrestrial plant growth - modeling the interaction between nitrogen and phosphorus. New Phytologist 194: 953960

Azani N, Babineau M, Bailey CD, Banks H, Barbosa AR, Pinto RB, et al (2017) A new subfamily classification of the Leguminosae based on a taxonomically comprehensive phylogeny The Legume Phylogeny Working Group (LPWG). Taxon 66: 44-77

Bagchi R, Salehin M, Adeyemo OS, Salazar C, Shulaev V, Sherrier DJ, Dickstein R (2012) Functional assessment of the Medicago truncatula NIP/LATD protein demonstrates that it is a high-affinity nitrate transporter. Plant Physiology 160: 906-916

Bailey JA, ed. (1986) Biology and Molecular Biology of Plant-Pathogen Interactions. SpringerVerlag, Long Ashton, UK

Barker DG, Bianchi S, Blondon F, Dattée Y, Duc G, Essad S, Flament P, Gallusci P, Génier G, Guy P, et al (1990) Medicago truncatula, a model plant for studying the molecular genetics of the Rhizobium-legume symbiosis. Plant Molecular Biology Reporter 8: 40-49

Benedito VA, Dai X, He J, Zhao PX, Udvardi MK (2006) Functional genomics of plant transporters in legume nodules. Functional Plant Biology 33: 731

Benedito VA, Li H, Dai X, Wandrey M, He J, Kaundal R, Torres-Jerez I, Gomez SK, Harrison MJ, Tang Y, et al (2010) Genomic inventory and transcriptional analysis of Medicago truncatula transporters. Plant Physiology 152: 1716-1730

Benedito VA, Torres-Jerez I, Murray JD, Andriankaja A, Allen S, Kakar K, Wandrey M, Verdier J, Zuber H, Ott T, et al (2008) A gene expression atlas of the model legume Medicago truncatula. Plant Journal 55: 504-513

Bicer Y, Dincer I, Vezina G, Raso F (2017) Impact assessment and environmental evaluation of various ammonia production processes. Environmental Management 1:14

Catalano CM, Czymmek KJ, Gann JG, Sherrier DJ (2007) Medicago truncatula syntaxin SYP132 defines the symbiosome membrane and infection droplet membrane in root nodules. Planta 225: 541-550

Catalano CM, Lane WS, Sherrier DJ (2004) Biochemical characterization of symbiosome membrane proteins from Medicago truncatula root nodules. Electrophoresis 25: 519-531 
Catoira R (2000) Four genes of Medicago truncatula controlling components of a Nod factor transduction pathway. Plant Cell 12: 1647-1666

Chaturvedi N, Shanker S, Singh VK, Sinha D, Pandey PN (2011) Hidden markov model for the prediction of transmembrane proteins using MATLAB. Bioinformation 7: 418-421

Cong L, Ran FA, Cox D, Lin S, Barretto R, Habib N, Hsu PD, Wu X, Jiang W, Marraffini LA, Zhang F (2013) Multiplex genome engineering using CRISPR/Cas systems. Science 339: 819-823

Collier R, Tegeder M (2012) Soybean ureide transporters play a critical role in nodule development, function and nitrogen export. Plant Journal 72: 355-367

Cook DR (1999) Medicago truncatula - a model in the making! Current Opinion in Plant Biology 2: 301-304

Cook DR, VandenBosch K, de Bruijn FJ, Huguet T (1997) Model Legumes Get the Nod. Plant Cell 9: 275-280

Czernic P, Gully D, Cartieaux F, Moulin L, Guefrachi I, Patrel D, et al (2015) Convergent evolution of endosymbiont differentiation in Dalbergioid and inverted repeat-lacking clade legumes mediated by nodule-specific cysteine-rich peptides. Plant Physiology 169: 1254-1265

Day DA,Kaiser BN, Thomson R, Udvardi MK, Moreau S, Puppo A (2001) Nutrient transport across symbiotic membranes from legume nodules. Aust. Journal of Plant Physiology 28: 667674

Desbrosses G, Kopka C, Ott T, Udvardi MK (2004) Lotus japonicus LjKUP is induced late during nodule development and encodes a potassium transporter of the plasma membrane. Molecular Plant Microbe Interactions 17: 789-797

Doidy J, van Tuinen D, Lamotte O, Corneillat M, Alcaraz G, Wipf D (2012) The Medicago truncatula sucrose transporter family: characterization and implication of key members in carbon partitioning towards arbuscular mycorrhizal fungi. Molecular Plant 5: 1346-1358

Erisman JW, Sutton MA, Galloway J, Klimont Z, Winiwarter W (2008) How a century of ammonia synthesis changed the world. Nature Geoscience 1: 636- 639

Esseling JJ (2003) Nod factor-induced root hair curling: Continuous polar growth towards the point of Nod factor application. Plant Physiology 132: 1982-1988

Flemetakis E, Dimou M, Cotzur D, Efrose RC, Aivalakis G, Colebatch G, Udvardi M, Katinakis P (2003) A sucrose transporter, LjSUT4, is up-regulated during Lotus japonicas nodule development. Journal of Experimental Botany 54: 1789-1791 
Food and Agriculture Organization of the United Nations. (2007) FAO.org. http://www.fao.org/faostat/en/\#data/QC

Food and Agriculture Organization of the United Nations. (2007) FAO.org.

http://www.fao.org/faostat/en/\#data/RFN

Gibson KE, Kobayashi H, Walker GC (2008) Molecular determinants of a symbiotic chronic infection. Annual Review Genetics 42: 413-441

Guan D, Stacey N, Liu C, Wen J, Mysore KS, Torres-Jerez I, Vernié T, Tadege M, Zhou C, Wang Z, et al (2013) Rhizobial infection is associated with the development of peripheral vasculature in nodules of Medicago truncatula. Plant Physiology 162: 107-115

Graham PH, Vance CP (2003) Legumes: importance and constraints to greater use. Plant Physiology 131: 872-877

Grant D, Nelson RT, Cannon SB, Shoemaker RC (2010) SoyBase, the USDA-ARS soybean genetics and genomics database. Nucleic Acids Research 38: 843-846

Györgyey J, Vaubert D, Jiménez-Zurdo JI, Charon C, Troussard L, Kondorosi A, Kondorosi E (2000) Analysis of Medicago truncatula nodule expressed sequence tags. Molecular PlantMicrobe Interactions 13: 62-71

Haurwitz RE, Jinek M, Wiedenheft B, Zhou K, Doudna JA (2010) Sequence- and structurespecific RNA processing by a CRISPR endonuclease. Science 329: 1355-1358

He J, Benedito VA, Wang M, Murray JD, Zhao PX, Tang Y, Udvardi MK (2009) The Medicago truncatula gene expression atlas web server. BMC Bioinformatics 10: 441

Herridge DF, Peoples MB, Boddey RM (2008) Global inputs of biological nitrogen fixation in agricultural systems. Plant Soil 311: 1-18

Jinek M, Chylinski K, Fonfara I, Hauer M, Doudna JA, Charpentier E (2012) A programmable dual-RNA-guided DNA endonuclease in adaptive bacterial immunity. Science 337: 816-821

Jacobs TB, LaFayette PR, Ortega MA, Schmitz RJ, Parrott WA (2015). Targeted genome modifications in soybean with CRISPR/Cas9. BMC Biotechnology 15: 16

Jones KM, Kobayashi H, Davies BW, Taga ME, Walker GC (2007) How rhizobial symbionts invade plants: the Sinorhizobium-Medicago model. Nature Reviews Microbiology 5: 619-633

Kaiser BN, Finnegan PM, Tyerman SD, Whitehead LF, Bergersen FJ, Day DA, Udvardi MK (1998) Characterization of an ammonium transport protein from the peribacteroid membrane of soybean nodules. Science 281: 1202-1206 
Kaiser BN, Moreau S, Castelli J, Thomson R, Lambert A, Bogliolo S, Puppo A, Day DA (2003) The soybean NRAMP homologue, GmDMT1, is a symbiotic divalent metal transporter capable of ferrous iron transport. Plant Journal 35: 295-304

Kazmierczak T, Nagymihaly M, Lamouche F, Barriere Q, Guefrachi I, Alunni B, Ouadghiri M, Ibijbijen J, Kondorosi É, Mergaert P, Gruber V (2017) Specific host-responsive associations between Medicago truncatulaaccessions and Sinorhizobium strains. Molecular PlantMicrobe Interactions 30: 399-409

Kool A, Marinussen M, Blonk H (2012) LCI data for the calculation tool Feedprint for greenhouse gas emissions of feed production and utilization. GHG Emissions of N, P and K fertilizer production Gravin Beatrixstraat 34: 2805

Krishnakumar, V, et al (2015) MTGD: the Medicago truncatula genome database. Plant Cell Physiology 56: 1

Krusell L, Krause K, Ott T, Desbrosses G, Krämer U, Sato S, Nakamura Y, Tabata S, James EK, Sandal N, et al (2005) The sulfate transporter SST1 is crucial for symbiotic nitrogen fixation in Lotus japonicus root nodules. Plant Cell 17: 1625-1636

Krylova V, Andreev IM, Zartdinova R, Izmailov SF (2013) Biochemical characteristics of the $\mathrm{Ca} 2+$ pumping ATPase in the peribacteroid membrane from broad bean root nodules. Protoplasma 250: 531-538

Kryvoruchko IS, Routray P, Sinharoy S, Torres-Jerez I, Tejada-Jiménez M, Finney LA, Nakashima J, Pislariu CI, Benedito VA, González-Guerrero M, Roberts DM and Udvardi MK (2018) An Iron-Activated Citrate Transporter, MtMATE67, Is Required for Symbiotic Nitrogen Fixation. Plant Physiology 176: 2315-2329

Kryvoruchko IS, Sinharoy S, Torres-Jerez I, Sosso D, Pislariu CI, Guan D, Murray J, Benedito VA, Frommer WB, Udvardi MK (2016) MtSWEET11, a nodule-specific sucrose transporter of Medicago truncatula. Plant Physiology 171: 554-565

Lamblin AF, et al (2003) MtDB: a database for personalized data mining of the model legume Medicago truncatula transcriptome Nucleic Acids Research 31: 196-201

Li X, Wei Y, Acharya A, Jiang Q, Kang J, Brummer EC (2014) A saturated genetic linkage map of autotetraploid alfalfa (Medicago sativa L.) developed using Genotyping-by-Sequencing is highly syntenous with the Medicago truncatula genome. Genes/Genomes/Genetics 4: 1971-1979

Limpens E, Moling S, Hooiveld G, Pereira PA, Bisseling T, Becker JD, Küster H (2013) Celland tissue-specific transcriptome analyses of Medicago truncatula root nodules. PLoS One 8: 64377 
Lodwig EM, Hosie AHF, Bourdès A, Findlay K, Allaway D, Karunakaran R, Downie JA, Poole PS (2003) Amino-acid cycling drives nitrogen fixation in the legume-Rhizobium symbiosis. Nature 422: 722-726

Małolepszy A, Mun T, Sandal N, Gupta V, Dubin M, Urbański D, Shah N, Bachmann A, Fukai E, Hirakawa H, et al (2016) The LORE1 insertion mutant resource. Plant Journal 88: 306317

Maunoury N, Redondo-Nieto M, Bourcy M, Van de Velde W, Alunni B, Laporte P, Durand P, Agier N, Marisa L, Vaubert D, et al (2010) Differentiation of symbiotic cells and endosymbionts in Medicago truncatula nodulation are coupled to two transcriptome-switches. PLoS One 5: 9519

Mergaert, P, et al (2006) Eukaryotic control on bacterial cell cycle and differentiation in the Rhizobium-legume symbiosis. Proceedings of the National Academy of Sciences of the United States of America 103: 5230-5235

Möller S, Croning MD, Apweiler R (2001) Evaluation of methods for the prediction of membrane spanning regions. Bioinformatics 17: 646-653

Moreau D Voisin A-S, Salon C, Munier-Jolain N (2008) The model symbiotic association between Medicago truncatulacv. Jemalong and Rhizobium meliloti strain 2011 leads to N-stressed plants when symbiotic $\mathrm{N}_{2}$ fixation is the main $\mathrm{N}$ source for plant growth. Journal of Experimental Botany 59: 3509-3522

Moreau S, Thomson RM, Kaiser BN, Trevaskis B, Guerinot ML, Udvardi MK, et al (2002) GmZIP1 encodes a symbiosis-specific zinc transporter in soybean. Journal of Biological Chemistry 277: 4738-4746

Morieri G, Martinez EA, Jarynowski A, Driguez H, Morris R, Oldroyd GED, Downie JA (2013) Host-specific Nod-factors associated with Medicago truncatula nodule infection differentially induce calcium influx and calcium spiking in root hairs. New Phytologist 200: 656662

Mylona P, Pawlowski K, Bisseling T (1995) Symbiotic Nitrogen Fixation. Plant Cell 7: 869-885

Oldroyd GED, Downie JA (2008) Coordinating nodule morphogenesis with rhizobial infection in legumes. Annual Review in Plant Biology 59: 519-546

Oldroyd GED, Murray JD, Poole PS, Downie JA (2011) The rules of engagement in the legumerhizobial symbiosis. Annual Review Genetics 45: 119-144

Pellizzaro A, et al. (2014) The nitrate transporter MtNPF6.8 (MtNRT1.3) transports abscisic acid and mediates nitrate regulation of primary root growth in Medicago truncatula. Plant Physiology 166: 2152-2165 
Pierre O, Engler G, Hopkins J, Brau F, Boncompagni E, Hérouart D (2013) Peribacteroid space acidification: a marker of mature bacteroid functioning in Medicago truncatula nodules. Plant, Cell \& Environment 36: 2059-2070

Pislariu CI, Murray JD, Wen J, Cosson V, Muni RRD, Wang M, Benedito VA, Andriankaja A, Cheng X, Jerez IT, et al (2012) A Medicago truncatula tobacco retrotransposon insertion mutant collection with defects in nodule development and symbiotic nitrogen fixation. Plant Physiology 159: 1686-1699

Popp C, Ott T (2011) Regulation of signal transduction and bacterial infection during root nodule symbiosis. Current Opinion in Plant Biology 14: 458-467

Postgate JR (1982) The fundamentals of nitrogen fixation. Cambridge, United Kingdom: Cambridge University Press.

Prell J, Bourdès A, Kumar S, Lodwig E, Hosie A, Kinghorn S, White J, Poole P (2010) Role of symbiotic auxotrophy in the Rhizobium-legume symbioses. PLoS One 5: 13933

Prell J, White JP, Bourdes A, Bunnewell S, Bongaerts RJ, Poole PS (2009) Legumes regulate Rhizobium bacteroid development and persistence by the supply of branched-chain amino acids. Proceedings of the National Academy of Sciences, USA 106: 12477-12482

Rastogi VK, Watson RJ (1991) Aspartate aminotransferase activity is required for aspartate catabolism and symbiotic nitrogen fixation in Rhizobium meliloti. Journal of Bacteriology 173: 2879-2887

Qin L, Zhao J, Tian J, Chen L, Sun Z, Guo Y, et al (2012) The high-affinity phosphate transporter GmPT5 regulates phosphate transport to nodules and nodulation in soybean. Plant Physiology 159: 1634-1643

Reeves TG, Thomas G, Ramsay G (2016) Save and Grow in Practice: Maize, Rice, Wheat. A Guide to Sustainable Cereal Production (FAO UN)

Ren G (2018) The evolution of determinate and indeterminate nodules within the Papilionoideae subfamily. Dissertation

Sato S, et al (2008) Genome structure of the legume, Lotus japonicus. DNA Research 15: 227239

Schroeder JI, Delhaize E, Frommer WB, Guerinot M Lou, Harrison MJ, Herrera-Estrella L, Horie T, Kochian L V, Munns R, Nishizawa NK, et al (2013) Using membrane transporters to improve crops for sustainable food production. Nature 497: 60-66

Senovilla M, Castro-Rodriguez R, Abreu I, Escudero V, Kryvoruchko IS, Udvardi M, Imperial J, Gonzalez-Guerrero M (2018) Medicago truncatula copper transporter1 (MtCOPT1) delivers copper for symbiotic nitrogen fixation. New Phytologist 218: 696-709 
Severin AJ, Woody JL, Bolon YT, Joseph B, Diers BW, et al (2010) RNA-Seq Atlas of Glycine max: A guide to the soybean transcriptome. BMC Plant Biology 10: 160

Simon-Rosin U, Wood C, Udvardi MK (2003) Molecular and cellular characterisation of LjAMT2; 1 an ammonium transporter from the model legume Lotus japonicus. Plant Molecular Biology 51: 99-108

Smil, V (1999) Nitrogen in crop production: An account of global flows. Global Biogeochemical Cycles, 13(2), 647-662

Sprent, JI (2001) Nodulation in legumes (p. 146). R. B. Gardens (Ed.). Kew: Royal Botanic Gardens

Sprent JI (2007) Evolving ideas of legume evolution and diversity: a taxonomic perspective on the occurrence of nodulation. New Phytologist 174: 11-25

Sugiyama A, Saida Y, Yoshimizu M, Takanashi K, Sosso D, Frommer WB, Yazaki K (2017) Molecular characterization of LjSWEET3, a sugar transporter in nodules of Lotus japonicas. Plant \& Cell Physiology 58: 298-306

Tadege M, Wen J, He J, Tu H, Kwak Y, Eschstruth A, Cayrel A, Endre G, Zhao PX, Chabaud M, et al (2008) Large-scale insertional mutagenesis using the Tnt1 retrotransposon in the model legume Medicago truncatula. Plant Journal 54: 335-47

Takanashi K, Yokosho K, Saeki K, Sugiyama A, Sato S, Tabata S, Ma JF, Yazaki K (2013) LjMATE1: a citrate transporter responsible for iron supply to the nodule infection zone of Lotus japonicus. Plant Cell Physiology 54: 585-594

Takanashi K, Sasaki T, Kan T, Saida Y, Sugiyama A, Yamamoto Y, et al (2016) A dicarboxylate transporter, LjALMT4, mainly expressed in nodules of Lotus japonicus. Mol. Plant Microbe Interactions 29: 584-592

Tang HB, Krishnakumar V, Bidwell S, Rosen B, Chan AN, Zhou SG, et al. (2014). An improved genome release (version Mt4.0) for the model legume Medicago truncatula.BMC Genomics 15: 312

Tang L, Zeng Y, Du H, et al (2017) CRISPR/Cas9-mediated gene editing in human zygotes using Cas9 protein. Mol Genet Genomics 292: 525

TCDB.org Transporter Classification Database. 2005-2012. Saier Lab Group.

$<$ http://tcdb.org>

Tejada-Jiménez M, Gil-Díez P, León-Mediavilla J, Wen J, Mysore KS, Imperial J, et al (2017) Medicago truncatula Molybdate Transporter type 1 (MtMOT1.3) is a plasma membrane 
molybdenum transporter required for nitrogenase activity in root nodules under molybdenum deficiency. New Phytologist 216: 1223-1235

Trinick MJ (1973) Symbiosis between Rhizobium and the non-legume, Trema aspera. Nature 244: 459-460

Tsuda M, Kaga A, Anai T, Shimizu T, Sayama T, Takagi K, et al (2015) Construction of a high-density mutant library in soybean and development of a mutant retrieval method using amplicon sequencing. BMC Genomics 16: 1014

Udvardi M, Poole PS (2013) Transport and metabolism in legume-rhizobia symbioses. Annual Review of Plant Biology 64: 781- 805

Udvardi MK, Price GD, Gresshoff PM, Day DA (1988) A dicarboxylate transporter on the peribacteroid membrane of soybean nodules. FEBS Letters 231: 36-40

Udvardi MK, Tabata S, Parniske M, Stougaard J (2005) Lotus japonicus: legume research in the fast lane. Trends in Plant Science 10: 222-228

Van de Velde W, Guerra JCP, De Keyser A, De Rycke R, Rombauts S, Maunoury N, Mergaert P, Kondorosi E, Holsters M, Goormachtig S (2006) Aging in legume symbiosis. A molecular view on nodule senescence in Medicago truncatula. Plant Physiology 141: 711-720

van Velzen R, Holmer R, Bu F, Rutten L, van Zeijl A, Liu W, Santuari L, et al (2018) Comparative genomics of the nonlegume Parasponia reveals insights into evolution of nitrogenfixing rhizobium symbioses. Proceedings of the National Academy of Sciences of the United States of America preprint

Veereshlingam H, Haynes JG, Penmetsa RV, Cook DR, Sherrier DJ, Dickstein R (2004) nip, a symbiotic Medicago truncatula mutant that forms root nodules with aberrant infection threads and plant defense-like response. Plant Physiology 136: 3692-702

Verdier J, Torres-Jerez I, Wang M, Andriankaja A, Allen SN, He J, et al (2013) Establishment of the Lotus japonicus Gene Expression Atlas (LjGEA) and its use to explore legume seed maturation. Plant Journal 74: 351-362

Vincill ED, Szczyglowski K, Roberts DM (2005) GmN70 and LjN70. Anion transporters of the symbiosome membrane of nodules with a transport preference for nitrate. Plant Physiology 137: 1435-1444

Wang J, Hou Q, Li P, Yang L, Sun X, Benedito, VA, et al (2017a) Diverse functions of multidrug and toxin extrusion (MATE) transporters in citric acid efflux and metal homeostasis in Medicago truncatula. Plant Journal 90: 79-95

Wang Q, Yang S, Liu J, Terecskei K, Ábrahám E, Gombár A, Domonkos Á, Szűcs A, Körmöczi P, Wang T, Fodor L, Mao L, Fei Z, Kondorosi É, Kaló P, Kereszt A, Zhu H (2017b) 
Host-secreted antimicrobial peptide enforces symbiotic selectivity in Medicago truncatula. Proceedings of the National Academy of Sciences USA 114: 6854

Weaver CD, Shomer NH, Louis CF, Roberts DM (1994) Nodulin 26, a nodule-specific symbiosome membrane protein from soybean, is an ion channel. Journal of Biological Chemistry 269: $17858-17862$

Yang S, Wang Q, Fedorova E, Liu J, Qin Q, Zheng Q, Price PA, Pan H, Wang D, Griffitts JS, Bisseling T, Zhu H (2017) Microsymbiont discrimination mediated by a host-secreted peptide in Medicago truncatula. Proceedings of the National Academy of Sciences USA 114: 6848

Young ND, Debellé F, Oldroyd GED, Geurts R, Cannon SB, Udvardi MK, Benedito VA, Mayer KFX, Gouzy J, Schoof H, et al (2011) The Medicago genome provides insight into the evolution of rhizobial symbioses. Nature 480: 520-524

Yuegao H, Cash D (2009) Global status and development trends of alfalfa. Alfalfa management guide for Ningxia: 1-14

Zahran HH (1999) Rhizobium-legume symbiosis and nitrogen fixation under severe conditions and in an arid climate. Microbiology and Molecular Biology Reviews 63: 968-989

Zhao J, Dixon RA (2009) MATE transporters facilitate vacuolar uptake of epicatechin 3'-Oglucoside for proanthocyanidin biosynthesis in Medicago truncatula and Arabidopsis. Plant Cell 21: 2323-2340

Zhao J, Huhman D, Shadle G, He XZ, Sumner LW, Tang Y, Dixon RA (2011) MATE2 mediates vacuolar sequestration of flavonoid glycosides and glycoside malonates in Medicago truncatula. Plant Cell 23: 1536-1555 


\title{
Chapter 3
}

\section{Identification of Membrane Transporters of the Amino Acid Polyamine-Organocation (APC) Superfamily in Medicago truncatula Reveals Key Candidates for Amino Acid Transporter in Root Nodules}

\begin{abstract}
Symbiotic nitrogen fixation in legumes relies profoundly on the transport of nutrients, including amino acids, to infected cells of the nodules. Secondary transporters supply the necessary amino acids to and from the nitrogen fixation zone of nodules to support symbiotic nitrogen fixation. The biosynthesis pathways of amino acids to feed symbiosis is well understood, but the involved transporters, including importers and exporters, of amino acids to support infected cells are largely unknown. Transporters mediate passage of amino acids across membranes within cell organelles, from cell to cell, and from organ to organ. Relatively few amino acid transporters have been functionally characterized in legumes. The assimilation of ammonium during nitrogen fixation by the cytosol of the infected cell in temperate legumes requires amino acids to be exported to the xylem in order to travel to sink tissues for translocation of fixed organic nitrogen throughout the plant. The Amino Acid Polyamine-Organocation (APC) superfamily consists of 18 families and is the second largest superfamily of secondary carriers behind the Major Facilitator Superfamily (MFS) characterized in the Transporter Classification Database. The APC family proper (TCDB 2.A.3) is categorized within the APC superfamily, and consists of 15 subfamilies, two of which are present in plants. Manual curation of APC superfamily members in the Medicago truncatula proteome was performed leading to the identification of amino acid transporters potentially involved in the flux of amino acids during the symbiotic nitrogen fixation within nodules and an ideal candidate was found within the Cationic Amino Acid Transporter (CAT) Subfamily.
\end{abstract}




\section{INTRODUCTION}

\section{Centrality of Amino Acids in Legume Metabolism}

Amino acids are vital to support plant growth and function through transport of organic nitrogen thorughout the plant as precursors to nucleic acids, secondary metabolites, and hormones, in addition to the essential role they play as building blocks of proteins. Recent and historical research proposed that amino acids are among the first metabolites created by living organisms (Miller 1953; Hernandez-Montes et al., 2008). Recent studies predict biosynthetic routes of amino acids have multiple origins and evolved to biosynthetic network branches converging to the same end product (Hernandez-Montes et al., 2008). This could explain the integral involvement of amino acids in metabolic and cellular processes in plants and why amino acids are used to shuttle organic nitrogen within a plant (Pratelli and Pilot, 2014). Depending on environmental context and structure, amino acids can be anionic, cationic, or zwitterionic. Side chains can be aromatic, aliphatic, hydrophobic, semipolar, or strongly hydrophilic (Saier et al., 2000). Because of the size and structure of amino acids, movement within plants requires the transport across many membranes both across membranes within the plant as well as through organellar membranes within the cell. In the legume-Rhizobium symbiosis, amino acids move across membranes present in infected cells of the nodule in support of symbiotic nitrogen fixation.

In the legume nodule, amino acid transporters are essential to feed the nitrogen fixation process, as well as to dessiminate the fixed nitrogen throughout the plant. During symbiotic nitrogen fixation, plants provide dicarboxylic acids in the form of succinate or malate to the bacteroids as a carbon source and, in return, receive ammonia. Ammonia moves across the bacteroid membrane and is protonated in the acidic symbiosome space before being transported across the symbiosome membrane into the cytoplasm of the infected cell. There, ammonium and 2-oxoglutarate, also called $\alpha$-ketoglutarate, form glutamate through an amination reaction catalyzed by glutamate dehydrogenase (GDH). A condensation reaction of ammonia and glutamate by the enzyme glutamine synthetase (GS) forms glutamine, which can then be exported to sink tissues via the xylem of temperate legume species (Figure 3.1). Oxaloacetate originating from sucrose through the TCA cycle is converted to aspartate and 2-oxoglutarate by aspartate aminotransferase (AAT). Glutamine and aspartate can be converted to glutamate and asparagine 
by the enzyme asparagine synthetase (ASN) (Lea and Miflin, 1974; Temple et al., 1998; MasclauxDaubresse et al., 2005; Mérigout et al., 2008; Seabra and Carvalho, 2015; Zhang, 2017).

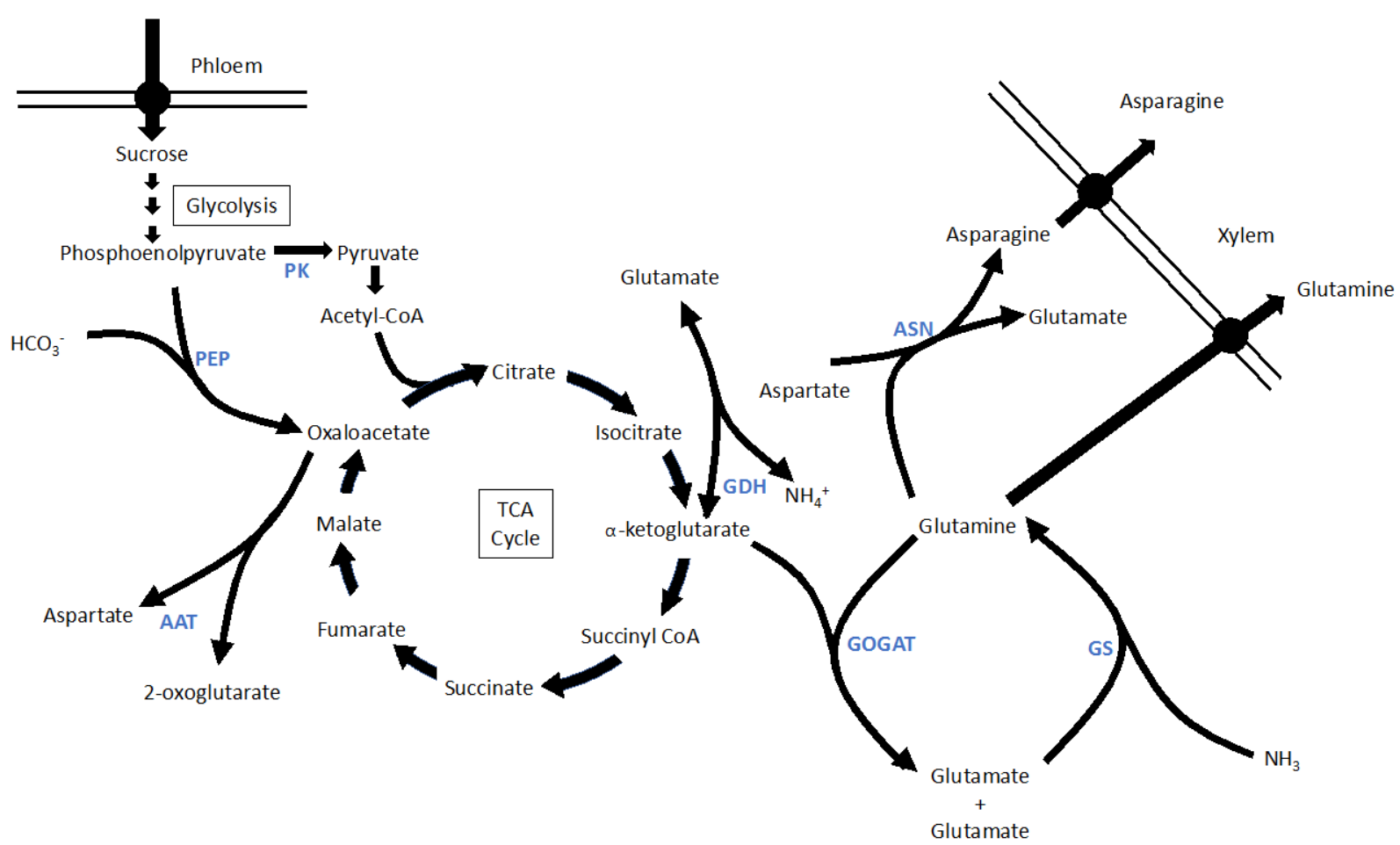

Figure 3.1. Nitrogen assimilation and the nitrogen cycle within nodules is highly integrated with carbon cycling. Anaplerotic reactions, such as those seen catalyzed by Phosphoenolpyruvate carboxylase (PEP) serve to form intermediates of the metabolic pathway and replenish the cycle.

An aspartate/glutamate shuttle has been proposed as an alternative way for the plant to supply reduced carbon to the bacteroid (Lodwig et al., 2003). The hypothesis is that glutamate, or a precursor to it, is delivered to the bacteroid to be utilized as a transamination donor during aspartate synthesis and then the shuttle delivers aspartate back out to the cytosol to be converted to asparagine by asparagine synthetase (ASN) and translocated to sink tissue (Lodwig et al., 2003). Another proposed model suggests alanine could be utilized to alternatively assimilate fixed nitrogen while still in the bacteroid and then transported into the plant cytosol where alanine, glutamate, and aspartate can be interconverted (Lodwig et al., 2003; Prell et al., 2009). This model has yet to be proven and creates the necessity to functionally characterize transporters involved in moving amino acids to, from and within infected cells to fill on the knowledge gaps of the field. 
In plants, amino acids are carriers of assimilated nitrogen between organs by both the xylem and phloem (Pratelli and Pilot, 2014). Glutamine and asparagine exported to the xylem are the primary amino acids used to shuttle organic nitrogen around the plant, and especially in temperate (galegoid) legumes, such as Medicago truncatula, pea, lentil, and chickpea. On the other hand, in tropical legumes, transport of nitrogen is done with the ureides allantoin and allantoic acid (Lea and Miflin, 1980; Peoples and Gifford, 1993; Lodwig et al., 2003; Pélissier et al., 2004, 2007).

In the galegoid clade, supplying branched-chain amino acids (BCAA: valine, leucine, and isoleucine) by the plant to bacteroids is essential for bacteroid development and persistance during symbiotic nitrogen fixation, since under symbiotic conditions bacteroids become auxotrophs for these amino acids. The specific transporters carrying out this essential function at the symbiosome membrane have not been identified (Rastogi and Watson, 1991; Lodwig et al., 2003; Prell et al., 2009, 2010).

We further explore the Medicago truncatula genome to identify genes coding for membrane proteins potentially related to amino acid transport activity. We aimed to create and curate an inventory of the APC superfamily, which encompasses important amino acid transporters in living organisms, and especially in plants. Then, we explore the transcriptional activity of these transporter genes to identify those highly or uniquely expressed in the nodule during active symbiotic nitrogen fixation. This catalogue is a resource to identify genes for further functional characterization in the search to better understand amino acid transport in the legume plant, and particularly, the role of amino acids in nodules.

\section{The APC Superfamily}

As with the Enzyme Commission (E.C.) numerical classification established for enzymes by the International Union of Biochemistry and Molecular Biology (IUBMB: http://www.sbcs.qmul.ac.uk/iubmb/), transporters are hierarchically classified according to their function and phylogenetic relationships accordingly with the IUBMB-ratified Transporter Classification system (TCDB: http://www.tcdb.org). The Amino Acid-Polyamine-Organocation (APC) superfamily is the second largest superfamily of electrochemical potential-driven secondary transporters (Wong et al., 2012; Vastermark et al., 2014), after only the Major Facilitator Superfamily (MFS), and includes 162 members in the TCDB. Since it was first described in 2000 
(Jack et al., 2000), the APC superfamily has expanded multiple times due to new phylogenetic relationships found with several other transporter families (Figure 3.2). The current composition of this superfamily consists of 18 families (Table 3.1), amongst which is the APC family proper (Jack et al., 2000; Wong et al., 2012; Vastermark et al., 2014).

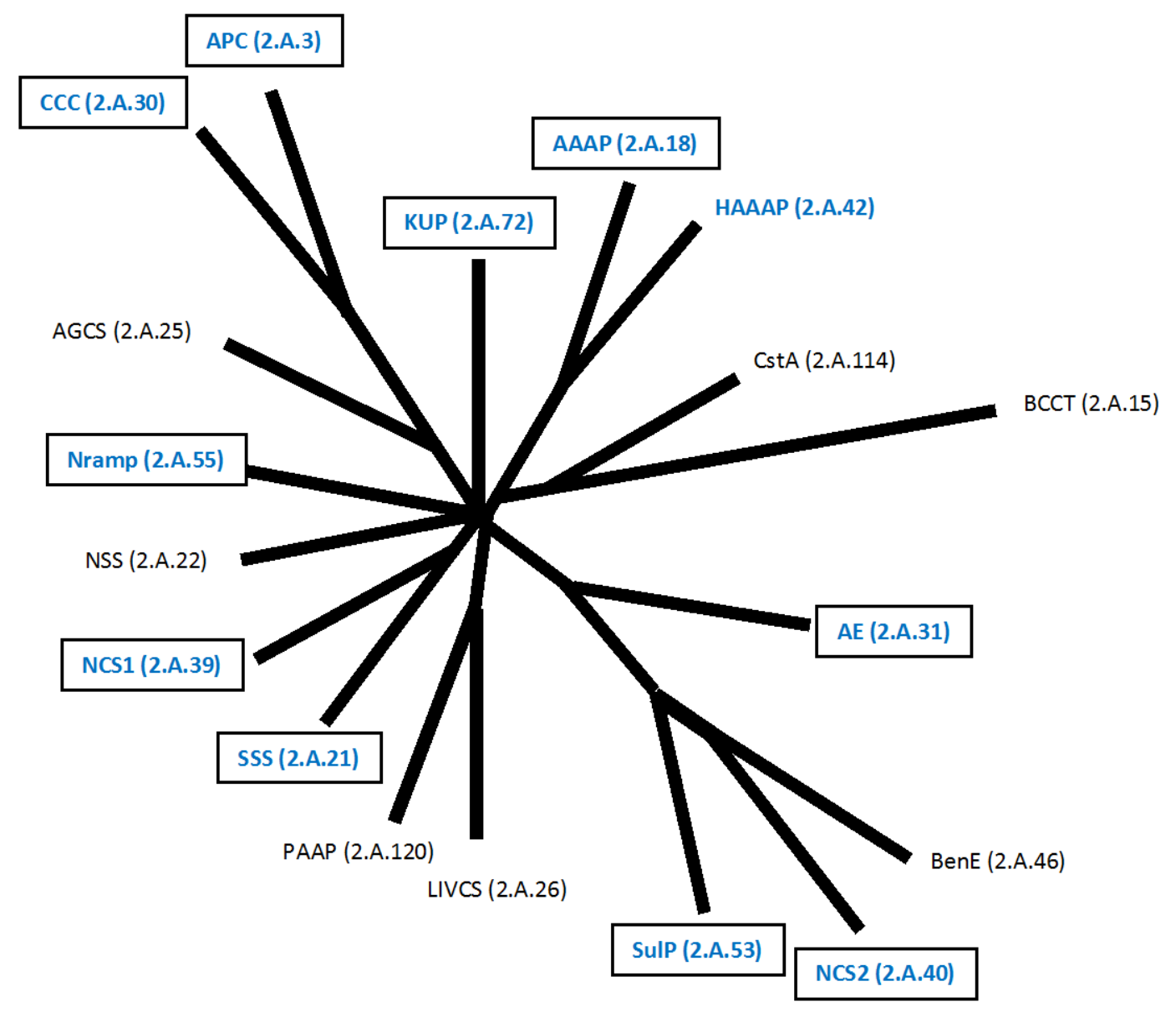

Figure 3.2. The APC Superfamily shows evolutionary relationships among several transporter families. Families identified in the Medicago truncatula genome are shown in blue, whereas those families with plant members in the TCDB database are shown in boxes. Adapted from Vastermark et al. (2014).

Transporters in the APC superfamily show an archetype with 4-7 transmembrane domains (TMD) that evolved into duplicated repeat sequences with some transporters exhibiting additional TMDs at the N- and C-termini (Wong et al., 2012; Vastermark et al., 2014). As a result, most families of the APC superfamily exhibit a 5+5 topology, with some showing a 7+7 topology 
structure, including SulP, BenE, AE, and NCS2 (Figure 3.2). The APC family proper (TCDB\# 2.A.3) is classified with a $5+5+2$ topology (12 TMD), the same as NSS (2.A.22), LIVCS (2.A.26), NRAMP (2.A.55), and KUP (2.A.72) (Vastermark et al., 2014).

\section{The APC Family proper}

The Amino acid-Polyamine-Organocation (APC, 2.A.3) family of membrane transporters contains solute:cation symporters and solute:solute antiporters (Schweikhard and Ziegler, 2012). APC transporters are present in all kingdoms of life, with polypeptide chains varying in lengths between 350 and 850 amino acid residues (Reig et al., 2007). Most members of the family have 12 transmembrane domains, but some have 10 or 14 TMDs.

The founding member of the APC family, the Arabidopsis thaliana amino acid permease AAP1, was first reported to have broad specificity of amino acid transport (Frommer et al., 1993; Kwart et al., 1993). However, another group reported it to rather be a histidine and alanine symporter (Hsu et al., 1993). AAP1 was later established to have affinity for glutamate, histidine, phenylalanine, and alanine and localize to the plasma membrane of root epidermal cells, root hairs, and the root tip for the uptake of organic nitrogen from the soil (Lee et al., 2007).

Okumoto and Pilot (2011) noted earlier that very few exporters have so far been identified due to inefficient screening techniques. Despite the fact that amino acid export activity is central for plant physiology, this statement still holds true to today. The Arabidopsis thaliana Bidirectional Amino acid Transporter 1 (BAT1) is expressed in vascular tissues and exports lysine and glutamic acid across the mitochondrial membrane as well as imports GABA, alanine, arginine in vascular tissues, therefore potentially being involved in phloem loading and unloading (Dündar and Bush, 2009; Michaeli et al., 2011). The Arabidopsis, Siliques are Red1 (SiAR1) is another bidirectional amino acid transporter at the plasma membrane capable of exporting glutamine and valine and importing aspartate (Ladwig et al., 2012). Bidirectional amino acid transport is also carried out by AtUMAMIT14, which imports glutamate and citrulline in seeds and exports glutamine, proline,

alanine, leucine, and lysine by unloading from phloem in roots (Müller et al., 2015; Besnard et al., 2016).

In the Transporter Classification Database (TCDB), 15 subfamilies are recognized under the APC family. TCDB refers to them as families, but for clarity here we will refer to them as 
subfamilies. So far, only two of these subfamilies have characterized plant members classified in the TCDB database: CAT and PHS (Table 3.1).

Table 3.1. The APC family proper consists of 15 subfamilies. Bolded subfamilies represent those in the Transporter Classification Database with functionally characterized plant members.

\begin{tabular}{|l|l|l|}
\hline APC subfamilies & TCDB \# \\
\hline Acronym & Subfamily & 2.A.3.1 \\
\hline AAT & Amino Acid Transporter & 2.A.3.2 \\
\hline APA & Basic Amino Acid/Polyamine Antiporter & 2.A.3.3 \\
\hline CAT & Cationic Amino Acid Transporter & 2.A.3.4 \\
\hline EAT & Amino Acid/Choline Transporter & 2.A.3.5 \\
\hline ABT & Ethanolamine Transporter & 2.A.3.6 \\
\hline GGA & Archaeal/Bacterial Transporter & 2.A.3.7 \\
\hline LAT & Glutamate:GABA Antiporter & 2.A.3.8 \\
\hline SGP & L-type Amino Acid Transporter & 2.A.3.9 \\
\hline YAT & Spore Germination Protein & 2.A.3.10 \\
\hline AGT & Yeast Amino Acid Transporter & 2.A.3.11 \\
\hline PHS & Aspartate/Glutamate Transporter & 2.A.3.12 \\
\hline AAE & Polyamine:H ${ }^{+}$Symporter & 2.A.3.13 \\
\hline U-APC1 & Amino Acid Efflux & 2.A.3.14 \\
\hline U-APC2 & Unknown APC-1 & 2.A.3.15 \\
\hline
\end{tabular}

Identification of APC Superfamily members in the Medicago truncatula genome

To facilitate characterization of membrane transporters, we analyzed the Medicago truncatula proteome Mt4.0v2 annotation (Krishnakumar et al., 2014) using the TransportTP Prediction Server ( $\mathrm{Li}$ et al., 2009). Of the 57,585 genes annotated in the genome, we found 1774 putative transporters. With amino acid transport in mind, we further analyzed more closely and manually curated putative transporters within the 18 families encompassing the APC superfamily (Table 3.1). The TransportTP output rendered 212 putative transporters within 10 of the APC families. The transporters were curated for family and subfamily feature consistencies with functionally characterized transporters in the TCDB, membrane topology (number of TMDs), expected size of the protein, similarity to proteins in the SwissProt database (Boeckmann et al., 
2003), Gene Ontology (GO) classification (Ashburner et al., 2000; The Gene Ontology Consortium, 2017), and identification of expected Pfam domains (Finn et al., 2016).

Table 3.2. Transporter identification of the Medicago truncatula proteome. Sequences were analyzed by the prediction server TransporterTP. Proteins belonging to the APC Superfamily were further manually curated for potential functionality according to key characteristics of their respective families.

\begin{tabular}{|l|r|}
\hline Protein Sequences & Number \\
\hline Number of proteins annotated in the genome & 57,585 \\
\hline Proteins with TCDB homologs & 1774 \\
\hline APC Superfamily transporters (10 families) & 212 \\
\hline $\begin{array}{l}\text { Curated APC superfamily proteins consistent with transporter } \\
\text { function }\end{array}$ & 130 \\
\hline
\end{tabular}

Transporter families have distinguishing characteristics including protein length, number of transmembrane domains, and conserved domains. These characteristics were used to classify transporters and to determine the level of confidence for that classification and functionality of the transporter, as described in Benedito et al. (2010). A confidence ranking of level 1 was used for putative transporters consistent with all features of the family of proteins. A confidence level 2 was used when the protein deviated marginally from expected features or did not find a hit in annotated databases. A confidence level 3 was assigned when the function of a protein is doubtful due to major deviations of key features of the family (e.g., unexpected number of TMDs, inconsistent protein size, lack of a key conserved domain, similarity to well-characterized nontransporter proteins).

Of the 212 proteins found in the APC superfamily, 130 are consistent with potential function demonstrating typical protein length, typical number of TMDs for the family, and conserved protein domains predicted by Pfam (Finn et al., 2016), Gene Ontology (GO) classification (http://www.geneontology.org/), and significant similarity with proteins in the curated Swiss-Prot database (Boeckmann et al., 2003). (Supplemental Table 1).

\section{Transporter gene expression shows two nodule specific members in the APC Superfamily}

Fourteen transporters were expressed in an organ-specific manner across five APC families (APC, AAAP, AE, NCS2, Nramp). Three transporters were expressed in only roots and nodules: 
Medtr8g089320.1 and Medtr8g089340.1 (2.A.3.3), and Medtr1g093030.1 (2.A.18). Two genes were specific to nodules, with one very lowly expressed (AAAP, 2.A.18.2: Medtr4g103890.1) and the highly expressed Medtr8g089360.1 (Supplemental Table 1) (Young et al., 2011). Indeed, Medtr8g089360.1 (MtAPC1 - cf. Chapter 4 of this dissertation) is expressed in a nodule-specific manner (Figure 3.3) and belongs to the cationic amino acid transporter (CAT) subfamily (TCDB \#2.A.3.3), which is conserved in both animal and plant kingdoms (Tegeder and Ward, 2012).

Interestingly, two of the three genes expressed exclusively in roots and nodules are closely related to and clustered in tandem with Medtr8g089360.1 on chromosome 8. Given the limited number of nodule-specific transporters in the APC Superfamily, it is reasonable to propose that this specific expression is indicative of an essential function to symbiotic nitrogen fixation in the transport of crucial amino acids to the process. 


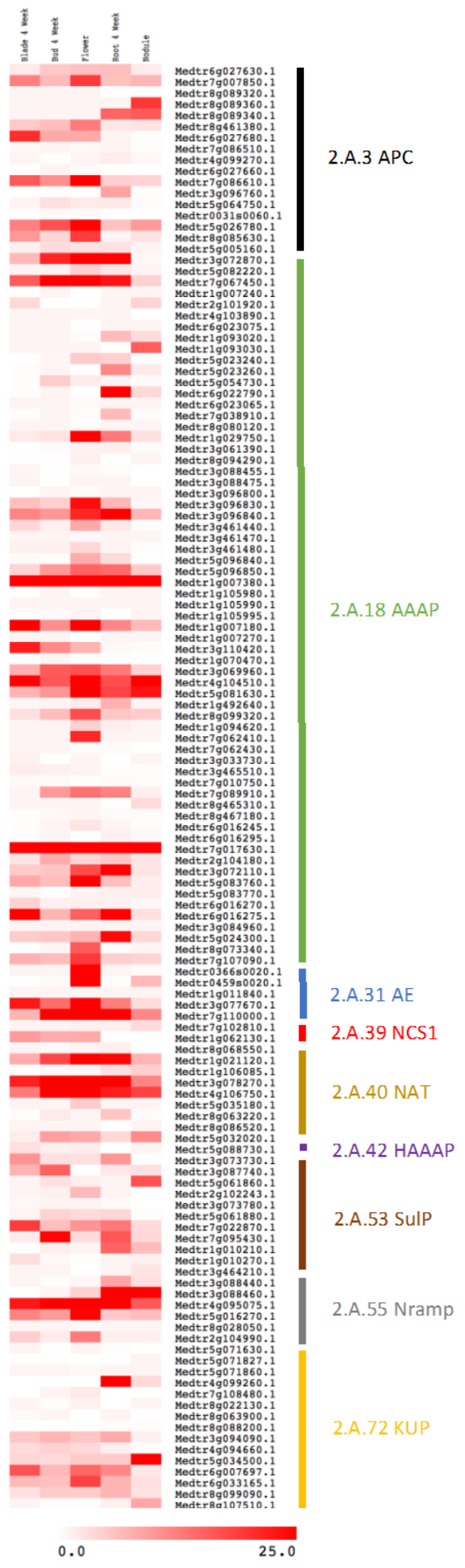

Figure 3.3. Expression of APC Superfamily members with expression in blade, bud, flower, root and nodule organs that were classified with either confidence level 1 or 2 constructed using $\mathrm{MeV}$ (Howe et al., 2011) from RNA-seq data based on TPM (transcripts per million reads) (Young et al., 2011). White shows basal expression with higher expression shown in red. 


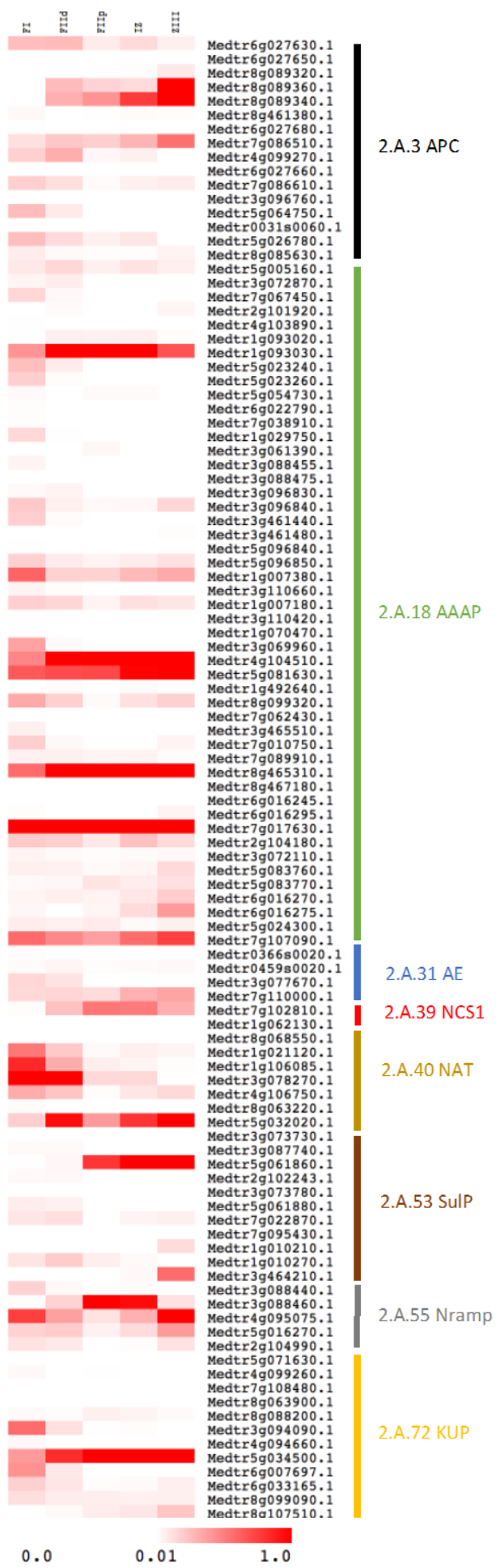

Figure 3.4. Expression of APC Superfamily members with expression in the nodule zones that were classified with either confidence level of one or two constructed using MeV (Howe et al., 2011) from RNAseq data based on TPM (transcripts per million reads) (Roux et al., 2014). FI, meristem; FIId, distal to the interzone; FIIp, proximal to the interzone; IZ, interzone; ZIII, nitrogen fixation zone. White shows basal expression with higher expression shown in red. 


\section{The Cationic Amino acid Transporter (CAT) subfamily in plants}

The most highly expressed nodule specific gene found during our transporter analysis of the APC superfamily belongs to the Cationic Amino acid Transporter subfamily. The CAT subfamily was so named because the first transporters characterized from mammalian species had preferential affinity to cationic amino acids including arginine, leucine, and lysine (Van Winkle et al., 1985; Van Winkle et al., 1988; Kim et al., 1991; Wang et al., 1991). However, only some plant members show preferential transport of cationic amino acids. Eukaryotic CAT transporters show a unique topology with 14 TMDs while prokaryotic CAT members consistently have 12 TMDs. Moreover, most other transporters within the APC superfamily also have 12 TMDs regardless of whether they are prokaryotic or eukaryotic, excluding those in the Spore Germination Protein Subfamily, which typically have 10 TMDs (2.A.3.9) (Jack et al., 2000). Arabidopsis CAT proteins localize to several types of membranes including the plasma membrane, tonoplast and endoplasmic reticulum and do not show specificity for individual amino acids, but rather groups of amino acids (Table 3.3) (Su et al., 2004; Hammes et al., 2006; Yang et al., 2010; Yang et al., 2014).

Table 3.3. Functionally characterized CAT transporters in Arabidopsis thaliana.

\begin{tabular}{|c|c|c|c|}
\hline Gene & Gene ID & Substrate Affinity & $\begin{array}{c}\text { Subcellular } \\
\text { Localization }\end{array}$ \\
\hline CAT1 & At4g21120 & basic, acidic, neutral & PM \\
\hline CAT2 & At1g58030 & n.d. & VM \\
\hline CAT3 & At5g36940 & neutral or acidic & ER \\
\hline CAT4 & At3g03720 & n.d. & VM \\
\hline CAT5 & At2g34960 & basic & PM \\
\hline CAT6 & At5g04770 & neutral or acidic & PM \\
\hline CAT7 & At3g10600 & n.d. & n.d. \\
\hline CAT8 & At1g17120 & neutral or acidic & VM \\
\hline CAT9 & At1g05940 & n.d. & VM \\
\hline
\end{tabular}

PM, plasma membrane; VM, vacuolar membrane; ER, endoplasmic reticulum. (Su et al., 2004; Hammes et al., 2006; Yang et al., 2010; Yang et al., 2014). n.d.: not determined. 


\section{The CAT subfamily in the model legume, Medicago truncatula}

In the Medicago truncatula genome, we identified thirteen CAT transporter genes. The nodule-specific MtAPC1 transporter (Medtr8g089360.1) is closely related to Arabidopsis CAT1 (Figure 3.5), which transports basic amino acids with high affinity (Fisher et al., 1995) as well as acidic and neutral amino acids to a lesser extent (Frommer et al., 1995). 


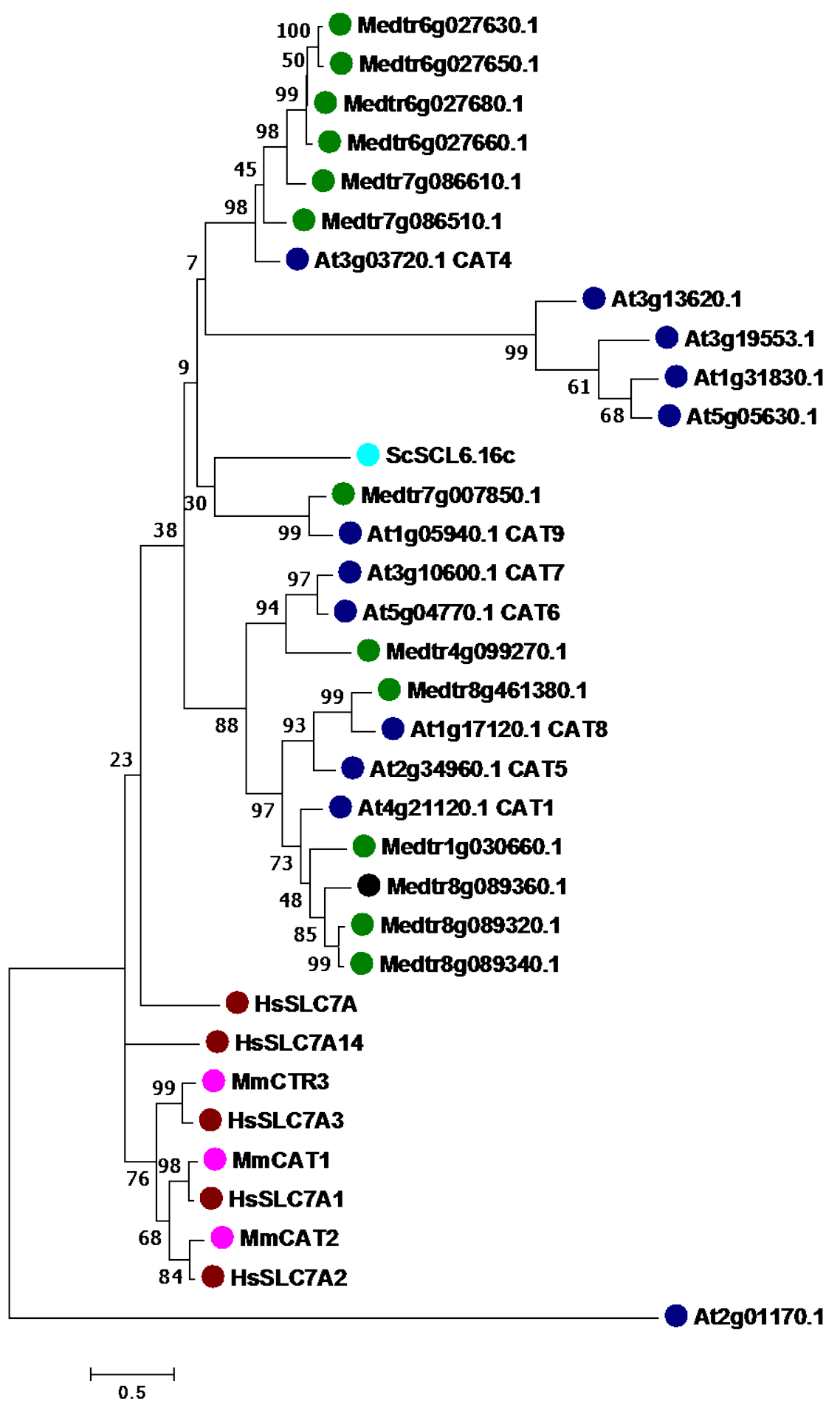

Figure 3.5. Maximum likelihood phylogenetic analysis of all prokaryotic and eukaryotic CAT subfamily transporters present in the Transporter Classification Database (www.TCDB.org) along with all Arabidopsis thaliana members (shown with blue dots) and all Medicago truncatula family members (shown with green dots and nodule specific Medtr8g089360.1 shown with a black dot). Human subfamily members are shown with red dots, mouse (Mus musculus) are shown with pink dots, and Saccharomyces cerevisiae is shown with a light blue dot. Branch length represents average residue substitution per site. 
Medtr8g089360.1, MtAPC1, is closely related to Medtr8g089340.1 and Medtr8g089320.1. This local triplication was possibly created by asymmetrical recombinations during the evolution of the Medicago genome and may account for potential functional redundancies (Figure 3.5). Also closely related is the Arabidopsis CAT1, which has been shown to transport basic amino acids and positively charged amino acids and localize to the plasma membrane (Frommer et al., 1995; Su et al., 2004). The Arabidopsis CAT5 transports basic amino acids and localized to the plasma membrane (Su et al., 2004).

Herein, we identified 212 genes potentially coding for membrane transporters belonging to the APC Superfamily. Amongst these, we found that 130 present features consistent with functional activity. 106 were expressed in nodules, with 2 being nodule-specific. We have selected Medtr8g0893601.1 (MtAPC1) for further functional characterization, which is presented in the next chapter of this dissertation.

\section{MATERIALS AND METHODS}

Transporter analysis: Medicago truncatula genome Mt4.0v2 protein annotation from (http://www.medicagogenome.org/downloads) was uploaded to the TransportTP Transporter Prediction server (http://bioinfo3.noble.org/transporter/; Li et al., 2009). Reference organism used was Arabidopsis thaliana with an E-value threshold of 0.05. Amino acid length was added as well as gene expression data from Young et al., 2011. Levels of classification were annotated based on protein characteristics of families classified in TCDB.org (protein length, number of TMDs) and through Pfam (https://pfam.xfam.org/; Finn et al., 2016), Gene Ontology (GO) (http://www.geneontology.org/), and the well annotated Swiss-Prot database (http://www.uniprot.org/; Boeckmann et al., 2003). Level 1 confidence indicated consistency to family characteristics, level 2 indicated slight divergence from family characteristics, and level 3 indicated doubtful functionality of a protein due to (small or large protein size and absence of or unexpected TMDs not characteristic of the family).

Heatmap analysis: The heatmap showing gene expression in mature plant organs growing under optimal conditions was constructed using MeV (http://mev.tm4.org/; Howe et al., 2011) from RNA-seq data based on TPM (transcript per million total reads) (Young et al., 2011; Roux et al., 2014).

Phylogenetic Analyses and membrane topology prediction: Phylogenetic trees were produced using MEGA v.7 (Molecular Evolutionary Genetics Analysis) software (Tamura et al., 2012) by the maximum likelihood method with 1,000 bootstraps. Protein sequences were aligned using 
muscle and imported into construct/test maximum parsimony tree with the following parameters: Ten initial trees, MP search level 1, and complete deletion of Gaps/Missing data. The evolutionary history was inferred by using the Maximum Likelihood method based on the JTT matrix-based model (Jones et al., 1992). The tree with the highest log likelihood is shown. The percentage of trees in which the associated taxa clustered together is shown next to the branches. Initial tree(s) for the heuristic search were obtained automatically by applying the Maximum Parsimony method. The tree is drawn to scale, with branch lengths measured in the number of substitutions per site. All positions containing gaps and missing data were eliminated. Evolutionary analyses were conducted in MEGA7 (Kumar et al., 2016). Medicago truncatula sequences were obtained from http://bioinfo3.noble.org/getseq/. 


\section{REFERENCES}

Ashburner M, et al (2000) Gene ontology: tool for the unification of biology. Nature Genetics 25: 25-29

Benedito VA, Li H, Dai X, Wandrey M, He J, Kaundal R, Torres-Jerez I, Gomez SK, Harrison MJ, Tang Y, Zhao PX, Udvardi M (2010) Genomic inventory and transcriptional analysis of Medicago truncatula transporters. Plant Physiology 152: 1716-1730

Besnard J, Pratelli R, Zhao C, Sonawala U, Collakova E, Pilot G, Okumoto S (2016) UMAMIT14 is an amino acid exporter involved in phloem unloading in Arabidopsis roots. Journal of Experimental Botany 67: 6385-6397

Boeckmann B, Bairoch A, Apweiler R, Blatter MC, Estreicher A, Gasteiger E, Martin MJ, Michoud K, O'Donovan C, Phan I, et al (2003) The SWISS-PROT protein knowledgebase and its supplement TrEMBL in 2003. Nucleic Acids Research 31: 365-370

Chaturvedi N, Shanker S, Singh VK, Sinha D (2011) Hidden markov model for the prediction of transmembrane proteins using MATLAB. Bioinformation 7: 418-421

Coruzzi G (2003) Primary N-assimilation into amino acids in Arabidopsis. The Arabidopsis book. Edited by: Meyerowitz EM. Rockville, MD, American Society of Plant Biologists

Dündar E, Bush DR (2009) BAT1, a bidirectional amino acid transporter in Arabidopsis. Planta 229: $1047-1056$

Finn RD, Coggill P, Eberhardt RY, Eddy SR, Mistry J, Mitchell AL, et al (2016) The Pfam protein families database: towards a more sustainable future. Nucleic Acids Research 44: 279-285

Fischer WN, Kwart M, Hummel S, Frommer WB (1995) Substrate specificity and expression profile of amino acid transporters (AAPs) in Arabidopsis. Journal of Biological Chemistry 270: $16315-16320$

Frommer WB, Hummel S, Riesmeier JW (1993) Expression cloning in yeast of a cDNA encoding a broad specificity amino acid permease from Arabidopsis thaliana. Proceedings of the National Academy of Sciences, USA 90: 5944-5948

Frommer WB, Ninnemann O (1995) Heterologous expression of genes in bacterial, fungal, animal and plant cells. Annual Review of Plant Physiology and Plant Molecular Biology 46: 419444

The Gene Ontology Consortium (2017) Expansion of the Gene Ontology knowledgebase and resources. Nucleic Acids Research 45: 331-338

Hammes UZ, Nielsen E, Honaas LA, Taylor CG, Schachtman DP (2006) AtCAT6, a sink tissue-localized transporter for essential amino acids in Arabidopsis. Plant Journal 48: 414-426 
Hernandez-Montes G, Diaz-Mejia JJ, Perez-Rueda E, Segovia L (2008) The hidden universal distribution of amino acid biosynthetic networks: a genomic perspective on their origins and evolution. Genome Biology 9: 95

Howe EA, Sinha R, Schlauch D, Quackenbush J (2011) RNA-Seq analysis in MeV. Bioinformatics 27: 3209-10

Hsu LC, Chiou TJ, Chen L, Bush DR (1993) Cloning a plant amino acid transporter by functional complementation of a yeast amino acid transport mutant. Proceedings of the National Academy of Sciences, USA 90: 7441-7445

Jack DL, Paulsen IT, Saier MH, Jr (2000). The amino acid/polyamine/organocation (APC) superfamily of transporters specific for amino acids, polyamines and organocations. Microbiology 146: $1797-1814$

Jones DT, Taylor WR, Thornton JM (1992) The rapid generation of mutation data matrices from protein sequences. Computer Applications in the Biosciences 8: 275-282

Kim JW, Closs EI, Albritton LM, Cunningham JM (1991) Transport of cationic amino acids by the mouse ecotropic retrovirus receptor. Nature 352: 725-728

Krishnakumar V, Kim M, Rosen BD, Karamycheva S, Bidwell SL, Tang T, Town CD (2014) MTGD: The Medicago truncatula genome database. Plant and Cell Physiology 56: 1

Kumar S, Stecher G, Tamura K (2016). MEGA7: Molecular Evolutionary Genetics Analysis version 7.0 for bigger datasets. Molecular Biology and Evolution 33: 1870-1874

Kwart M, Hirner B, Hummel S, Frommer WB (1993) Differential expression of two related amino acid transporters with differing substrate specificity in Arabidopsis thaliana. Plant Journal 4: 993-1002

Ladwig F, Stahl M, Ludewig U, Hirner AA, Hammes UZ, Stadler R, Harter K, Koch W (2012) Siliques Are Red1 from Arabidopsis acts as a bidirectional amino acid transporter that is crucial for the amino acid homeostasis of siliques. Plant Physiology 158: 1643-1655

Lea PJ (1993) Nitrogen metabolism. In PJ Lea, RC Leegood, eds, Plant Biochemistry and Molecular Biology. John Wiley \& Sons, Chichester, UK, 155-180

Lea PJ, Miflin BJ (1974) Alternative route for nitrogen assimilation in higher plants. Nature 251: 614-616

Lea PJ, Miflin BJ (Ed.), (1980). The Biochemistry of Plants, 5, Academic Press, New York: 569

Lee YH, Foster J, Chen J, Voll LM, Weber APM, Tegeder M (2007) AAP1 transports uncharged amino acids into roots of Arabidopsis. Plant Journal 50: 305-319 
Li H, Benedito VA, Udvardi MK, Zhao PX (2009) TransportTP: A two-phase classification approach for membrane transporter prediction and characterization. BMC Bioinformatics 10: 418

Lodwig EM, Hosie AHF, Bourdès A, Findlay K, Allaway D, Karunakaran R, Downie JA, Poole PS (2003) Amino-acid cycling drives nitrogen fixation in the legume-Rhizobium symbiosis. Nature 422: 722-726

Masclaux-Daubresse C, Carrayol E, Valadier MH (2005) The two nitrogen mobilisation- and senescence-associated GS1 and GDH genes are controlled by C and N metabolites. Planta 221: 580-588

Merigout P, Lelandais M, Bitton F, Renou JP, Briand X, Meyer C, Daniel-Vedele F (2008) Physiological and transcriptomic aspects of urea uptake and assimilation in Arabidopsis plants. Plant Physiology 147: 1225-1238

Michaeli S, Fait A, Lagor K, Nunes-Nesi A, Grillich N, Yellin A, Bar D, Khan M, Fernie AR, Turano FJ, Fromm H (2011) A mitochondrial GABA permease connects the GABA shunt and the TCA cycle, and is essential for normal carbon metabolism. The Plant Journal 67: 485-498

Miller SL (1953) A production of amino acids under possible primitive earth conditions. Science 117: 528-529

Möller S, Croning MD, Apweiler R (2001) Evaluation of methods for the prediction of membrane spanning regions. Bioinformatics 17: 646-653

Müller B, Fastner A, Karmann J, Mansch V, Hoffmann T, Schwab W, Suter-Grotemeyer M, Rentsch D, Truernit E, Ladwig F, Bleckmann A, Dresselhaus T, Hamme UZ (2015) Amino acid export in developing arabidopsis seeds depends on UmamiT facilitators. Current Biology 25: 3126-3131

Okumoto S, Pilot G (2011) Amino acid export in plants: A missing link in nitrogen cycling. Molecular Plant 4: 453

Peoples MB, Gifford RM (1990) Plant Physiology, Biochemistry and Molecular Biology (Dennis D. T., Turpin D. H., eds.) 442-455, Longman Scientific, Essex

Pélissier HC, Frerich A, Desimone M, Schumacher M, Tegeder M (2004) PvUPS1, an allantoin transporter in nodulated roots of French bean. Plant Physiology 134: 664- 675

Pélissier HC, Tegeder M (2007) PvUPS1 plays a role in source-sink transport of allantoin in French bean (Phaseolus vulgaris L.). Functional Plant Biology, 34: 282- 291

Pratelli R, Pilot G (2014) Regulation of amino acid metabolic enzymes and transporters in plants. Journal of Experimental Botany 65: 5535-5556 
Prell J, Bourdès A, Kumar S, Lodwig E, Hosie A, Kinghorn S, White J, Poole P (2010) Role of symbiotic auxotrophy in the Rhizobium-legume symbioses. PLoS One 5: 13933

Prell J, White JP, Bourdes A, Bunnewell S, Bongaerts RJ, Poole PS (2009) Legumes regulate Rhizobium bacteroid development and persistence by the supply of branched-chain amino acids. Proceedings of the National Academy of Sciences, USA 106: 12477-12482

Rastogi VK, Watson RJ (1991) Aspartate aminotransferase activity is required for aspartate catabolism and symbiotic nitrogen fixation in Rhizobium meliloti. Journal of Bacteriology 173: 2879-2887

Reig N, del Rio C, Casagrande F, Ratera M, Gelpí JL, Torrents D, Henderson PJF, Xie H, Baldwin SA, Zorzano A, Fotiadis D, Palacin M (2007) Functional and structural characterization of the first prokaryotic member of the L-amino acid transporter (LAT) family: a model for APC transporters. Journal of Biological Chemistry 282: 13270-13281

Roux B, Rodde N, Jardinaud MF, Timmers T, Sauviac L, Cottret L, Carrère S, Sallet E, Courcelle E, Moreau S, Debellé F, Capela D, de Carvalho-Niebel F, Gouzy J, Bruand C, Gamas P (2014), An integrated analysis of plant and bacterial gene expression in symbiotic root nodules using laser-capture microdissection coupled to RNA sequencing. Plant Journal 77: 817837

Saier MH, Jr (2000) A functional-phylogenetic classification system for transmembrane solute transporters. Microbiology and Molecular Biology Review 64: 354-411

Schweikhard ES, Ziegler CM (2012) Amino acid secondary transporters: toward a common transport mechanism. Current Topics in Membranes 70: 1-28

Seabra AR, Carvalho HG (2015) Glutamine synthetase in Medicago truncatula, unveiling new secrets of a very old enzyme. Frontiers in Plant Science 6: 578

Su YH, Frommer WB, Ludewig U (2004) Molecular and functional characterization of a family of amino acid transporters from Arabidopsis. Plant Physiology 136: 3104-3113

Tamura K, Battistuzzi FU, Billing-Ross P, Murillo O, Filipski A, Kumar S (2012) Estimating divergence times in large molecular phylogenies. Proceedings of the National Academy of Sciences, USA 109: 19333-19338

Tegeder M, Ward JM (2012) Molecular evolution of plant AAP and LHT amino acid transporters. Frontiers in Plant Science 3: 21

Temple SJ, Vance CP, Gantt JS (1998) Glutamate synthase and nitrogen assimilation. Trends Plant Science 3: 51-56 
Van Winkle, LJ, Christensen HN, Campione AL (1985). Na-dependent transport of basic, zwitterionic, and bicyclic amino acids by a broad-scope system in mouse blastocysts. Journal of Biological Chemistry 260: 12118-12123

Van Winkle LJ, Campione AL, Gorman JM (1988) $\mathrm{Na}^{+}$-independent transport of basic and zwitterionic amino acids in mouse blastocysts by a shared system and by processes which distinguish between these substrates. Journal of Biological Chemistry 263: 3150-3163

Vastermark A, Wollwage S, Houle ME, Rio R, Saier MH (2014) Expansion of the APC superfamily of secondary carriers. Proteins 82: 2797-2811

Wang H, Kavanaugh MP, North RA, Kabat D (1991) Cell-surface receptor for ecotropic murine retroviruses is a basic amino-acid transporter. Nature 352: 729-731

Wong FH, Chen JS, Reddy V, Day JL, Shlykov MA, Wakabayashi ST, Saier MH, Jr (2012) The amino acid-polyamine-organocation superfamily. Journal of Molecular Microbiology Biotechnology 22: 105-113

Yang H, Bogner M, Stierhof YD, Ludewig U (2010) H+-independent glutamine transport in plant root tips PLoS ONE 5: 8917

Yang, H, Krebs M, Stierhof YD, Ludewig U (2014) Characterization of the putative amino acid transporter genes AtCAT2, 3 \&4: the tonoplast localized AtCAT2 regulates soluble leaf amino acids. Journal of Plant Physiology 171: 594-601

Young ND, Debellé F, Oldroyd GED, Geurts R, Cannon SB, Udvardi MK, Benedito VA, Mayer KFX, Gouzy J, Schoof H (2011) The Medicago genome provides insight into the evolution of rhizobial symbioses. Nature 480: 520-524

Zhang Z, Xiong S, Wei Y, Meng X, Wang X, Ma X (2017) The role of glutamine synthetase isozymes in enhancing nitrogen use efficiency of N-efficient winter wheat. Scientific Reports 7: 1000 


\section{Chapter 4}

\section{Functional characterization of the Medicago truncatula nodule-specific amino acid transporter MtAPC1}

Amino acid transport in legumes is crucial to shuttle organic nitrogen throughout the plant and aid in cellular and metabolic processes. During symbiotic nitrogen fixation, when atmospheric nitrogen is reduced and assimilated into amino acids in the nodule, amino acids must cross membranes to feed bacteroids, allow nitrogen assimilation, and be exported to other parts of the plant. Little is known about the genetic identities of transporters involved in moving amino acids across membranes in the root nodule. In an attempt to better understand the molecular mechanisms involved in the symbiotic nitrogen fixation process, we aimed to study Amino Acid PolyamineOrganocation (APC) transporters within the model organism Medicago truncatula. APC transporters generally have affinity for groups of amino acids rather than to a specific amino acid. In plants, the Cationic Amino acid Transporter (CAT) (sub)family encompassed by the APC family shows affinity to basic, acidic, and neutral amino acids. In the Medicago truncatula genome, we identified thirteen CAT genes. Medtr8g089360.1, here called MtAPC1 is nodule specific and highly expressed in the nitrogen fixation zone. RNAi analysis showed MtAPC1 is non-essential to symbiotic nitrogen fixation, potentially due to gene redundancy with another CAT gene that co-expresses strongly, but non-specifically in nodules. MtAPC1 is localized to the plasma membrane in the Nicotiana benthamiana leaf infiltration heterologous transient expression system. MtAPC1 did not show amino acid import activity in yeast. Altogether, our results suggest that MtAPC1 may be associated with, but not essential for amino acid trafficking within the infected cells in the nitrogen fixation zone, or the translocation of amino acids to the rest of the plant. 


\section{INTRODUCTION}

\section{The essentiality of amino acid transporters in legumes to enable symbiotic nitrogen fixation}

Plants are capable of taking up nitrogen from the soil in the form of ammonium or nitrate and assimilating it into amino acids for plant utilization (Andrews et al., 2013). Remarkably, legumes can also assimilate into amino acids the ammonium produced via symbiotic nitrogen fixation resulting from the reduction of atmospheric dinitrogen. After assimilation by the plant, amino acids serve many critical roles for plant function, ranging from shuttling organic nitrogen throughout the plant, to acting as precursors of hormones, nucleic acids and secondary metabolites, to providing the building blocks of proteins (Wink, 2013; Tegeder, 2014). Transport of amino acids is essential to allow translocation from the point of assimilation in the cytosol of the nodule infected cells after nitrogen fixation to elsewhere in the plant (Day et al., 2001; Tegeder, 2012). In order for polar or large substances, such as amino acids, to be translocated in the plant or moved within organelles in the cell, appropriate transporters embedded in biological membranes must be present. Currently, despite its essentiality to the process, very little is known about the molecular identifies of amino acid transporters that sustain symbiotic nitrogen fixation in legumes. This missing information is, however, key for our full understanding and further biotechnological manipulations of this important agricultural trait. 


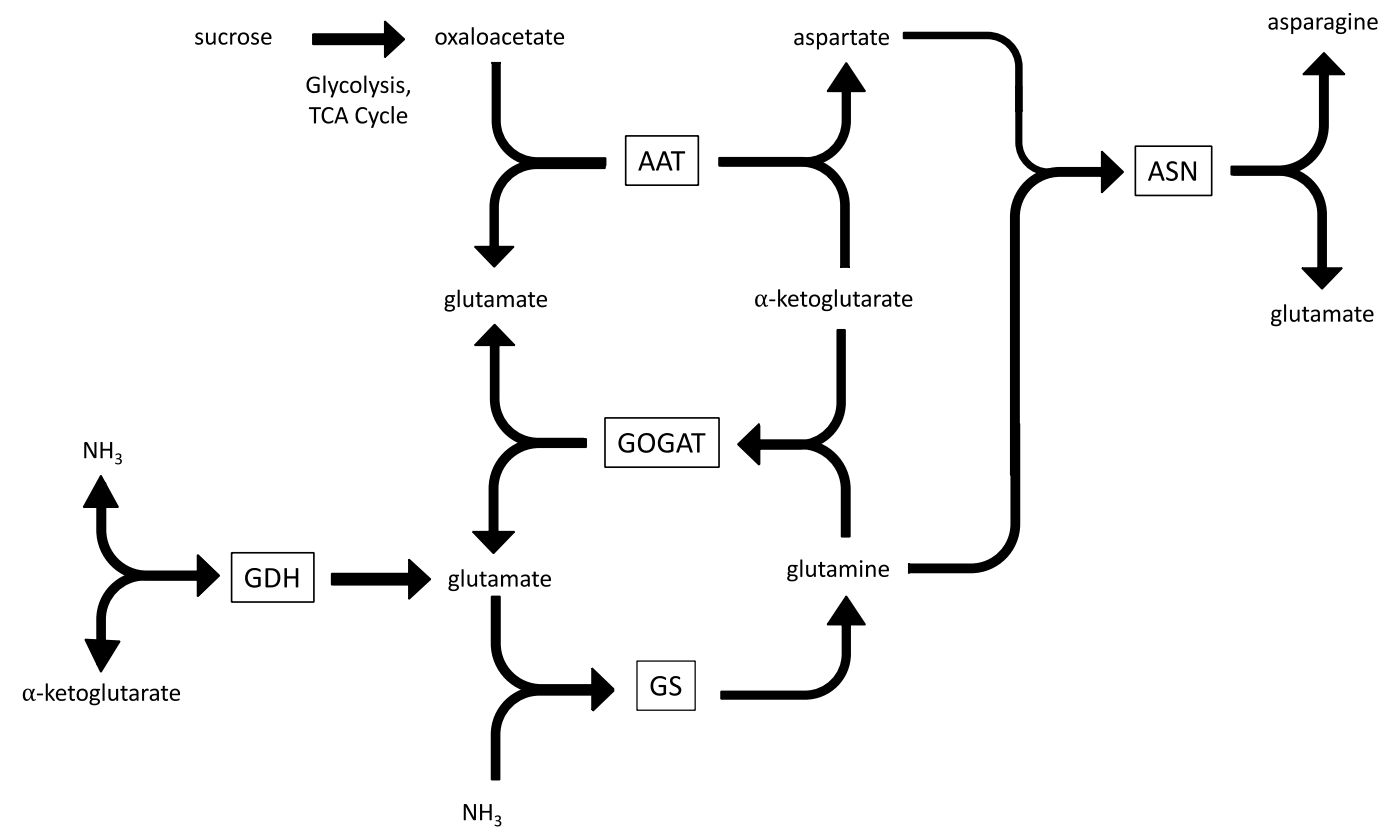

Figure 4.1. Nitrogen assimilation cycle in legumes. 2-oxoglutarate is aminated by GDH to form glutamate. Glutamate can interchange to glutamine and back via the GS/GOGAT cycle. AAT interconverts oxaloacetate plus glutamate into aspartate plus 2-oxoglutarate. Glutamine can be used to transaminate aspartate in order to produce glutamate and asparagine by ASN. In temperature legumes like Medicago truncatula, the assimilated forms of symbiotically fixed nitrogen translocated from nodules to other parts of the plants via xylem are glutamine and asparagine. GDH, Glutamate Dehydrogenase; GOGAT, Glutamate Synthase; GS, Glutamine Synthetase; AAT, Aspartate Aminotransferase; ASN, Asparagine Synthetase. Adapted from Mérigout et al., 2008.

It is estimated that in higher plants 95 percent of ammonium is assimilated via the GS/GOGAT pathway. Glutamate is formed by 2-oxoglutarate, also called $\alpha$-ketoglutarate, via amination by Glutamate Dehydrogenase (GDH) (Figure 4.1). Glutamine Synthetase (GS) catalyzes the first step of nitrogen assimilation via a condensation reaction of ammonia and glutamate to form glutamine. Glutamate Synthase (GOGAT) acts opposite to GS, synthesizing glutamate from glutamine. Oxaloacetate can be converted to aspartate by the enzyme Aspartate Aminotransferase (AAT). Asparagine Synthetase (ASN) converts aspartate and glutamine to asparagine and glutamate (Lea and Miflin, 1974; Masclaux-Daubresse et al., 2005; Mérigout et al., 2008; Seabra and Carvalho, 2015; Zhang et al., 2017). The amides asparagine and glutamine carrying the assimilated nitrogen are transported out of the cell to the xylem and throughout the 
plant (Lodwig et al., 2003; Pratelli and Pilot, 2014). Glutamine can be used for the synthesis of all other essential nitrogenous compounds in the cell (Kaiser et al., 1998; Seabra and Carvalho, 2015).

In Medicago, as well as in peas, supplying branched-chain amino acids (BCAA: valine, leucine, and isoleucine) from the infected nodule cell to bacteroids is essential for bacteroid differentiation into the nitrogen-fixing form and persistance during symbiotic nitrogen fixation, since the rhizobia shuts down the synthesis of BCAA under symbiotic conditions. Therefore, bacteroids become symbiotic auxotrophs for these amino acids providing the plant with greater control over the symbiotic balance of power. However, the genetic identify of transporter or transporters for branched chain amino acids have not yet been elucidated. This information may lead to better understanding of molecular mechanisms responsible for feeding symbiotic nitrogen fixation (Rastogi and Watson, 1991; Lodwig et al., 2003; Prell et al., 2009, 2010).

During symbiotic nitrogen fixation, plants provide dicarboxylic acids in the form of succinate or malate to the bacteroids as a carbon source (Ronson et al., 1981; Finan et al., 1983; Udvardi et al., 1988). In addition to the supply of dicarboxylic acids to the bacteroid, Lodwig et al. (2003) proposed the additional transport of glutamate, or a glutamate precursor, to be supplied to the bacteroid to act as a transamination donor for the production of aspartate or possibly alanine in the bacteroid cytosol. They also proposed the export of aspartate to the cytosol of the infected plant cell, which would then be converted to asparagine by ASN. Exported alanine could be converted to glutamate by Glutamate Pyruvate Transaminase or to aspartate by ASN. Similarly to the mitochondrial system, the aspartate-glutamate shuttle in the bacteroid membrane would move glutamate into the bacteroid and transport the aspartate back out towards the cytosol (Lodwig et al., 2003). Although already 15 years old, this hypothesis has not yet been proven, leaving unanswered questions about the transport and involved transporters of amino acids intimatly integrated in supporting symbiotic nitrogen fixation. Herein, we identified potential amino acid transporters expressed in the legume nodule and carried out functional analyses aiming to shed light to these questions. 


\section{RESULTS AND DISCUSSION}

\section{Transporter families involved in amino acid transport and the nodule-specific MtAPC1}

In the Medicago truncatula genome, thirteen family members of the Cationic Amino Acid Transporter family (TCDB\# 2.A.3.3) were identified. Gene expression analysis of these putative transporters revealed a single gene showing nodule specific expression: Medtr8g089360.1, herein called MtAPC1, which could potentially be involvement in amino acid transport to enable symbiotic nitrogen fixation.

Eighteen transporter families are categorized under the Amino Acid PolyamineOrganocation (APC) superfamily in the Transporter Classification Database (TCDB: www.tcdb.org), the second largest superfamily of transporters. Within the APC superfamily, is the APC family proper (2.A.3), which encompasses fifteen transporter families and, among those is the Cationic Amino Acid (CAT) (sub)family of transporters (TCDB\# 2.A.3.3) (Vastermark et al., 2014; Saier at al., 2016). Within the CAT family, relatively few members of the CAT family have been functionally characterized in plants.

In Arabidopsis thaliana, CAT transporters have been shown to have affinity to basic, acidic, and neutral amino acids and to localize to several membranes in the cell including the plasma membrane, endoplasmic reticulum, and tonoplast (Su et al., 2004; Hammes et al., 2006; Yang et al., 2010; Yang et al., 2014). In poplar, CAT11 was shown to have affinity to glutamine and arginine in senescent cells (Couturier et al., 2010). In Camellia sinensis, CAT transporters have affinity to glutamate, glutamine and theanine, a non-protein amino acid found in tea plants (Feng et al., 2017) and the tomato SlCAT9 was shown to be a glutamate, aspartate and GABA exchanger at the tonoplast (Snowden et al., 2015).

The phylogenetic relationships of the thirteen Medicago CAT transporters were examined along with their expression patterns in mature organs of Medicago (Figure 4.2). Three closely related genes are displayed in tandem on chromosome 8 , and another more distantly related is located on the same chromosome. The predicted architectures (i.e., exon-intron structure) among the Medicago CAT genes vary, and distinct patterns were noticed. Interestingly, the 3'-UTR of Medtr1g030860.1 is split into the first and second exons, which is uncommon. Medtr8g089360.1 is expressed in the nodule, and the closely related Medtr8g089340.1 is expressed in the root and 
nodule. This local gene duplication and possible redundancy may have implications on the essentiality of Medtr8g089360.1 in nodules. Two alternative splicing variants of Medtr8g089360 are predicted, as well as four alternative splice variants for another gene, Medtr7g007850. Expression patterns for both Medtr8g089360.1 and Medtr8g089360.2 forms show high expression in nodules over other organs, while none of the four variants of Medtr7g007850 show organ specific expression (Young et al., 2011). 


\section{Divergence of gene structure in Medicago truncatula CAT family members is mirrored with diverse organ expression}

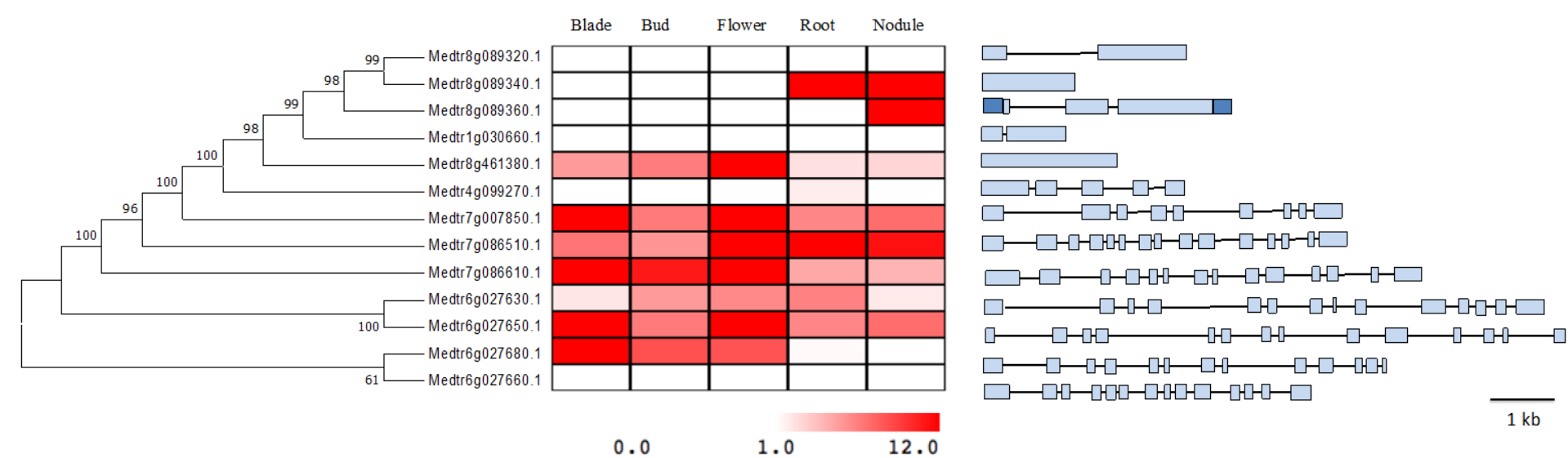

Figure 4.2. Phylogenic tree of the thirteen Medicago truncatula CAT transporters. The tree was constructed using the Maximum Likelihood method with 1,000 bootstraps in MEGA 7. The heatmap showing gene expression in mature plant organs growing under optimal conditions was constructed using MeV from RNA-seq data based on TPM (transcripts per million reads) (Young et al., 2011). Expression level is denoted by red scale, with white denoting no expression. MtAPC1 is the only nodule-specific CAT member in the Medicago genome. Gene architectures show the evolution of introns and exons of Medicago CAT genes. Dark blue boxes represent UTRs, light blue boxes represent exons, and black lines represent introns. 


\section{The MtAPC1 membrane topology is representative of the CAT family}

MtAPC1 is predicted to have three exons and two introns (Figure 4.3), a structure somehow distinct from its two in-tandem duplicates, Medtr8g089340.1 and Medtr8g098320.1, which have one exon and two exons, respectively (Figure 4.2).

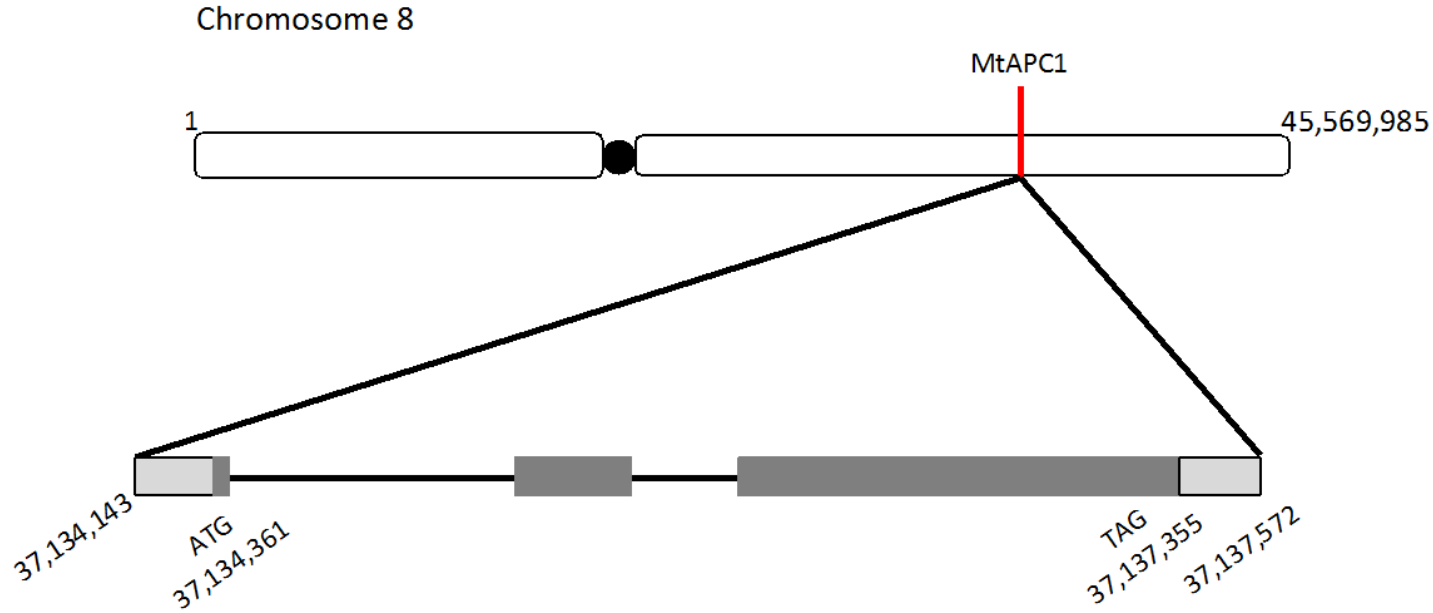

Medtr8g089360

Figure 4.3. Map of chromosome 8 with expanded view of MtAPC1 (Medtr8g089360.1). Predicted architecture of the nodule-specific MtAPC1 transporter gene with three exons (dark gray boxes) and two introns (black lines). Untranslated regions (UTRs) are shown as light gray boxes. Chromosomal coordinates of the transcribed region as well as the start and stop codons are indicated (genome annotation IMGAG v.4.0).

The protein structures of Medtr8g089320.1, Medtr8g089340.1, and Medtr8g089360.1 show the predicted amino acids of the putative transporters as well as the transmembrane domains relative to Medtr8g089360.1 (Figure 4.4). Together, their phylogenetic relationships, gene architectures, and protein sequences indicate that Medtr8g089340 is the ancestral gene, with the nodule-specific Medtr8g089360 being the last one to appear in the cluster. 


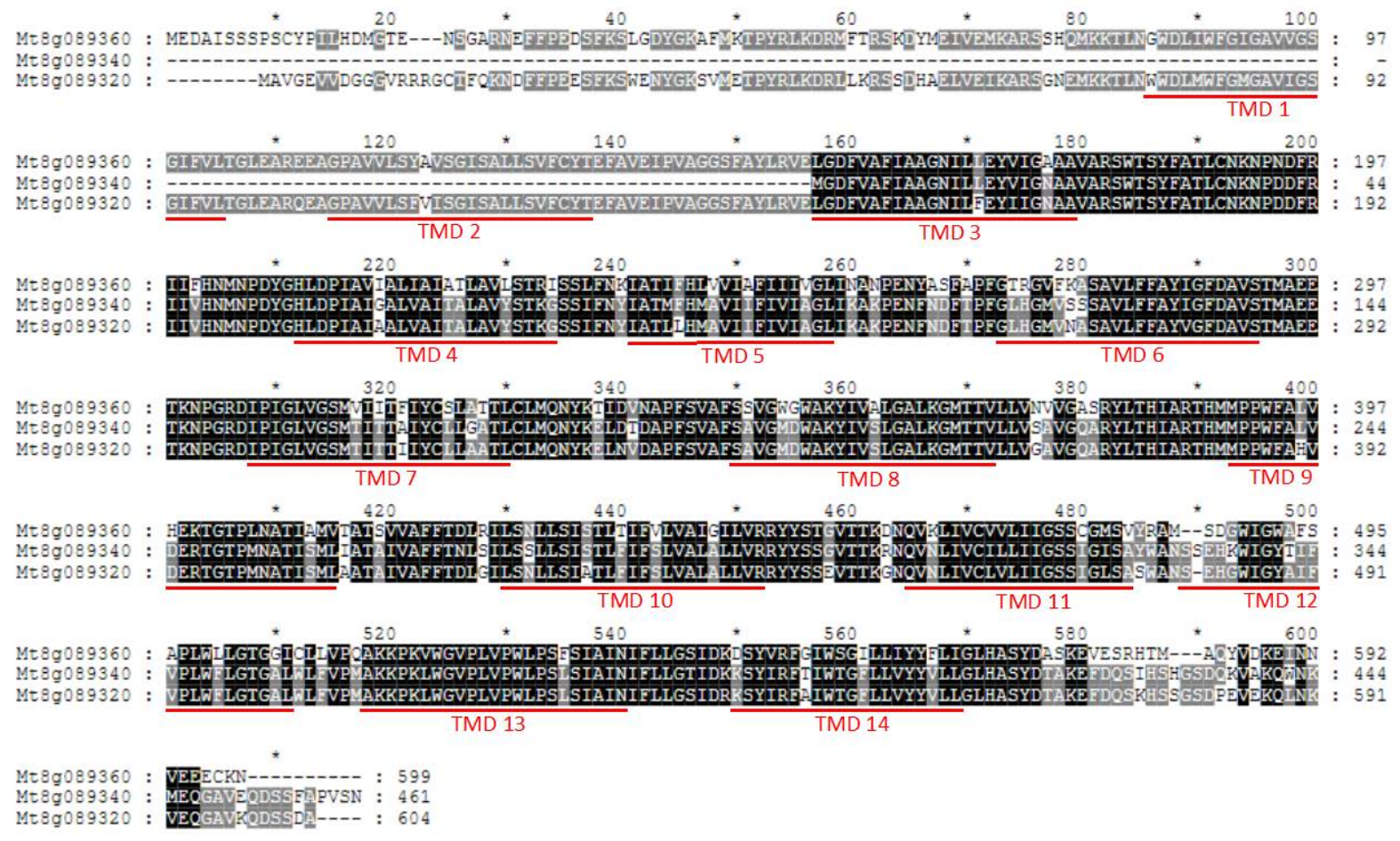

Figure 4.4. Protein alignment of the CAT membrane transporters in Medicago truncatula that are located in tandem with the nodule-specific Medtr8g089360.1. According to TMHMM v.2 (http://www.cbs.dtu.dk/services/TMHMM-2.0/), the Medtr8g089360.1 gene product spans 14 transmembrane domains (TMD, indicated by red underlines). The three neighboring CAT transporters show highly conserved protein sequences.

Despite their similar protein structures (Table 4.1), we noticed distinct transcription patterns. Medtr8g089340.1 showed expression levels closer to Medtr8g089360.1 in nodules in addition to high expression in roots, while Medtr8g089320.1 showed overall only a low, basal expression level in all plant organs. Unless the Medtr8g089320 gene is induced in a very special circumstance not captured in the sampling, it is possible that it is undergoing pseudogenization.

Table 4.1. Identity and similarity matrix of Medtr8g089320.1, Medtr8g089340.1, and Medtr8g089360.1 protein sequences.

\begin{tabular}{|l|l|l|l|}
\cline { 2 - 4 } \multicolumn{1}{c|}{} & Medtr8g089320.1 & Medtr8g089340.1 & Medtr8g089360.1 \\
\hline Medtr8g089320.1 & & 94\% similarity & 85\% similarity \\
\hline Medtr8g089340.1 & 91\% identity & & 82\% similarity \\
\hline Medtr8g089360.1 & 74\% identity & 73\% identity & \\
\hline
\end{tabular}


Both TMHMM and Protter predicted MtAPC1 to have 14 transmembrane domains which is typical of eukaryotic APC family members as well as CAT family members (Saier, 2000; Omasits et al., 2014) (Figure 4.5).

A

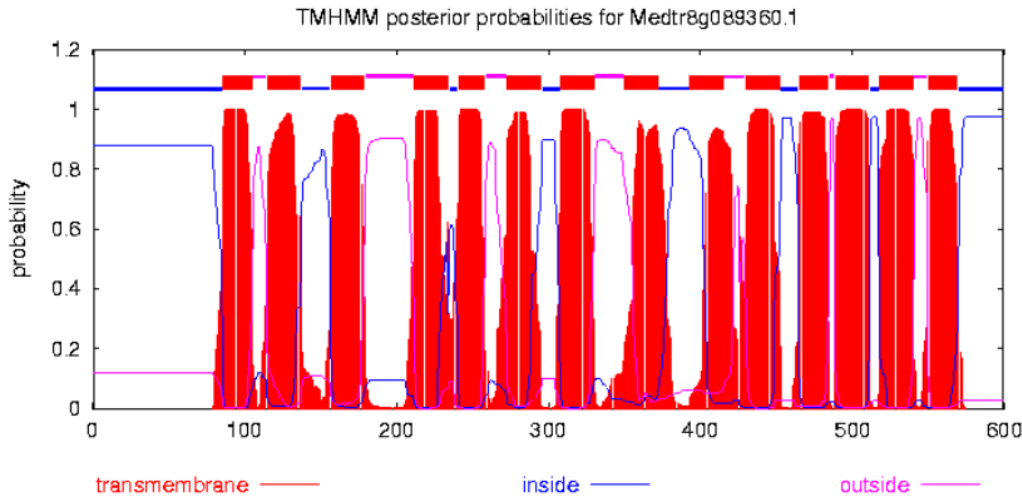

B

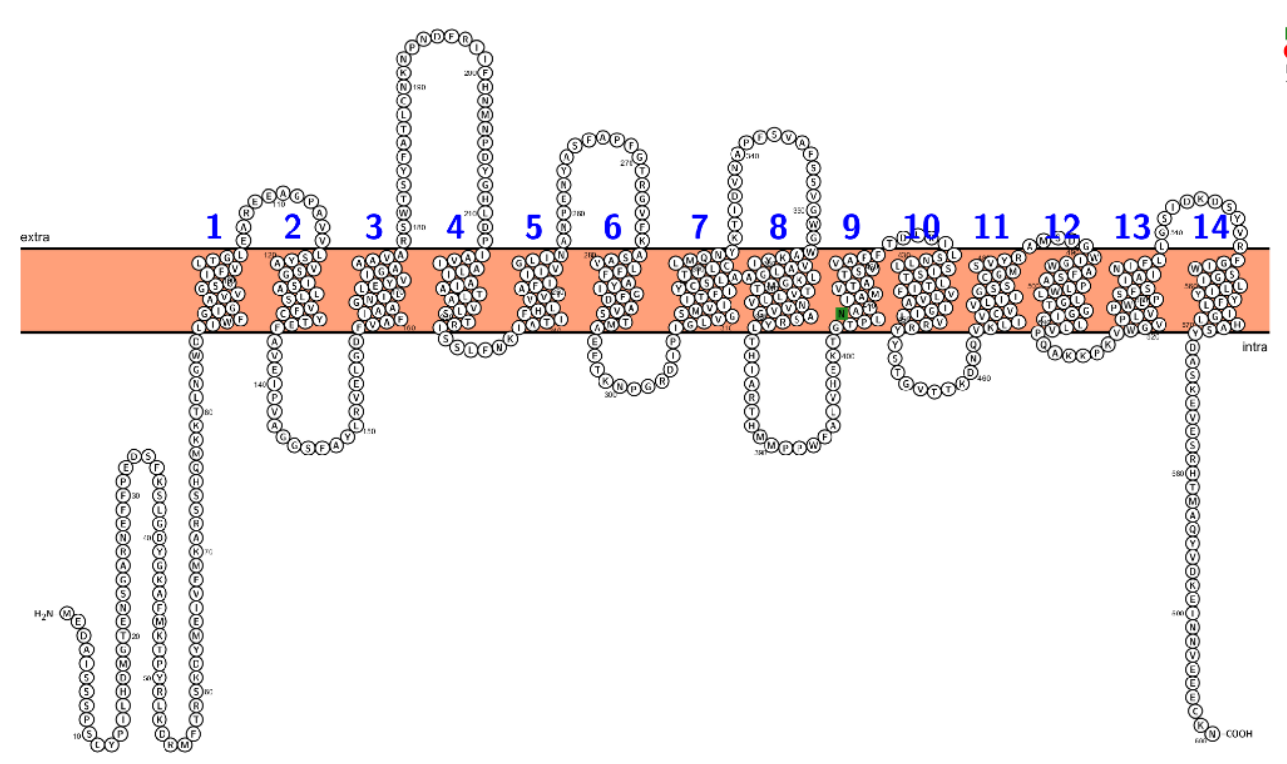

Figure 4.5. Membrane topology of MtAPC1 (Medtr8g089360.1). (A) Fourteen predicted transmembrane $\alpha$-helices were found using the TMHMM v.2 (Sonnhammer et al., 1998; Krogh et al., 2001; http://www.cbs.dtu.dk/services/TMHMM-2.0/). Eukaryotic APC transporters and CAT family members typically have 14 putative $\alpha$-helical transmembrane domains (TMDs) (Jack et al., 2000; Fotiadis et al., 2013). (B) Medicago truncatula APC1 protein topology analysis in Protter (Omasits et al., 2014; http://wlab.ethz.ch/protter) confirmed the 14 predicted TMDs. 


\section{Transcriptional analysis showed high expression of MtAPC1 in the fixation zone}

The MtAPC1 transporter is expressed specifically in nodules in the mature organs of the plant, with the maximum level of expression found during later nodule development after 10 days post inoculation, and especially in the nitrogen fixation zone (Figure 4.6).
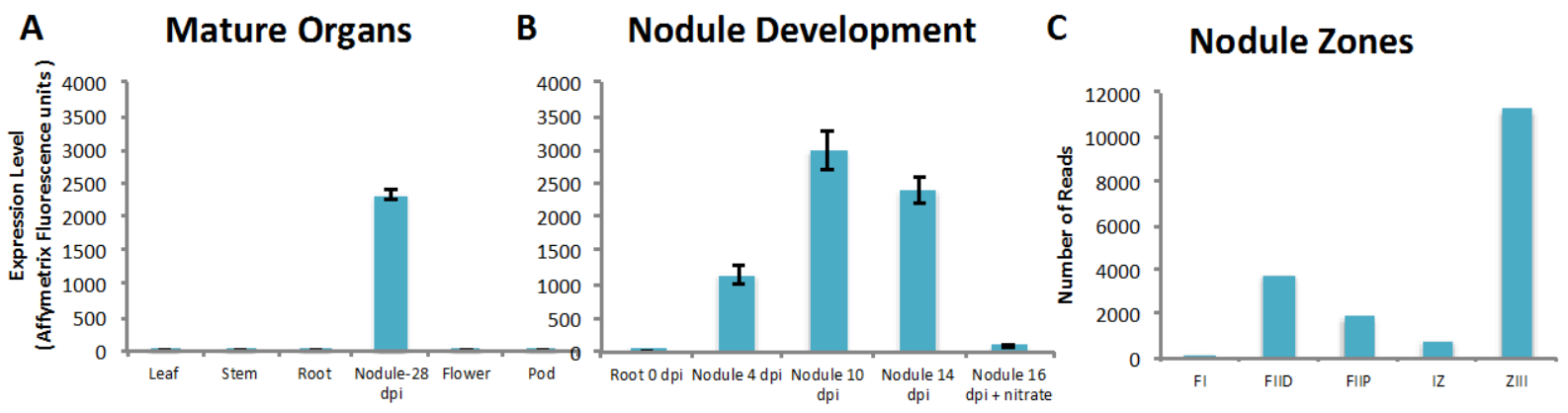

Figure 4.6. Expression profile of the nodule-specific MtAPC1 gene (Medtr8g089360.1). (A) MtAPC1 is expressed exclusively in the nodule. (B) MtAPC1 expression starts early during nodule development (4 days post inoculation, dpi), peaking in young, mature nodules at 10 dpi. The expression of MtAPC1 is inhibited by nitrate, a known inhibitor of nodulation and symbiotic nitrogen fixation. (C) In mature nodules, MtAPC1 expression is highest in the nitrogen fixation zone. Data were collected from public gene expression databases: (A, B) Medicago Gene Atlas (probeset number Mtr.42325.1.S1_at; http://mtgea.noble.org/v3/; Benedito et al., 2008, 2010; He et al., 2009); (C) Roux et al., 2014 (gene number Mt0009_00215)

Real time analysis was conducted on Medicago genotype R108 infected with a functional lacZ S. meliloti rhizobia strain or non-functional mutants that fail in proceeding in specific stages of symbiosis establishment. exoA rhizobia cannot infect root cells, bacA rhizobia are unable to differentiate into bacteroids, and the fix $J$ strain proceeds through bacteroid differentiation, but is inefficient to fix nitrogen (Mitra and Long, 2004; Griffitts and Long, 2008). Rhizobial infection is necessary for gene expression of MtAPC1 to occur, but not bacteroid differentiation or nitrogen fixation per se (Figure 4.7). MtAPC1 expression was not detected at 3 dpi but it is perceived at $10 \mathrm{dpi}$ (young, functional nodules) until later in mature nodules at $28 \mathrm{dpi}$. These results indicate that MtAPC1 has a role after the initial infection and invasion of rhizobia. 


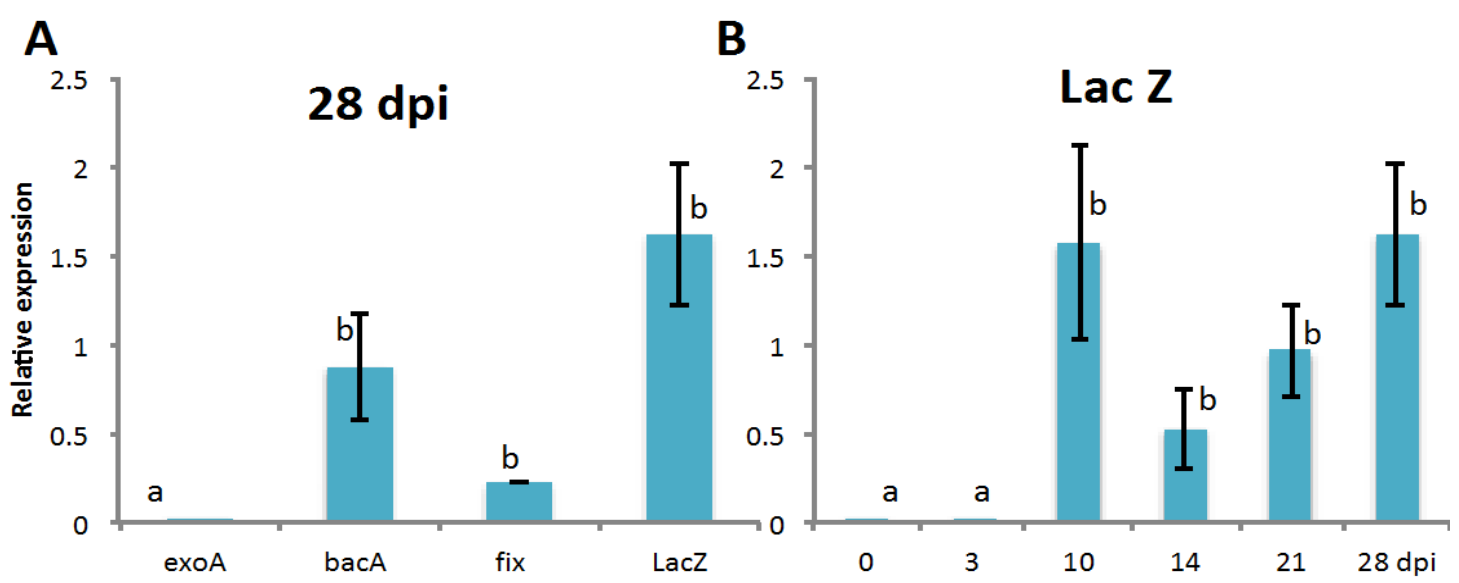

Figure 4.7. Analysis of expression of MtAPC1 by real-time PCR analysis. (A) Expression analysis of nodulating roots infected with rhizobial mutants and the functional LacZ rhizobia in Medicago truncatula genotype R108. (B) Time-course of MtAPC1 gene expression in of in Medicago truncatula genotype R108 roots infected with the functional LacZ rhizobia. Relative expression analysis used non-inoculated root as control. Error bars represent standard error. Statistical significance of $\mathrm{p}<0.05$ using Tukey-Kramer.

\section{RNAi knockdown of MtAPC1 shows no phenotypical change in the nodule}

Hairpin-based RNAi was used to knockdown the expression of MtAPC1 in root nodules. Expression of MtAPC1 in RNAi nodulating roots was less than 4\% of that of the WT nodulating roots (Figure 4.8). No phenotypic differences were observed between the wild-type (WT) and MtAPC1-RNAi transgenic nodules (Figure 4.8). Both WT and RNAi nodules have normal size and shape and show pink fixation zones indicative of active nitrogen fixation. Despite the fact that expression of MtAPC1 was greatly reduced, phenotypic changes of the nodule was not seen. This could be explained by the normally high expression of MtAPC1 in nodules, making the residual expression enough to carry its function, or that its closely-related Medtr8g089360 gene, which is expressed in nodules, is functionally redundant. If the latter, MtAPC1 may be playing a function in a membrane system common to root and nodule cells, such as the plasma membrane, rather than localizing to a specific membrane system of infected cells (the symbiosome membrane). 


\section{A}
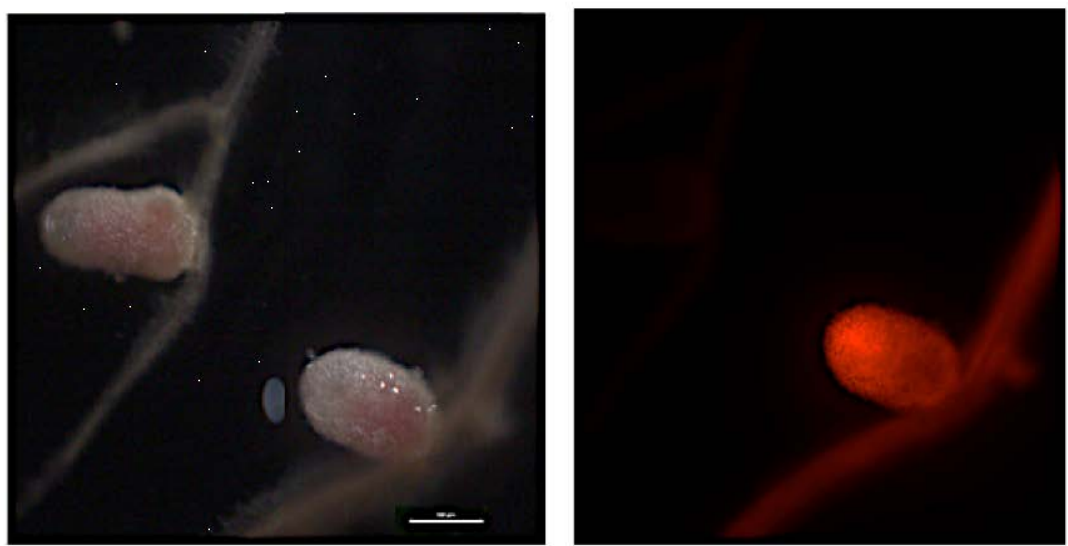

B

1.2

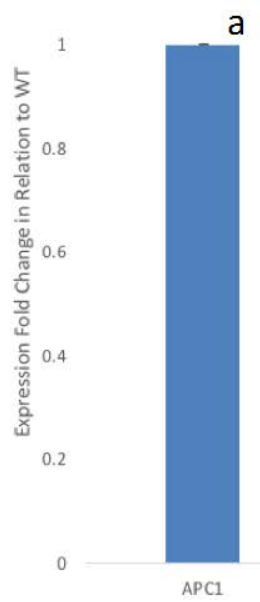

a
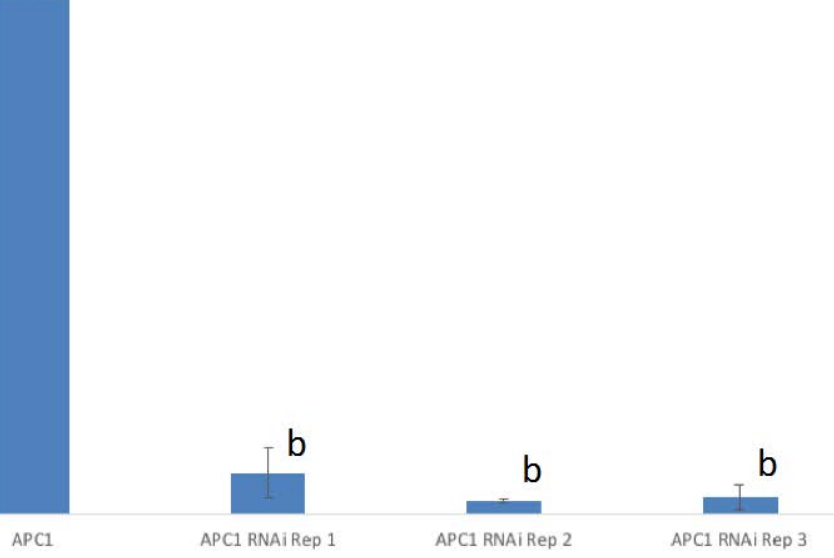

Figure 4.8. MtAPC1 (Medtr8g089360.1) RNAi nodules are visually indistinct from non-transgenic nodules. Wild type and transformed RNAi nodules under fluorescent stereoscope. (A, left) Brightfield. (A, right) A constitutive DsRed marker was utilized to visualize transgenic root systems. The nodule sizes are representative of wild-type control and RNAi nodules. Scale bar: $500 \mu \mathrm{m}$. (B) Real-time qPCR expression profile of MtAPC1 wild-type versus RNAi nodulating roots. Error bars represent standard error. Significant difference shown between control nodules and MtAPC1 RNAi using Tukey-Kramer $\mathrm{p}<0.05$. 


\section{MtAPC1 is expressed in infected cells within the nitrogen fixation zone}

MtAPC1 is highly expressed in the nitrogen fixation and senescence zones (Figure 4.9A). Within the nitrogen fixation zone, infected cells show MtAPC1 expression (Figure 4.9B). This localization indicates MtAPC1 may be playing a role in nitrogen fixation.

A

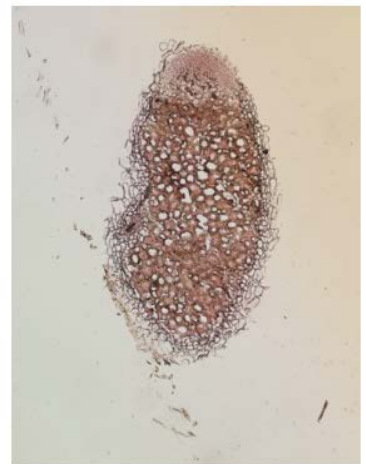

C

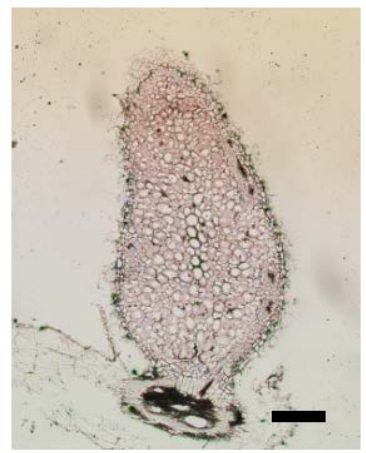

B

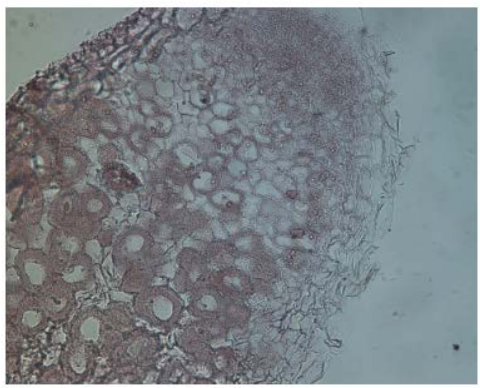

D

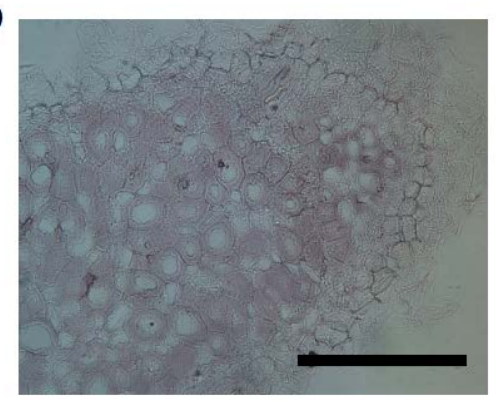

Figure 4.9. In situ hybridization of mature nodule sections using MtAPC1 probe. (A and B) Antisense probe (C and D) Sense probe. Scale bar: $200 \mu \mathrm{m}$.

\section{Subcellular localization of MtAPC1 shows localization to the plasma membrane}

To investigate the subcellular localization of MtAPC1, localization was performed in epidermal peels of Nicotiana benthamiana leaves after infiltration of Agrobacterium tumefaciens. Red fluorescence at the periphery of epidermal cells indicated localization of the MtAPC1 to the plasma membrane of the epidermal cells (Figure 4.10). 


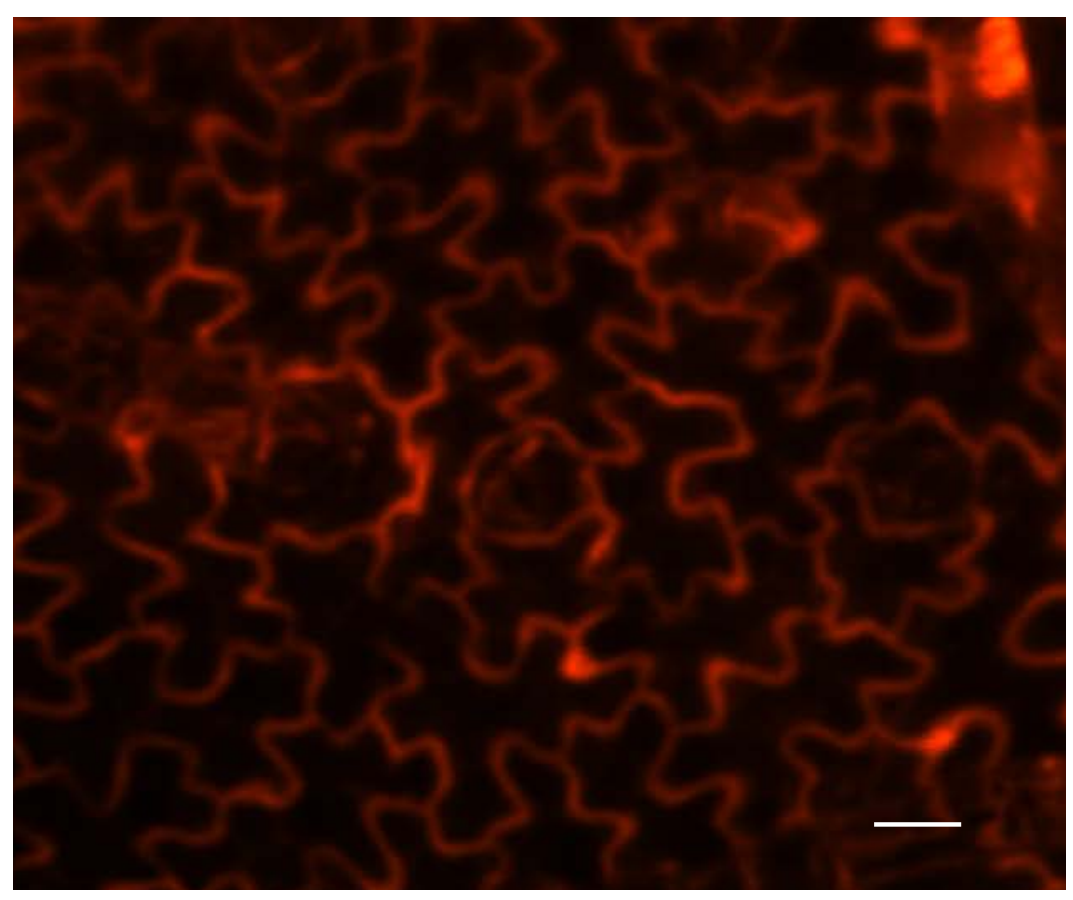

Figure 4.10. Epidermal peel of Nicotiana benthamiana leaf three days after Agrobacterium tumefaciens infiltration with MtAPC1mRFP fusion expressed under the CaMV35S constitutive promoter. In this heterologous transient system, MtAPC1 localized to the plasma membrane. Scale bar: $10 \mu \mathrm{m}$.

\section{MtAPC1 did not show amino acid import activity in yeast}

Transformed 22 $10 \mathrm{AA}$ Saccharomyces cerevisiae strain complemented with MtAPC1 was grown separately on $10 \mathrm{mM}$ of each of the 16 amino acids strain $22 \Delta 10 \mathrm{AA}$ cannot utilize as a sole nitrogen source. Growth was seen in empty vector and MtAPC1 lines at similar rates and suggests that MtAPC1 is not an importer. Growth in liquid cultures was also monitored with the 16 amino acids over a 24-h period (Supplemental Figure S1) and results corroborated the data on agar plates. 


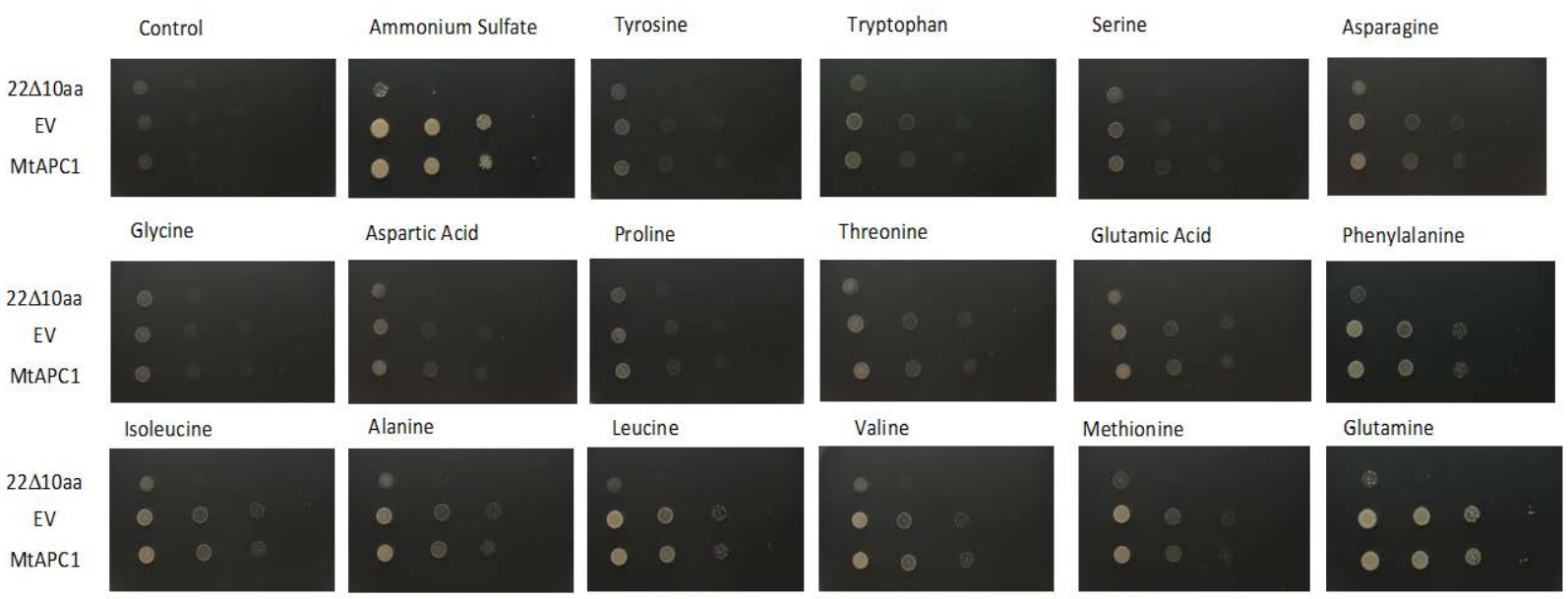

Figure 4.11. Amino acid import assay in yeast strain 22 $\Delta 10 \mathrm{AA}$. Four ten-fold serial dilutions were made from $5 \mathrm{uL}$ liquid culture (initial $\mathrm{OD}_{600}=1.0$ ). Plates contained YNB medium supplemented with $10 \mathrm{mM}$ amino acid (or ammonium sulfate). Yeast was grown for three days at $28^{\circ} \mathrm{C}$. The negative control medium lacks a nitrogen source. The positive control medium is supplemented with $10 \mathrm{mM}$ ammonium sulfate. All except for tyrosine grew healthily at $10 \mathrm{mM}$. No differences in growth between empty vector (EV: pDR196GW and MtAPC1-complemmented lines were noticed, denoting no amino acid import activity of MtAPC1 in this system.

Syntenic analysis revealed no synteny among Medicago CAT family members and other legume model organisms

Comparative analysis between the thirteen Medicago truncatula CAT genes and the Arabidopsis thaliana, Lotus japonicus, and the Glycine max genomes revealed no synteny. Microsynteny was not found within the Medicago truncatula genome regarding Medtr8g089360 or any of the loci containing CAT genes. However, reiterated tandem duplications were found, forming a cluster formed by four CAT genes, of which three possess the typical 14 transmembrane domains and expected length of protein sequence (Table 4.3).

Table 4.3. Comparative Genomics analysis of APC tandem duplications using CoGe: Comparative Genomics web tool and SynMap (https://genomevolution.org/coge/; Lyons and Freeling, 2008; Lyons et al., 2008).

\begin{tabular}{|l|l|}
\hline APC Tandem Duplication Gene Set & Medtr8g089360.1 \\
& Medtr8g089320.1 \\
& Medtr8g089360.2 \\
& Medtr8g089340.1 \\
& Medtr8g089342.1 \\
\hline
\end{tabular}




\section{Gene Network analysis shows correlation to Nodule-Specific Cysteine-Rich Secreted Proteins}

A gene expression network was constructed with first-order Pearson's correlations centered on MtAPC1 (Figure 4.12, Supplemental Table S1). Interestingly, the three highest associations are with genes coding for Nodule-specific Cysteine-Rich (NCR) secreted proteins (Medtr6g057520.1, Medtr3g015870.1, Medtr5g072420.1). Additionally, the expression of two genes coding for peptide transporters (Medtr7g098180.1 and Medtr1g116930.1) and another coding for a MATE transporter (Medtr7g082810.1) are also significantly correlated with MtAPC1.

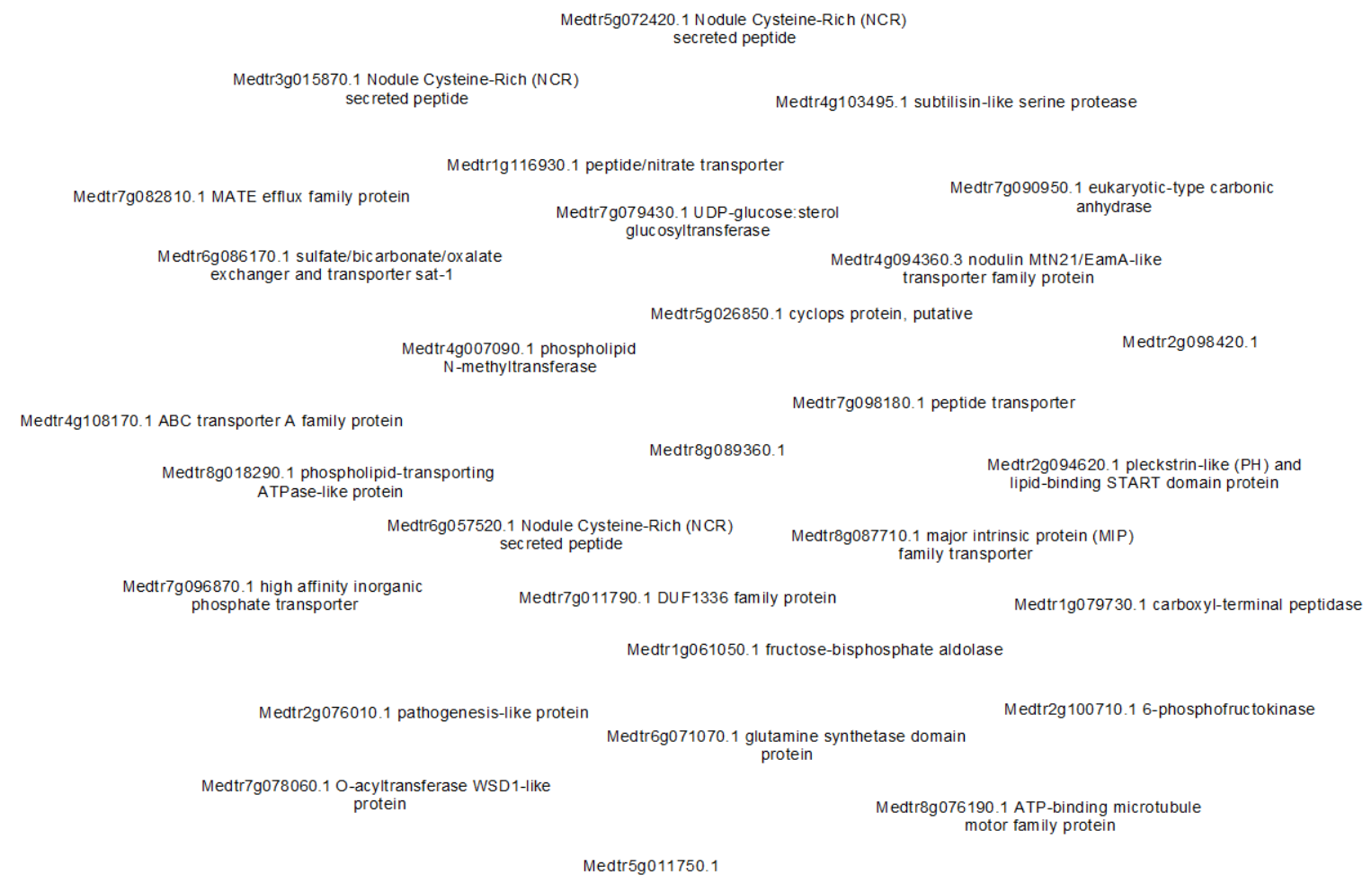

Figure 4.12. Gene network centered on MtAPC1. Primary gene interactions were determined using Pearson's coefficient correlation. Correlation threshold was set at $\rho \geq 0.90$. Maximum correlation obtained for MtAPC1 was $\rho=0.94$. Visualization was produced using Cytoscape (Shannon et al., 2003). 


\section{CONCLUSION}

MtAPC1 is a nodule specific protein, with expression beginning at 4 days post inoculation. In the mature nodule, APC1 starts expressing during bacteroid differentiation in the interzone and shows highest expression in the nitrogen fixation and senescence zones. RNAi knockdown showed no visible phenotypic changes to the nodule size, form or color. It remains to be determined, however, whether the efficiency of symbiotic nitrogen fixation remained the same in both treatments. The heterologous transient system utilizing Nicotiana benthamiana showed protein localization to the plasma membrane indicating the MtAPC1 transporter may localize to the plasma membrane or a plasma membrane-derived membrane, such as the symbiosome membrane in Medicago truncatula. Altogether, our results support the hypothesis that MtAPC1 is as a nonessential transporter aiding in the flux of amino acids to sustain symbiotic nitrogen fixation.

The lack of syntenic regions of members of the CAT gene family between Medicago truncatula and Arabidopsis thaliana or even the other legume models indicates their function could be performed by other transporter families. This is a possibility given the broad substrate affinity of CAT transporters and that other families in the APC superfamily may have taken over the MtCAT1 function in nodules of other legumes.

Future studies should focus on knocking out both nodule-expressed CAT genes, Medtr8g089360.1 and the closely related Medtr8g089340.1 to assess the functional redundancy as well as essentiality of this function for symbiotic nitrogen fixation. Given the lack of synteny found for CAT genes within model legumes, a comparative analysis of the CAT gene family in legumes could elucidate whether nodule CAT transporters are specific to the Medicago clade to support symbiotic nitrogen fixation. The study of MtAPC1 subcellular localization in nodule cells will also help elucidate whether it localizes in the plasma membrane or in the symbiosome membrane, which has obvious implications to its physiological role in the nodule. 


\section{MATERIAL AND METHODS}

Phylogenetic analysis and membrane topology prediction: The phylogenetic tree was produced using MEGA v.7 (Molecular Evolutionary Genetics Analysis) software (Tamura et al., 2011; Tamura et al., 2012) by the maximum likelihood method with 1,000 bootstraps. Protein sequences were aligned using Muscle and imported into construct/test maximum parsimony tree with the following parameters: Ten initial trees, MP search level 1, and complete deletion of Gaps/Missing data. Medicago truncatula sequences (IMGAG annotation Mt3.5v4) were obtained from http://bioinfo3.noble.org/getseq/. TMHMM (http://www.cbs.dtu.dk/services/TMHMM-2.0/; Möller et al., 2001) and Protter (wlab.ethz.ch/protter) were used to predict transmembrane domains with protein sequences as input.

Gene expression analyses: Gene expression was assessed from the Affymetrix Medicago GeneChip microarray data deposited at the Samuel Roberts Noble Foundation Medicago truncatula Gene Expression Atlas (http://mtgea.noble.org/v3/; Benedito et al., 2008). Gene expression analyses of membrane transporters in rhizobial mutants was performed in R108 roots inoculated with bacA, exoA, fixJ or hemA::LacZ strains of Sinorhizobium meliloti in Sm1021 background. A control group was not inoculated with rhizobia and was provided full nitrogen fertilization. Plant roots were harvested at 0, 3, 14, 21, and 28 dpi. Total RNA was extracted with mirVana miRNA Isolation kit (ThermoFisher Scientific) using the total RNA isolation protocol, followed by DNA removal with Turbo DNA-free kit (Applied Biosystems/ThermoFisher Scientific). First strand complementary DNA was synthesized by priming with oligo-dT using the SuperScript III First-Strand Synthesis Super mix (ThermoFisher Scientific) according to the manual. Primers used were: MtAPC1 forward: 5' TGC GTC GTT ATT ATT CAA CTG G, and MtAPC1 reverse: 5' CCA ACC ATC ACT CAT TGC TC. Three biological and three technical replicates were used used for qPCR. SYBR green master mix (Applied Biosystems/ThermoFisher Scientific) and $5 \mu \mathrm{L}$ reactions were used on Applied Biosystems 7500 Real Time PCR System and 7500 software. All templates were amplified using the same protocol: $50^{\circ} \mathrm{C}$ for 2 minutes; $95^{\circ} \mathrm{C}$ for 10 minutes; 40 cycles of $95^{\circ} \mathrm{C}$ for 15 seconds and $60^{\circ} \mathrm{C}$ for 1 minute. Melt curves were produced following the 40 cycles by heating to $95^{\circ} \mathrm{C}$ for 15 seconds followed by $60^{\circ} \mathrm{C}$ for 15 seconds and $95^{\circ} \mathrm{C}$ for 15 seconds. 7500 Software (Applied Biosystems) gave $\mathrm{C}_{\mathrm{T}}$ threshold cycle values. Excel was used to organize data and calculate geometric means of technical replications and calculate averages and standard errors. Technical outliers were eliminated from analysis.

The symbiotic marker genes used were: NCR2A (Medtr2g042480.1 - marker of bacteroid differentiation; Moreau et al., 2011), LEG (Medtr5g081000.1 - nitrogen fixation; Vinardell et al., 2003), (Medtr7g104360.1 - senescence zone marker; Zhou et al., 2011), LYK3 (NCBI accession AY372406 - root hair curling; Smit et al., 2007), ENOD11 (AJ297721 - preinfection and infection; Svistoonoff et al., 2010), and HAP2-1 (EF488826 - meristem zone marker; Combier et al., 2006; Combier et al., 2008). The housekeeping genes chosen for this experiment were: EF1 $\alpha$ (Medtr6g021800), tubulin (Medtr7g089120), and MSC27 (X98618.1). NormFinder software (Andersen et al., 2004) was used to identify stably expressed housekeeping genes in the experiment and MSC27 was excluded from the calculations. Statistical analysis was performed using TukeyKramer at $\mathrm{p}=0.05$. 
Cloning of coding regions: cDNA of the gene of interest was amplified using KOD Hot Start DNA polymerase (EMD Millipore) and cloned into the pENTR Gateway entry vector using the Directional pENTR-D/TOPO Cloning Kit (Life Technologies). The transcribed region was obtained from the IMGAG gene model (http://bioinfo3.noble.org/getseq/) and primers were designed using Primer3 (http://primer3.ut.ee) using the following parameters: primer size between $18-25 \mathrm{bp}$, melting temperature of primers $(\mathrm{Tm})$ between $58-62^{\circ} \mathrm{C}$, GC content between $40-60 \%$, max self-complementarity $=3$ bases, max 3 ' end complementarity $=1$ base. Primers used for cloning the coding regions were: forward MtAPC1: 5' CAC CAT GGA AGA CGC AAT TTC TTC, reverse MtAPC1 with stop codon: 5' GGG GAC CAC TTT GTA CAA GAA AGC TGG GTA TAG AAT AAC AAT AGC ATT ATT TAT C, reverse MtAPC1 with no stop codon: 5' ATT TTT ACA TTC CTC TTC AAC ATT G. PCR cycling conditions used were: initiation at $95^{\circ} \mathrm{C}$ for 2 minutes, followed by 35 to 39 cycles at $95^{\circ} \mathrm{C}$ for 20 seconds, $60^{\circ} \mathrm{C}$ for 10 seconds, and $70^{\circ} \mathrm{C}$ for 1 minute; termination at $70^{\circ} \mathrm{C}$ for 5 minutes, followed by constant $4^{\circ} \mathrm{C}$. Applied Biosystems GeneAmp PCR System 9700 or Eppendorf Mastercycler EP thermocyclers were used.

cDNA amplicons were cloned into pUBIcGFP-DR destination vector for complementation and subcellular localization by LR Gateway recombination (Life Technologies) before being moved into Agrobacterium rhizogenes strain ARqua1 for ex vitro root transformation purposes.

Yeast analyses: Transcript coding regions with stop codons of gene of interest were transferred from the entry vector to the destination vector pDR196-GW via LR recombination, followed by yeast transformation with the LiAc/SS-DNA/PEG transformation procedure (Gietz and Woods, 2002). Yeast transport mutant strains for substrates of interest were selected.

For influx transport, the wild-type non-transformed yeast strain and the empty vector yeast strains were the positive controls for auxotrophic yeast strains with the plasmid containing the transcripts' coding region (Kraidlova et al., 2011). Yeast cells were grown on selective media (YNB) supplemented with ammonium sulfate or amino acids. Tenfold serial dilutions of yeast cell suspensions were spotted and incubated for 3 days at $28^{\circ} \mathrm{C}$.

Amino acid import assays: MtAPC1 was cloned into pDR196-GW. Empty pDR196-GW was the control. Both were transformed into 22 $\Delta 10 \mathrm{AA}$ (MATa gap1-1 put4-1 uga4-1 can1::HisG lyp1alp1::HisG hip1::HisG dip5::HisG gnp1 $\Delta$ agp1 $\Delta$ ura3-1) received from Dr. Guillaume Pilot of Virginia Tech. This line can for the 16 amino acids (Gly, Ala, Val, Met, Ile, Leu, Phe, Trp, Pro, Ser, Thr, Tyr, Asp, Asn, Glu, or Gln) whereas it cannot test for Lys, His, or Cys (Besnard et al., 2016). 22 $\triangle 10 \mathrm{AA}$ grows normally on Arg at $10 \mathrm{mM}$ and $10 \mathrm{mM}$ ammonium sulfate and therefore cannot test Arg import. MtAPC1 were inserted into pDR196-GW vector and transformed into $22 \triangle 10 \mathrm{AA}$ cells and selected on medium without uracil. The line complemented with MtAPC1 was grown separately on $10 \mathrm{mM}$ of each of the 16 amino acids the original strain $22 \Delta 10 \mathrm{AA}$ cannot utilize as a sole nitrogen source.

The BioTek Gen5 software with the BioTek Epoch 2 microplate reader was used for yeast import assays. A 24-hour read period was recorded with readings taken every 20 minutes. Plates were shaken in a linear fashion for 8 minutes prior to each reading. Five biological replications were used for each treatment. 
RNAi knockdown of MtAPC1 in Medicago truncatula cv. 'R108' roots: Since no Medicago mutant Tnt1 line were identified for MtAPC1 genetic analysis, RNAi was employed. The 481-bp segment was received from Dr. Caroll Vance's lab (University of Minnesota) in the pK7GWIWG2 RNAi vector (Limpens et al., 2005) and transformed into Agrobacterium rhizogenes strain ArQua1 for ex-vitro root transformation. Root systems were subsequently inoculated with SmABS7-LacZ rhizobial line and nodules harvested at 28dpi. Control and RNAi transformed nodulating roots were harvested, RNA isolation was performed, followed by cDNA synthesis and qPCR. Olympus MVX10 MacroView microscope with the RFP filter was used. Camera was Hamamatsu ORCA_Flash4.0 v2 CMOS (C11440-22CU) for fluorescence imaging at the WVU Imaging Core Facility.

Leaf infiltration of Nicotiana benthamiana: Nicotiana benthamiana leaves were infiltrated with Agrobacterium tumefaciens according to the protocol described by Li (2011). MtAPC1 (primers: forward 5' CACCATGGAAGACGCAATTTCTTC, reverse 5' CACCCTAATTTTTACATTCCTCTTCAACATTG) in pDR196-GW was transformed into Agrobacterium tumefaciens. Leaves were infiltrated by a needle-less syringe and imaged on a Leica M125 stereoscope with a red filter and Leica MC170HD camera three days later.

In situ hybridization: Mature 28-dpi nodules (Medicago truncatula 'R108' inoculated with rhizobial strain ABS7 were harvested, fixed with 3\% paraformaldehyde and $0.25 \%$ glutaraldehyde in $0.1 \mathrm{M}$ sodium phosphate buffer under benchtop vacuum for one hour at room temperature and stored overnight at room temperature. Nodules were dehydrated by a graded ethanol series ( $50 \%$, $75 \%, 80 \%, 95 \%$ and $100 \%$ twice) for 45 mins each, followed by xylene for $15 \mathrm{~min}$ and moved to a 50:50 mixture of xylene and paraplast for two hours at $60^{\circ} \mathrm{C}$ and then embedded in paraplast and sectioned into $10-\mathrm{mm}$ slices with a microtome. Sections were dried overnight at $37^{\circ} \mathrm{C}$ and incubated at $60^{\circ} \mathrm{C}$ for one hour, emerged twice in xylene ( $15 \mathrm{~min}$ each), and rehydrated according to BioChain protocol. The probe was produced by cloning a 150-bp fragment of the MtAPC1 gene (primers: forward 5' CACCAGCAGCCACCAAATGAAGAA, reverse 5' CGGAGACAGCATACGACAAA) into the pGEM-T Easy vector. The cloned vector was opened with restriction enzymes SpeI and SacII and transcribed in vitro with T7 RNA polymerase (antisense probe) and Sp6 RNA polymerase (sense probe). In situ hybridization was performed according to BioChain manual and instructions (catalog number K2191020) and Sigma Aldrich DIG RNA Labeling (SP6/T7) protocol.

Synteny analysis: Comparison of output from CoGe: Comparative Genomics web tool and SynMap software using coding sequence (was used to compare the thirteen CAT family members of Medicago truncatula (JCVI unmasked v4, id22582), to Lotus japonicus (unmasked v3.0, id37292), Glycine max (unmasked, id37627), and Arabidopsis thaliana (unmasked v1, id18626) to find syntenic regions of genomes. Syntenic blocks in microsynteny within a genome or synteny between genomes was considered at a minimum of 5 gene pairs aligning within a span of 20 genes. Default settings were utilized. Tandem duplication gene sets were also examined using the comparitive genomics tool (https://genomevolution.org/coge/; Lyons and Freeling, 2008; Lyons et al., 2008). 


\section{REFERENCES}

Andersen CL, Ledet-Jensen J, Ørntoft T (2004) Normalization of real-time quantitative RTPCR data: a model based variance estimation approach to identify genes suited for normalization - applied to bladder- and colon-cancer data-sets. Cancer Research 64: 5245-5250

Andrews M, Raven JA, Lea PJ (2013) Do plants need nitrate? The mechanisms by which nitrogen form affects plants. Annals of Applied Biology 163: 174-199

Benedito VA, Li H, Dai X, Wandrey M, He J, Kaundal R, Torres-Jerez I, Gomez SK, Harrison MJ, Tang Y, Zhao PX, Udvardi M (2010) Genomic inventory and transcriptional analysis of Medicago truncatula transporters. Plant Physiology 152: 1716-1730

Benedito VA, Torres-Jerez I, Murray JD, Andriankaja A, Allen S, Kakar K, Wandrey M, Verdier J, Zuber H, Ott T, Moreau S, Niebel A, Frickey T, Weiller G, He J, Dai X, Zhao PX, Tang Y, Udvardi MK (2008) A gene expression atlas of the model legume Medicago truncatula. Plant Journal 55: 504-513

Besnard J, Pratelli R, Zhao C, Sonawala U, Collakova E, Pilot G, Okumoto S (2016). UMAMIT14 is an amino acid exporter involved in phloem unloading in Arabidopsis roots. Journal of Experimental Botany 67: 6385-6397

Combier JP, Frugier F, de Billy F, Boualem A, El-Yahyaoui F, Moreau S, Vernie, T, Ott T, Gamas P, Crespi M, Niebel A (2006) MtHAP2-1 is a key transcriptional regulator of symbiotic nodule development regulated by microRNA169 in Medicago truncatula. Genes \& Development 20: 3084-3088

Combier JP, de Billy F, Gamas P, Niebel A, Rivas S (2008) Trans-regulation of the expression of the transcription factor MtHAP2-1 by a uORF controls root nodule development. Genes \& Development 22: 1549-1559

Couturier J, Doidy J, Guinet F, Wipf D, Blaudez, Chalot M (2010) Glutamine, arginine and the amino acid transporter Pt-CAT11 play important roles during senescence in poplar. Annals of Botany 105: 1159-1170

Day DA, Poole PS, Tyerman SD, Rosendahl L (2001) Ammonia and amino acid transport across symbiotic membranes in nitrogen-fixing legume nodules. Cellular and Molecular Life Sciences CMSL 58: 61-71

Dündar E, Bush DR (2009) BAT1, a bidirectional amino acid transporter in Arabidopsis. Planta 229: 1047-1056

Feng L, Yang YT, Zhang ZL, Li FD, Chen Q, Sun J, Shi CY, Deng WW, Tao MM, Tai YL, Yang H, Cao Q, Wan XC (2017) Identification and characterization of cationic amino acid transporters (CATs) in tea plant (Camellia sinensis) Plant Growth Regulation 84: 57-69 
Finan TM, Wood JM, Jordan DC (1983) Symbiotic properties of C4-dicarboxylic acid transport mutants of Rhizobium leguminosarum. Journal of Bacteriology. 154: 1403-1413

Fotiadis D, Kanai Y, Palacín A (2013) The SLC3 and SLC7 families of amino acid transporters. Molecular Aspects of Medicine 34: 139-158

Gietz RD, Woods RA (2002). Transformation of yeast by lithium acetate/single-stranded carrier DNA/polyethylene glycol method. Methods of Enzymology 350: 87-96

Griffitts JS, Long SR (2008) A symbiotic mutant of Sinorhizobium meliloti reveals a novel genetic pathway involving succinoglycan biosynthetic functions. Molecular Microbiology 67: 1292-1230

Hammes UZ, Nielsen E, Honaas LA, Taylor CG, Schachtman DP (2006) AtCAT6, a sink tissue-localized transporter for essential amino acids in Arabidopsis. Plant Journal 48: 414-426

He J, Benedito VA, Wang M, Murray JD, Zhao PX, Tang Y, Udvardi MK (2009) The Medicago truncatula gene expression atlas web server. BMC Bioinformatics 10: 441

Jack DL, Paulsen IT, Saier MHJ (2000) The amino acid/polyamine/organocation (APC) superfamily of transporters specific for amino acids, polyamines and organocations. Microbiology 146: 1797

Kaiser BN, Finnegan PM, Tyerman SD, Whitehead LF, Bergersen FJ, Day DA, Udvardi MK (1998) Characterization of an ammonium transport protein from the peribacteroid membrane of soybean nodules. Science 281: 1202-1206

JW, Closs EI, Albritton LM, Cunningham JM (1991) Transport of cationic amino acids by the mouse ecotropic retrovirus receptor. Nature 352: 725-728

Kraidlova L, Van Zeebroeck G, Van Dijck P, Sychrova H (2011) The Candida albicans GAP gene family encodes permeases involved in general and specific amino acid uptake and sensing. Eukaryotic Cell 10: 1219-1229

Krogh A, Larsson B, von Heijne G, Sonnhammer ELL (2001) Predicting transmembrane protein topology with a hidden Markov model: Application to complete genomes. $\begin{array}{llll}\text { Journal of } & \text { Molecular } & \text { Biology, } & 305\end{array}$

Ladwig F, Stahl M, Ludewig U, Hirner AA, Hammes UZ, Stadler R, Harter K, Koch W (2012) Siliques Are Red1 from Arabidopsis acts as a bidirectional amino acid transporter that is crucial for the amino acid homeostasis of siliques. Plant Physiology 158: 1643-1655

Lea P, Mifflin BJ (1974) Alternative route for nitrogen assimilation in higher plants. Nature 251: 614-616 
Li X (2011) Infiltration of Nicotiana benthamiana Protocol for Transient Expression via Agrobacterium. Bio-protocol 101: 95

Limpens E, Mirabella R, Fedorova E, Franken C, Franssen H, Bisseling T, Geurts R (2005) Formation of organelle-like $\mathrm{N}_{2}$-fixing symbiosomes in legume root nodules is controlled by DMI2. Proceedings of the National Academy of Sciences of the United States of America 102: 10375-10380

Lodwig EM, Hosie AHF, Bourdès A, Findlay K, Allaway D, Karunakaran R, Downie JA, Poole PS (2003) Amino-acid cycling drives nitrogen fixation in the legume-Rhizobium symbiosis. Nature 422: 722-726

Lyons E, Freeling M (2008) How to usefully compare homologous plant genes and chromosomes as DNA sequences. The Plant Journal 53: 661-673

Lyons E, Pedersen B, Kane J, Freeling M (2008) The value of nonmodel genomes and an example using SynMap within CoGe to dissect the hexaploidy that predates rosids. Tropical Plant Biology 1: 181-190

Masclaux-Daubresse C, Carrayol E, Valadier MH (2005) The two nitrogen mobilisation- and senescence-associated GS1 and GDH genes are controlled by C and N metabolites. Planta 221: 580-588

Merigout P, Lelandais M, Bitton F, Renou JP, Briand X, Meyer C, Daniel-Vedele F (2008) Physiological and transcriptomic aspects of urea uptake and assimilation in Arabidopsis plants. Plant Physiology 147: 1225-1238

Michaeli S, Fait A, Lagor K, Nunes-Nesi A, Grillich A, Yellin A, Bar D, Khan M, Fernie AR, Turano FJ, Fromm H (2011) A mitochondrial GABA permease connects the GABA shunt and the TCA cycle, and is essential for normal carbon metabolism. The Plant Journal 67: 485-498

Mitra RM, Long SR (2004) Plant and bacterial symbiotic mutants define three transcriptionally distinct stages in the development of the Medicago truncatula/Sinorhizobium meliloti symbiosis. Plant Physiology 134: 595-604

Möller S, Croning MD, Apweiler R (2001) Evaluation of methods for the prediction of membrane spanning regions. Bioinformatics 17: 646-653

Moreau S, Verdenaud M, Ott T, Letort S, de Billy F, Niebel A, Gouzy J, de Carvalho-Niebel F, Gamas P (2011) Transcription reprogramming during root nodule development in Medicago truncatula. PLoS One 6: 16463

Müller B, Fastner A, Karmann J, Mansch V, Hoffmann T, Schwab W, Suter-Grotemeyer M, Rentsch D, Truernit E, Ladwig F (2015) Amino acid export in developing arabidopsis seeds depends on UmamiT facilitators. Current Biology 25: 3126-3131 
Okumoto S, Pilot G (2011) Amino acid export in plants: A missing link in nitrogen cycling. Molecular Plant 4: 453

Omasits U, Ahrens CH, Muller S, Wollscheid B (2014) Protter: interactive protein feature visualization and integration with experimental proteomic data. Bioinformatics 30: 884-886

Pratelli R, Pilot G (2014) Regulation of amino acid metabolic enzymes and transporters in plants. Journal of Experimental Botany 65: 5535-5556

Prell J, Bourdès A, Kumar S, Lodwig E, Hosie A, Kinghorn S, White J, Poole P (2010) Role of symbiotic auxotrophy in the Rhizobium-legume symbioses. PLoS One 5: 13933

Prell J, White JP, Bourdes A, Bunnewell S, Bongaerts RJ, Poole PS (2009) Legumes regulate Rhizobium bacteroid development and persistence by the supply of branched-chain amino acids. Proceedings of the National Academy of Sciences United States of America 106: 12477-12482

Rastogi VK, Watson RJ (1991) Aspartate aminotransferase activity is required for aspartate catabolism and symbiotic nitrogen fixation in Rhizobium meliloti. Journal of Bacteriology 173: 2879-2887

Ronson CW, Lyttleton P, Robertson JG (1981) C4-dicarboxylate transport mutants of Rhizobium trifolii form ineffective nodules on Trifolium repens. Proceedings of the National Academy of Sciences United States of America 78: 4284-4288

Roux B, Rodde N, Jardinaud MF, Timmers T, Sauviac L, Cottret L, Carrère S, Sallet E, Courcelle E, Moreau S, Debellé F, Capela D, de Carvalho-Niebel F, Gouzy J, Bruand C, Gamas P (2014), An integrated analysis of plant and bacterial gene expression in symbiotic root nodules using laser-capture microdissection coupled to RNA sequencing. Plant Journal 77: 817837

Saier MH Jr. (2000) A functional-phylogenetic classification system for transmembrane solute transporters. Microbiology and Molecular Biology Reviews 64: 354-411

Saier MH, Reddy VS, Tsu BV, Ahmed MS, Li C, Moreno-Hagelsieb G (2016) The Transporter Classification Database (TCDB): recent advances. Nucleic Acids Research 44: 372-379

Seabra AR, Carvalho HG (2015) Glutamine synthetase in Medicago truncatula, unveiling new secrets of a very old enzyme. Frontiers in Plant Science 6: 578

Shannon P, Markiel A, Ozier O, Baliga NS, Wang JT, Ramage D, Amin N, Schwikowski B, Ideker T (2003) Cytoscape: a software environment for integrated models of biomolecular interaction networks. Genome Research 13: 2498-2504

Smit P, Limpens E, Geurts R, Fedorova E, Dolgikh E, Gough C, Bisseling T (2007) Medicago LYK3, an entry receptor in rhizobial nodulation factor signaling. Plant Physiology 145: 183-191 
Snowden CJ, Thomas B, Baxter CJ, Smith AC, Sweetlove LJ (2015) A tonoplast Glu/Asp/GABA exchanger that affects tomato fruit amino acid composition. Plant Journal 81: 651-660

Sonnhammer ELL, von Heijne G, Krogh A (1998) A hidden Markov model for predicting transmembrane helices in protein sequences. In J. Glasgow, T. Littlejohn, F. Major, R. Lathrop, D. Sankoff, and C. Sensen, editors, Proceedings of the Sixth International Conference on $\begin{array}{lllll}\text { Intelligent } & \text { Systems } & \text { for } & \text { Molecular } & \text { Biology }\end{array}$

Su YH, Frommer WB, Ludewig U (2004) Molecular and functional characterization of a family of amino acid transporters from Arabidopsis. Plant Physiology 136: 3104- 3113

Svistoonoff S, Benabdoun FM, Nambiar-Veetil M, Imanishi L, Vaissayre V, Cesari S, Diagne N, Hocher V, de Billy F, Bonneau J, Wall L, Ykhlef N, Rosenberg C, Bogusz D, Franche C, Gherbi H (2013) The Independent Acquisition of Plant Root Nitrogen-Fixing Symbiosis in Fabids Recruited the Same Genetic Pathway for Nodule Organogenesis. PLoS ONE 8: 64515

Tamura K, Peterson D, Peterson N, Stecher G, Nei M, Kumar S (2011) MEGA5: molecular evolutionary genetics analysis using maximum likelihood, evolutionary distance, and maximum parsimony methods. Molecular Biology Evolution 28: 2731-2739

Tamura K, Battistuzzi FU, Billing-Ross P, Murillo O, Filipski A, Kumar S (2012) Estimating divergence times in large molecular phylogenies. Proceedings of the National Academy of Science United States of America 109: 19333-19338

Tegeder M (2012) Transporters for amino acids in plant cells: some functions and many unknowns. Current Opinion in Plant Biology 15: 315-321

Tegeder M (2014) Transporters involved in source to sink partitioning of amino acids and ureides: opportunities for crop improvement. Journal of Experimental Botany 65: 1665-1678

Udvardi MK, Price GD, Gresshoff PM, Day DA (1988) A dicarboxylate transporter on the peribacteroid membrane of soybean nodules. FEBS Letters 231: 36-40

Vastermark A, Lunt B, Saier M (2014) Major facilitator superfamily porters, LacY, FucP and XylE of Escherichia coli appear to have evolved positionally dissimilar catalytic residues without rearrangement of 3-TMS repeat units. Journal of Molecular Microbiology and Biotechnology 24: $82-90$

Vinardell JM, Fedorova E, Cebolla A, Kevei Z, Horvath G, Kelemen Z, Tarayre S, Roudier F, Mergaert P, Kondorosi A, Kondorosi E (2003) Endoreduplication mediated by the anaphasepromoting complex activator CCS52A is required for symbiotic cell differentiation in Medicago truncatula nodules. Plant Cell 15: 2093-2105

Wang H, Kavanaugh MP, North RA, Kabat D (1991) Cell-surface receptor for ecotropic murine retroviruses is a basic amino-acid transporter. Nature 352: 729-731 
Wink M (2013) Evolution of secondary metabolites in legumes (Fabaceae). South African Journal of Bot any 89: 164-175

Yang H, Bogner M, Stierhof YD, Ludewig U (2010) H+-independent glutamine transport in plant root tips. PLoS ONE 5: 8917

Yang H, Krebs M, Stierhof YD, Ludewig U (2014) Characterization of the putative amino acid transporter genes AtCAT2, 3 \& 4: the tonoplast localized AtCAT2 regulates soluble leaf amino acids. Journal of Plant Physiology 171: 594-601

Young ND, Debellé F, Oldroyd GED, Geurts R, Cannon SB, Udvardi MK, Benedito VA, Mayer KFX, Gouzy J, Schoof H (2011) The Medicago genome provides insight into the evolution of rhizobial symbioses. Nature 480: 520-524

Zhang Z, Xiong S, Wei Y, Meng X, Wang X, Ma X (2017) The role of glutamine synthetase isozymes in enhancing nitrogen use efficiency of N-efficient winter wheat. Scientific Reports 7: 1000

Zhou C, Han L, Pislariu C, Nakashima J, Fu C, Jiang Q, Quan L, Blancaflor EB, Tang Y, Bouton JH, Udvardi M, Xia G, Wang Z (2011) From Model to Crop: Functional Analysis of a STAY-GREEN Gene in the Model Legume Medicago truncatula and Effective Use of the Gene for Alfalfa Improvement. Plant Physiology 157: 1483-1496 


\section{APPENDICIES}

Supplemental Table S1. RNA-seq data normalized and reanalyzed. Organ data comes from Young et al., 2011 and nodule zone data comes from Roux et al., 2014).

\begin{tabular}{|c|c|c|c|c|c|c|c|c|c|c|c|c|c|}
\hline APC & Annotation & 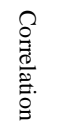 & 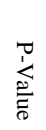 & $\frac{\frac{\sigma}{N}}{\frac{0}{0}}$ & $\stackrel{\stackrel{\sigma}{E}}{\check{E}}$ & $\begin{array}{l}\frac{\pi}{3} \\
\sum_{9}^{2}\end{array}$ & $\stackrel{200}{\circ}$ & $\begin{array}{l}\text { Z } \\
\text { Oे } \\
\text { 言 }\end{array}$ & 工 & 炜 & 罵 & $\bar{N}$ & $\stackrel{N}{\Xi}$ \\
\hline Medtr8g089360.1 & cationic amino acid transporter-like protein & 1 & 0 & 0 & 0 & 0 & 0 & 20 & 0 & 0 & 0 & 0 & 4 \\
\hline Medtr5g026850.1 & cyclops protein, putative & 0.94 & 0 & 0 & 0 & 0 & 21 & 52 & 1 & 0 & 1 & 2 & 5 \\
\hline Medtr6g057520.1 & $\begin{array}{l}\text { Nodule Cysteine-Rich (NCR) secreted } \\
\text { peptide }\end{array}$ & 0.94 & 0 & 0 & 0 & 0 & 3 & 864 & 0 & 1 & 157 & 419 & 369 \\
\hline Medtr7g011790.1 & DUF1336 family protein & 0.94 & 0 & 0 & 0 & 2 & 0 & 10 & 0 & 0 & 0 & 1 & 1 \\
\hline Medtr1g061050.1 & fructose-bisphosphate aldolase & 0.93 & 0 & 4 & 13 & 11 & 127 & 195 & 2 & 1 & 4 & 10 & 25 \\
\hline Medtr4g007090.1 & phospholipid N-methyltransferase & 0.93 & 0 & 0 & 0 & 0 & 1 & 53 & 1 & 6 & 8 & 12 & 11 \\
\hline Medtr7g079430.1 & UDP-glucose:sterol glucosyltransferase & 0.93 & 0 & 0 & 1 & 1 & 1 & 14 & 0 & 1 & 0 & 1 & 2 \\
\hline Medtr7g098180.1 & peptide transporter & 0.93 & 0 & 0 & 0 & 0 & 8 & 40 & 0 & 0 & 1 & 1 & 3 \\
\hline Medtr8g087710.1 & $\begin{array}{l}\text { major intrinsic protein (MIP) family } \\
\text { transporter }\end{array}$ & 0.93 & 0 & 7 & 8 & 1 & 3 & 395 & 1 & 2 & 12 & 23 & 110 \\
\hline Medtr1g116930.1 & peptide/nitrate transporter & 0.92 & 0 & 0 & 0 & 0 & 0 & 30 & 0 & 1 & 1 & 2 & 3 \\
\hline Medtr4g094360.3 & $\begin{array}{l}\text { nodulin MtN21/EamA-like transporter family } \\
\text { protein }\end{array}$ & 0.92 & 0 & 0 & 0 & 0 & 0 & 26 & 0 & 0 & 4 & 7 & 17 \\
\hline Medtr8g018290.1 & $\begin{array}{l}\text { phospholipid-transporting ATPase-like } \\
\text { protein }\end{array}$ & 0.92 & 0 & 1 & 3 & 4 & 2 & 12 & 0 & 0 & 0 & 0 & 1 \\
\hline Medtr2g076010.1 & pathogenesis-like protein & 0.91 & 0 & 1 & 4 & 58 & 0 & 88 & 0 & 0 & 1 & 2 & 2 \\
\hline Medtr2g094620.1 & $\begin{array}{l}\text { pleckstrin-like }(\mathrm{PH}) \text { and lipid-binding } \\
\text { START domain protein }\end{array}$ & 0.91 & 0 & 1 & 2 & 0 & 2 & 11 & 0 & 0 & 0 & 1 & 1 \\
\hline Medtr6g071070.1 & glutamine synthetase domain protein & 0.91 & 0 & 61 & 363 & 208 & 355 & 1435 & 4 & 3 & 14 & 39 & 94 \\
\hline Medtr6g086170.1 & $\begin{array}{l}\text { sulfate/bicarbonate/oxalate exchanger and } \\
\text { transporter sat-1 }\end{array}$ & 0.91 & 0 & 0 & 0 & 1 & 6 & 193 & 0 & 1 & 5 & 10 & 31 \\
\hline Medtr1g079730.1 & carboxyl-terminal peptidase & 0.9 & 0 & 0 & 2 & 1 & 1 & 19 & 0 & 0 & 1 & 1 & 2 \\
\hline Medtr2g098420.1 & hypothetical protein & 0.9 & 0 & 2 & 2 & 3 & 2 & 11 & 0 & 0 & 0 & 1 & 1 \\
\hline Medtr2g100710.1 & 6-phosphofructokinase & 0.9 & 0 & 5 & 5 & 42 & 15 & 49 & 0 & 0 & 1 & 2 & 4 \\
\hline Medtr3g015870.1 & $\begin{array}{l}\text { Nodule Cysteine-Rich (NCR) secreted } \\
\text { peptide }\end{array}$ & 0.9 & 0 & 0 & 0 & 0 & 1 & 577 & 0 & 1 & 70 & 186 & 285 \\
\hline Medtr4g103495.1 & subtilisin-like serine protease & 0.9 & 0 & 0 & 0 & 0 & 0 & 1 & 0 & 0 & 0 & 0 & 0 \\
\hline Medtr4g108170.1 & $\mathrm{ABC}$ transporter A family protein & 0.9 & 0 & 0 & 0 & 0 & 0 & 21 & 0 & 0 & 1 & 1 & 1 \\
\hline Medtr5g011750.1 & hypothetical protein & 0.9 & 0 & 0 & 3 & 2 & 0 & 19 & 2 & 2 & 2 & 4 & 9 \\
\hline Medtr5g072420.1 & $\begin{array}{l}\text { Nodule Cysteine-Rich (NCR) secreted } \\
\text { peptide }\end{array}$ & 0.9 & 0 & 0 & 0 & 0 & 1 & 33 & 0 & 0 & 2 & 3 & 3 \\
\hline Medtr7g078060.1 & O-acyltransferase WSD1-like protein & 0.9 & 0 & 0 & 0 & 0 & 0 & 14 & 0 & 0 & 1 & 1 & 1 \\
\hline Medtr7g082810.1 & MATE efflux family protein & 0.9 & 0 & 0 & 0 & 0 & 1 & 38 & 0 & 0 & 2 & 4 & 8 \\
\hline Medtr7g090950.1 & eukaryotic-type carbonic anhydrase & 0.9 & 0 & 0 & 0 & 9 & 0 & 16 & 0 & 0 & 2 & 5 & 14 \\
\hline Medtr7g096870.1 & high affinity inorganic phosphate transporter & 0.9 & 0 & 0 & 0 & 0 & 0 & 27 & 0 & 0 & 1 & 2 & 5 \\
\hline Medtr8g076190.1 & $\begin{array}{l}\text { ATP-binding microtubule motor family } \\
\text { protein }\end{array}$ & 0.9 & 0 & 0 & 0 & 2 & 0 & 19 & 0 & 0 & 1 & 1 & 3 \\
\hline
\end{tabular}



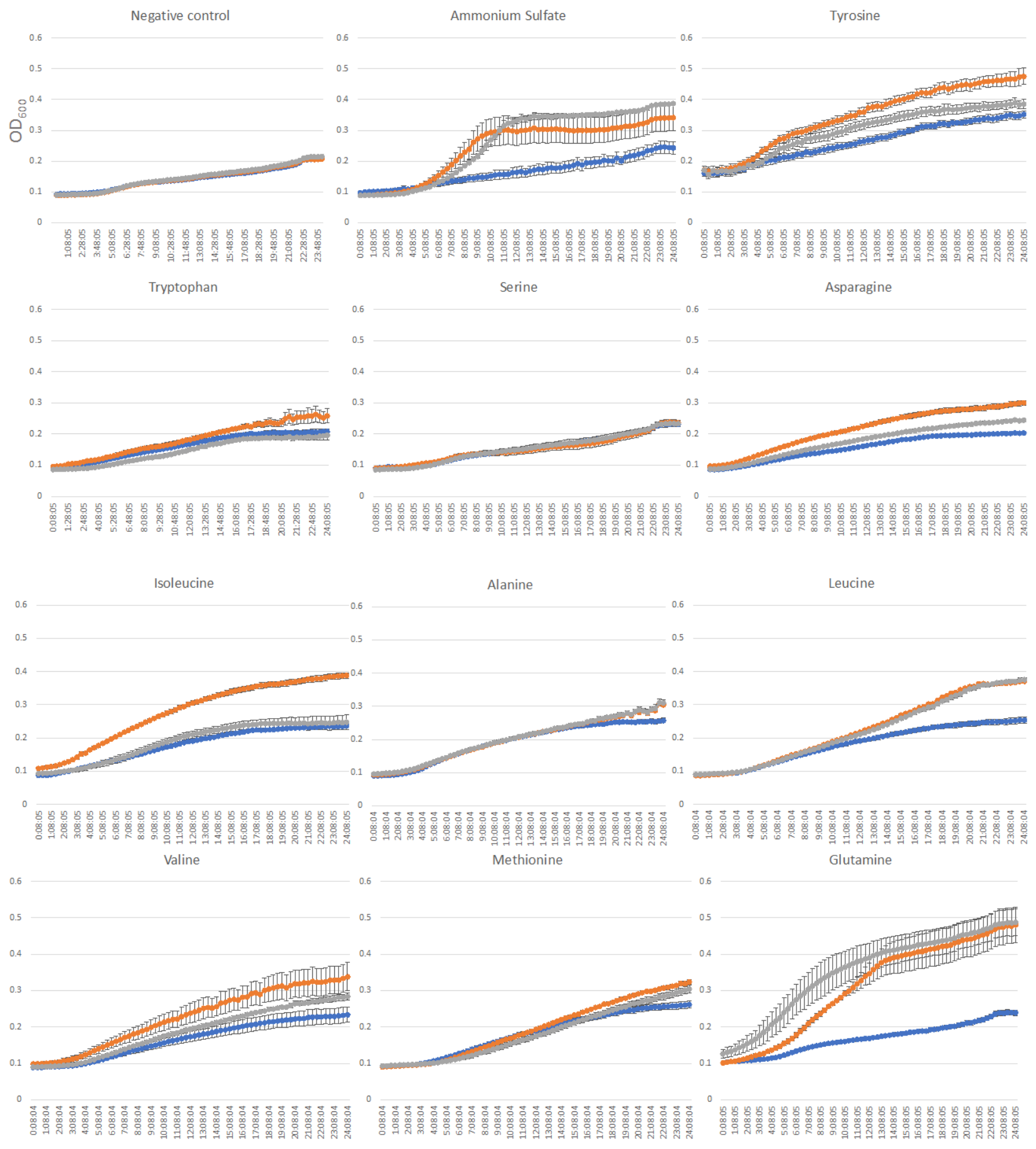


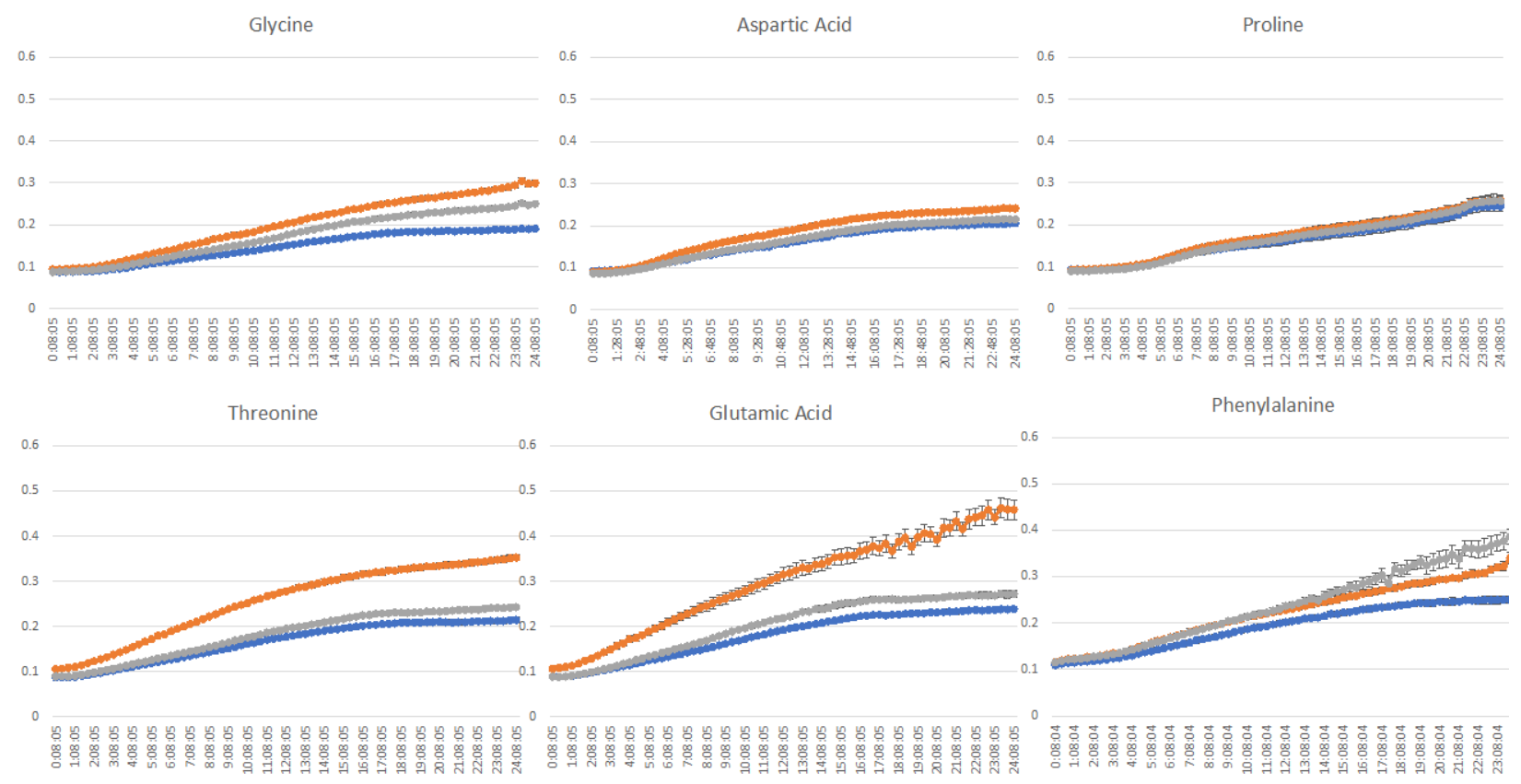

Supplemental Figure S1. Liquid cultures for amino acid import assays. Negative control lacked a nitrogen source. Ammonium sulfate was positive control. All concentrations of amino acids as well as ammonium sulfate were $10 \mathrm{mM}$. Blue line represents untransformed yeast strain 22 $\Delta 10 \mathrm{AA}$, orange line represents empty vector, and gray line represents yeast complemented with MtAPC1. Bars represent standard errors of 5 replicates. Growth curves were collected over 24 hours with readings every 20 minutes. 


\title{
Chapter 5
}

\section{Functional characterization of the Medicago truncatula nodule-specific copper transporter MtCOPT1}

\begin{abstract}
Copper $\left(\mathrm{Cu}^{2+}\right)$ is an essential micronutrient for plants, playing important roles in photosynthesis, mitochondrial respiration, detoxification of reactive oxygen species, and oxidative stress protection. A fine equilibrium must be maintained to move $\mathrm{Cu}^{2+}$ to the enzymes that require it as a cofactor, but not move so much as to cause toxicity through Fenton-like chemistry, cellular damage or displacement of other essential ions. This equilibrium is supported by specific membrane transporters. $\mathrm{Cu}^{2+}$ import into the cell by channels of the Copper transporter (Ctr) family (TCDB \#1.A.56) is conserved across eukaryotes. The three-transmembrane domain topology of this family is highly conserved. The signature domain motif, $\mathrm{MX}_{3} \mathrm{MX}_{12} \mathrm{GX}_{3} \mathrm{G}$ (where $\mathrm{X}$ represents any amino acid residue), spans from the end of the second through the third transmembrane domain. In legumes, the exact function of $\mathrm{Cu}^{2+}$ during symbiotic nitrogen fixation remains undetermined. We identified eight CTR genes in the genome of the model legume, Medicago truncatula. One in particular is expressed solely in the nodule (Medtr4g019870, MtCOPT1), leading us to hypothesize that it plays an essential role during symbiotic nitrogen fixation. MtCOPT1 is highly and specifically expressed in the interzone of infected nodule cells. Analysis of gene architecture, transmembrane topology, and gene expression data was performed and showed gene architecture and transmembrane domains comparable to COPT family members. Import assay in yeast showed MtCOPT1 has affinity for $\mathrm{Cu}^{2+}$, revealing that its expression in nodules may be essential for $\mathrm{Cu}^{2+}$ homeostasis during symbiotic nitrogen fixation.
\end{abstract}




\section{INTRODUCTION}

\section{The roles of copper in plant physiology}

Copper $\left(\mathrm{Cu}^{2+}\right)$ is an essential micronutrient utilized as a cofactor of enzymes involved in many biochemical plant processes including photosynthesis, cellular respiration, and oxidative stress protection through detoxification of reactive oxygen species (ROS) (Brunori et al., 2005; Andrés-Colás et al., 2010; Perea-García et al., 2013). Oxidative stress tolerance is regarded as especially important in legume nodules during symbiotic nitrogen fixation, as the reduction process is highly energetic (16 ATP $/ \mathrm{N}_{2}$ fixed; $\Delta \mathrm{G}^{\mathrm{o}}=-33 \mathrm{KJ} / \mathrm{mol} \mathrm{NH}_{3}$ ) (van Heeswijk et al., 2013), utilizes aerobic respiration and generates reactive oxygen species. ROS are formed during aerobic metabolism and include hydrogen peroxide $\left(\mathrm{H}_{2} \mathrm{O}_{2}\right)$, singlet oxygen molecules $\left({ }^{1} \mathrm{O}_{2}\right)$, superoxide anions $\left(\mathrm{O}_{2}{ }^{-}\right)$, and hydroxyl radicals $\left({ }^{\bullet} \mathrm{OH}\right)$. The high reactivity of these ROS leads to degradation of DNA, lipids, carbohydrates and proteins and, subsequently cell death (Overmyer et al., 2003; Moller et al., 2007). Although much is known about $\mathrm{Cu}^{2+}$ as an essential cofactor in plants, very little remains known about its precise role in symbiotic nitrogen fixation in legume nodules.

Copper is a transition metal found in the plant under two different redox states: $\mathrm{Cu}^{+}[\mathrm{Cu}(\mathrm{I})$, the reduced state] and $\mathrm{Cu}^{2+}$ [Cu(II), the oxidized state]. This metal binds to different substrates depending on its redox state. In its reduced form, $\mathrm{Cu}^{+}$will preferentially bind to sulfur-containing compounds with a thiol or thioester group, while in the oxidized state, $\mathrm{Cu}^{2+}$ will preferentially bind to imidazole nitrogen groups or oxygen (Cohu and Pilon, 2010; Printz et al., 2016). Plant compounds to which $\mathrm{Cu}^{2+}$ bind include ascorbate oxidase, polyphenol oxidase, $\mathrm{Cu}-\mathrm{Zn}$ superoxidase dismutase, plastocyanin, cytochrome c oxidase, and copper chaperones (O’Halloran and Culotta, 2000; Hansch and Mendel, 2009). Given the dual redox nature of $\mathrm{Cu}$ in physiological conditions, it can be used a wide range of interactions within the cell from stabilizing structures to driving reactions. However, excess $\mathrm{Cu}^{2+}$ is highly toxic and can lead to cell damage and death. This indicates a fine equilibrium must be maintained in cells to stave off damage but allow necessary physiological processes to occur with $\mathrm{Cu}^{2+}$ as a cofactor (Hansch and Mandel, 2009; Festa and Thiele, 2011).

Copper toxicity is due to the excess production of hydroxyl radicals when present in excess as free $\mathrm{Cu}$ ions, which can participate in Fenton-like redox reactions with organic molecules (Pham 
et al., 2013), thus damaging nucleic acids, proteins, and lipids in the cell. Additionally, it can also displace other essential cofactor metals, thus hampering enzymatic reactions (Burkhead et al., 2009). Organisms have developed mechanisms to maintain metal homeostasis to avoid $\mathrm{Cu}^{2+}$ deficiency as well as its toxicity within their cells.

$\mathrm{Cu}^{2+}$ is found in many plant cells spaces and organelles, including the cytosol, apoplast, thylakoid lumen, inner mitochondrial membrane and the endoplasmic reticulum. As a cofactor, $\mathrm{Cu}^{2+}$ is involved in photosynthesis by participating in the electron transfer process with plastocyanin, in addition to roles with $\mathrm{Cu}^{2+} / \mathrm{Zn}^{2+}$ superoxide dismutase (SOD) to detoxify ROS in chloroplasts, and as a cofactor in ethylene receptors, apoplastic oxidases, and mitochondrial cytochrome c oxidase in the electron transport chain (Tainer et al., 1983; Redinbo et al., 1994; Brunori et al., 1998). Additionally, superoxide dismutase (SOD) utilizes $\mathrm{Cu}^{2+}$ to activate the twostep dismutation of superoxide radicals to hydrogen peroxide and oxygen during aerobic respiration (Tainer et al., 1983; Culotta et al., 2006).

Plant phenotypes associated with $\mathrm{Cu}$ toxicity are quite similar to those of Fe deficiency, including increased oxidative stress and leaf chlorosis (Pätsikkä et al., 2002). $\mathrm{Cu}^{2+}$-deficient plants show chlorosis that first develops in young leaf tips before the formation of necrotic lesions. These symptoms are consistent with a decreased function of plastocyanin and evidenced by an impaired photosynthetic transport chain and a reduction in non-photochemical quenching (Abdel-Ghany and Pilon, 2008).

Copper is taken up from the soil as $\mathrm{Cu}^{2+}$ by specific transporters and reduced by a ferric reductase oxidase at the plasma membrane (Mukherjee et al., 2006; Bernal et al., 2012; Zhou et al., 2016; Printz et al., 2016). In plants, only a few transporter families have been specifically associated with $\mathrm{Cu}$ transport: channels of the Copper Transporter family (Ctr, TCDB 1.A.56) and secondary transporters of Plant Copper Uptake Porter family (Pl-Cu-UP, 2.A.1.82) (Andrés-Colás et al. 2010; Klaumann et al., 2011; Martins et al., 2012; Li et al., 2013). Additional families reported to be involved with transport of divalent metals, including copper, are the Oligopeptide Transporter (OPT) Family (2.A.67) (Waters et al., 2006) and the Zinc $\left(\mathrm{Zn}^{2+}\right)$-Iron (Fe ${ }^{2+}$ ) Permease (ZIP) Family (2.A.5) (Wintz et al., 2003; Puig et al., 2007; Del Pozo et al., 2010). Below, we further explore the Ctr channels in plants to contextualize the physiology roles members of this family play in $\mathrm{Cu}$ homeostasis. 


\section{The Copper transporter family in plants}

The transporter classification database (TCDB: www.tcdb.org) contains the family 1.A.56 known as the copper transporter (Ctr) family of channels.

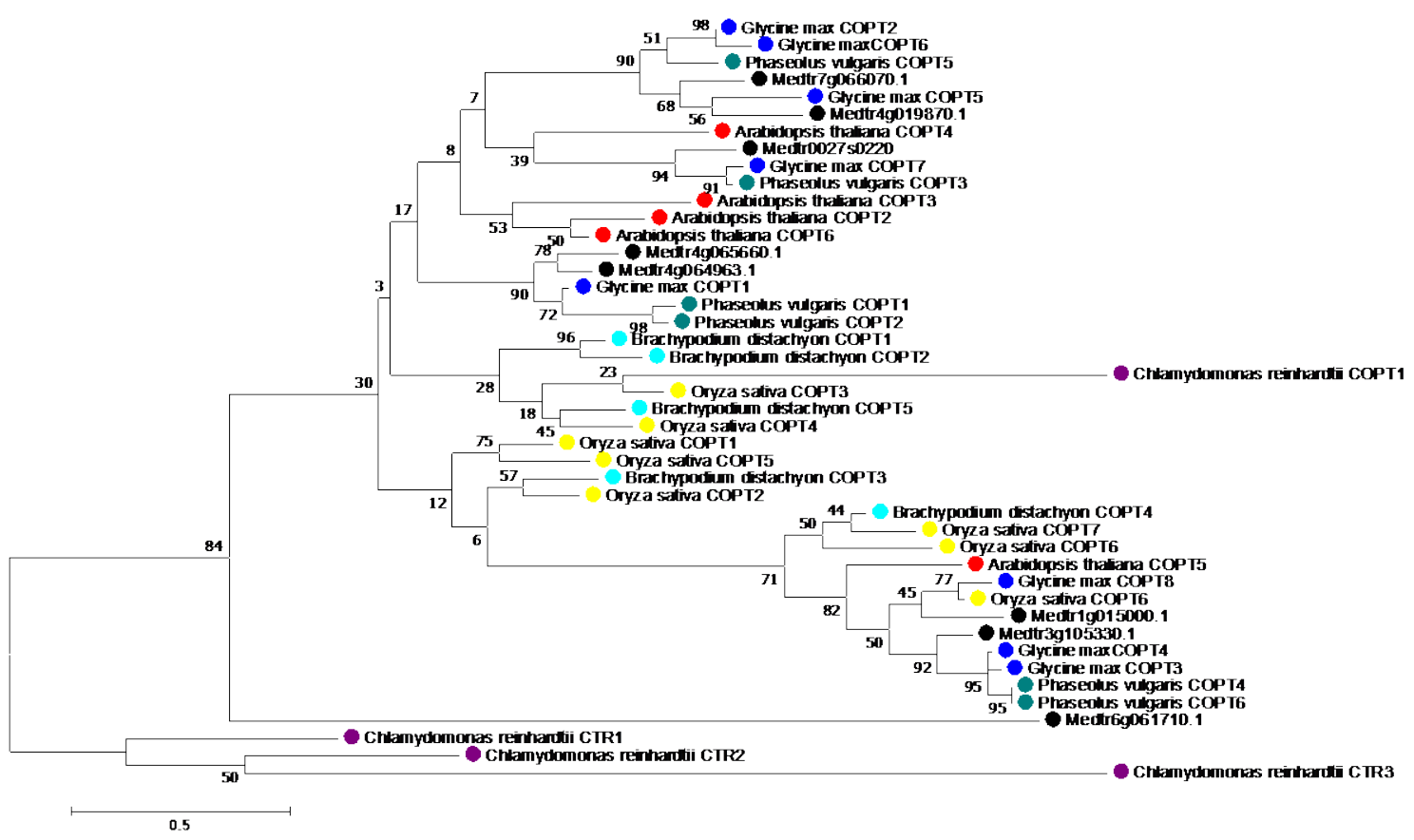

Figure 5.1. Phylogenetic analysis of all members of the Ctr/COPT channel family in select plant species. Some of the CTR protein in Chlamydomonas reinhardtii are more distantly related to members in higher plant species, including Arabidopsis thaliana, rice (Oryza sativa), and the legumes soybean (Glycine max), Medicago truncatula, and common bean (Phaseolus vulgaris). Branch length represents average residue substitution per site. Species are color coded with Medicago truncatula represented with black dots.

Within the Ctr family, proteins are denoted CTR in yeast, fungi and animals, whereas they have been named COPT in plants. Different quaternary structures can be utilized to create a functional $\mathrm{Cu}^{2+}$ transporter. CTR/COPT proteins can be functional as monomers, homodimers, homotrimers (Lee et al., 2002), or as heterocomplexes with other CTR/COPT proteins or nonCTR/COPT proteins to transport $\mathrm{Cu}^{2+}$ (Beaudoin et al., 2006; Yuan et al., 2010).

The founding member of this family is the Saccharomyces cerevisiae CTR1 transporter, which encodes a high affinity $\mathrm{Cu}^{2+}$ uptake protein localized to the plasma membrane. CTR1 loss of function leads to altered cellular responses to extracellular $\mathrm{Cu}^{2+}$, therefore demonstrating a physiologic role of $\mathrm{Cu}^{2+}$ transport in the cytosol (Dancis et al., 1994a; Dancis et al., 1994b). Unlike other members of the Ctr family, which can form heterogeneous complexes, the functional CTR1 
channel can only be formed as homotrimers (Dancis et al., 1994a; Beaudoin et al., 2006; Yuan et al., 2010).

Pertaining to the structure of Ctr transporters, in members across all kingdoms of life there is a well conserved $\mathrm{MX}_{3} \mathrm{M}$ motif (where $\mathrm{X}$ is any amino acid residue) within transmembrane domain (TMD) 2 and a conserved $\mathrm{GX}_{3} \mathrm{G}$ domain in TMD 3 (van den Berghe et al., 2007) - the so called $\mathrm{MX}_{3} \mathrm{MX}_{12} \mathrm{GX}_{3} \mathrm{G}$ motif. which interacts with the extracellular matrix. The $\mathrm{MX}_{3} \mathrm{M}$ motif is important to $\mathrm{Cu}^{2+}$ uptake, but not to protein-protein interactions (Puig et al., 2002). In turn, the $\mathrm{GX}_{3} \mathrm{G}$ motif is essential to the trimeric assembly of Ctr proteins in yeast (Puig et al., 2002; Aller et al., 2004). Both motifs are thought to play a role in the $\mathrm{Cu}^{2+}$ uptake and assembly of the functional heterotrimeric Ctr4/Ctr5 in yeast (Puig et al., 2002; Aller et al., 2004; Ioannoni et al., 2010; Beaudoin et al., 2011; Plante et al., 2014). With the exception of ScCTR3, all Ctr family members are rich in methionine residues within their hydrophilic N-terminal tails (Puig et al., 2002).

Saccharomyces cerevisiae imports $\mathrm{Cu}^{2+}$ into the cytosol via three high-affinity transporters: ScCTR1, ScCTR2, and ScCTR3. ScCTR1 and ScCTR3 are located in the plasma membrane and attain $\mathrm{Cu}^{2+}$ from the environment (Dancis et al., 1994a; Marjorette et al., 2000). Meanwhile ScCTR2 is found in the tonoplast and imports $\mathrm{Cu}^{2+}$ stored in the vacuole of the cell into the cytoplasm (Portnoy et al., 2001; Puig and Thiele, 2002). ScCTR proteins are highly specific for reduced $\mathrm{Cu}^{+}$. Copper exists extensively as $\mathrm{Cu}^{2+}$, and it must first be reduced by a ferric/cupric reductase in order to be transported (Hassett and Kosman, 1995).

The human CTR1 (hCTR1) forms homotrimer complexes that localize to the plasma membrane (Lee et al., 2002; Aller and Unger, 2006; Gupta and Lutsenko, 2009; Maryon et al., 2013). Certain intracellular elements of the protein, such as the carboxyl tail are not essential for the human hCTR1 transporter permeation, but they are essential for regulation of $\mathrm{Cu}^{2+}$ entry (Aller and Unger, 2006; Mayron et al., 2013). CTRs have metal-binding motifs in the $\mathrm{N}$ terminus as well as the second TMD (Puig et al., 2002; Guo et al., 2004; Eisses and Kaplan, 2005; Beaudoin et al., 2006). The two methionine residues in the $\mathrm{N}$ - terminus as well as two near in the extracellular end of the second TMD of hCTR1 are necessary for $\mathrm{Cu}^{2+}$ import (Puig et al., 2002; Eisses et al., 2005; Mayron et al., 2013). The TMD hydrophobicity pattern of CTR/COPT proteins indicates a conserved presence of three transmembrane domains, an external N-terminus, and a cytosolic Cterminus across species (Yuan et al., 2011; Jung et al., 2012; Bellemare et al., 2002; Eisses and 
Kaplan, 2002).

There are six COPT genes in the plant model, Arabidopsis thaliana. AtCOPT1 is a high-

affinity $\mathrm{Cu}^{2+}$ transporter expressed in primary and secondary root tips (Perea-García et al., 2013) and localized to the plasma membrane (Andrés-Colás et al., 2010). AtCOPT6 also localizes to the plasma membrane, it is highly expressed in leaves and can interact with itself or form complex with AtCOPT1 in vitro (Jung et al., 2012). AtCOPT2 is a high-affinity $\mathrm{Cu}^{2+}$ transporter that is induced under $\mathrm{Cu}^{2+}$ and iron deficiencies and expressed in subapical root regions where it localizes to the plasma membrane (Perea-García et al., 2013). In Arabidopsis, the tonoplast-localized COPT5 is mostly expressed in siliques and root vascular tissues and mobilizes $\mathrm{Cu}^{2+}$ under severe deficiency (Sancenón et al., 2004; Garcia-Molina et al., 2011; Klaumann et al., 2011; Perea-García et al., 2013). There are seven COPT genes in the monocot model, rice (Yuan et al., 2011). OsCOPT3 localizes to the plasma membrane and possibly cooperates with OsCOPT2, OsCOPT4 and OsCOPT6 to mediate $\mathrm{Cu}^{2+}$ transport (Yuan et al., 2011).

Following, we explore the genomic context of the model legume Medicago truncatula in search of key COPT transporters potentially related with $\mathrm{Cu}$ homeostasis in root nodules during symbiotic nitrogen fixation.

\section{RESULTS AND DISCUSSION}

\section{Phylogenetic analyses of the CTR/COPT transporters}

A phylogenetic analysis was performed with all eight Ctr family members in the Medicago truncatula genome and all members listed in the TCDB curated database (Figure 5.2). The closest paralog to MtCOPT1 in the Medicago genome is Medtr7g066070.1 which shares 56\% identity with MtCOPT1. Arabidopsis thaliana AtCOPT1 and AtCOPT6 are belong to the same clade as MtCOPT1. Arabidopsis thaliana COPT1 and COPT6 localize to the plasma membrane (AndrésColás et al., 2010, Jung et al., 2012). Arabidopsis COPT6 has been shown to interact with itself at the plasma membrane and also form heterologous interactions with COPT1 (Jung et al., 2012). The closely related Oryza sativa COPT3 also localizes to the plasma membrane and possibly cooperates in vivo with COPT2, COPT4 and COPT6 to mediate $\mathrm{Cu}^{2+}$ transport (Yuan et al., 2011). Whereas Ctr transporters from animals and fungi, as well as green algae, cluster in a clade, those 
from higher plants are grouped in their own clade, with the exception of Medtr6g061710.1, which locates as an outgroup member.

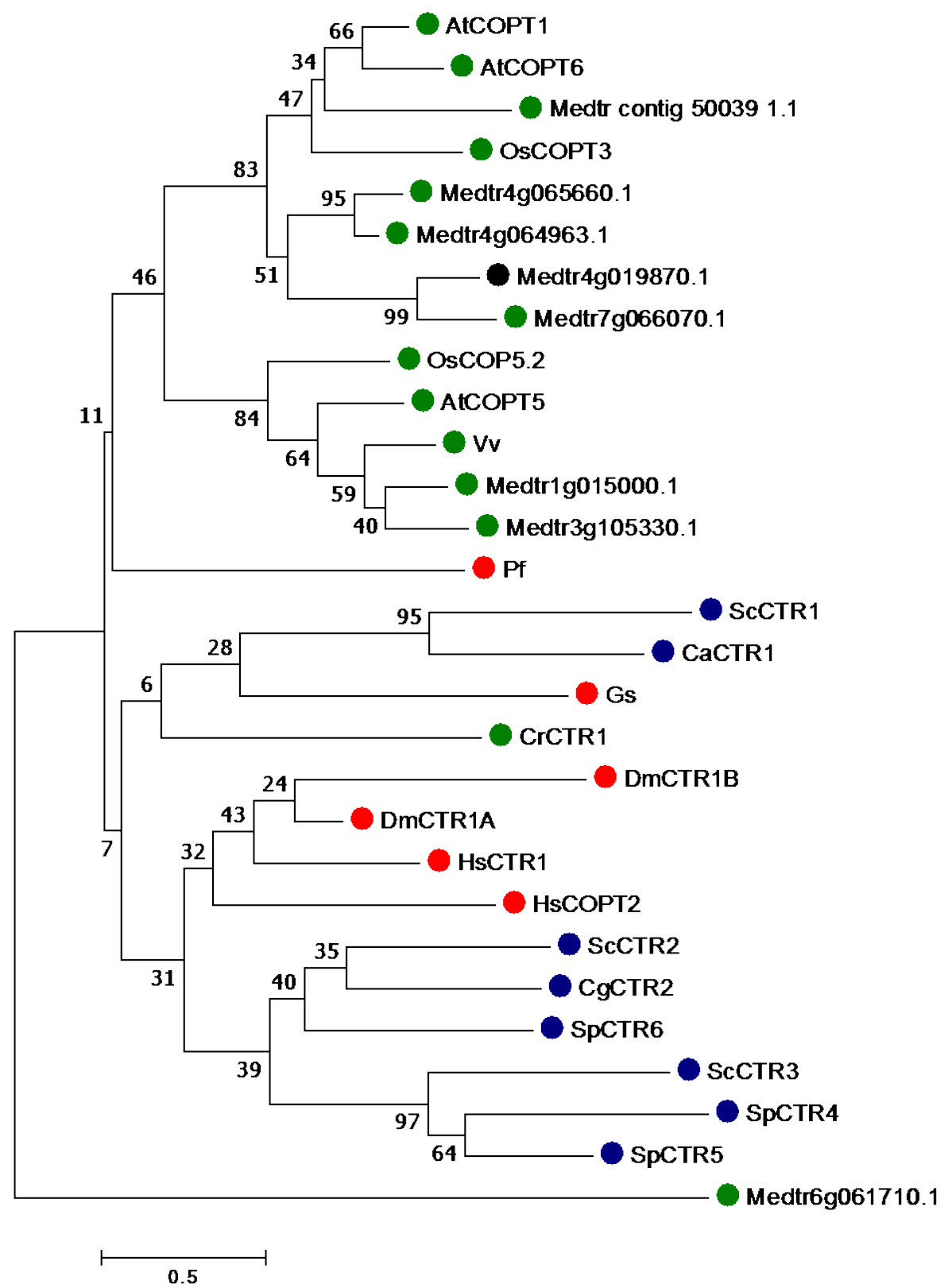

Figure 5.2. Molecular phylogenetic tree of the complete Ctr protein family in Medicago truncatula and the CTR family members found in the Transporter Classification Database (www.TCDB.org). At, Arabidopsis thaliana; Ca, Candida albicans; Cg, Colletotrichum gloeosporioides (fungus); Cr, Chlamydomonas reinhardtii; Dm, Drosophila melanogaster; Gs, Galdieria sulphuraria (red alga); Hs, Homo sapiens; Os, Oryza sativa; Pf, Plasmodium falciparum (malarial parasite, Alveolata, protist); Sc, Saccharomyces cerevisiae; Sp, Schizosaccharomyces pombe; Vv, Vitis vinifera. MtCOPT1 is represented by a black dot, green dots represent plants, blue represents fungi, and all others are red. Vv, CBI27797.3; Pf, XP_001348543.1; Gs, XP_005705236.1. 


\section{Medicago truncatula nodule specific putative copper transporter}

To analyze the Medicago Ctr family members, a phylogenetic analysis with the eight Medicago truncatula COPT (Figure 5.3) and a heatmap was constructed with gene expression of the six major organs of the mature plant. Only Medtr4g019870.1 is expressed nodule specifically, indicating a potential function related to symbiotic nitrogen fixation. 


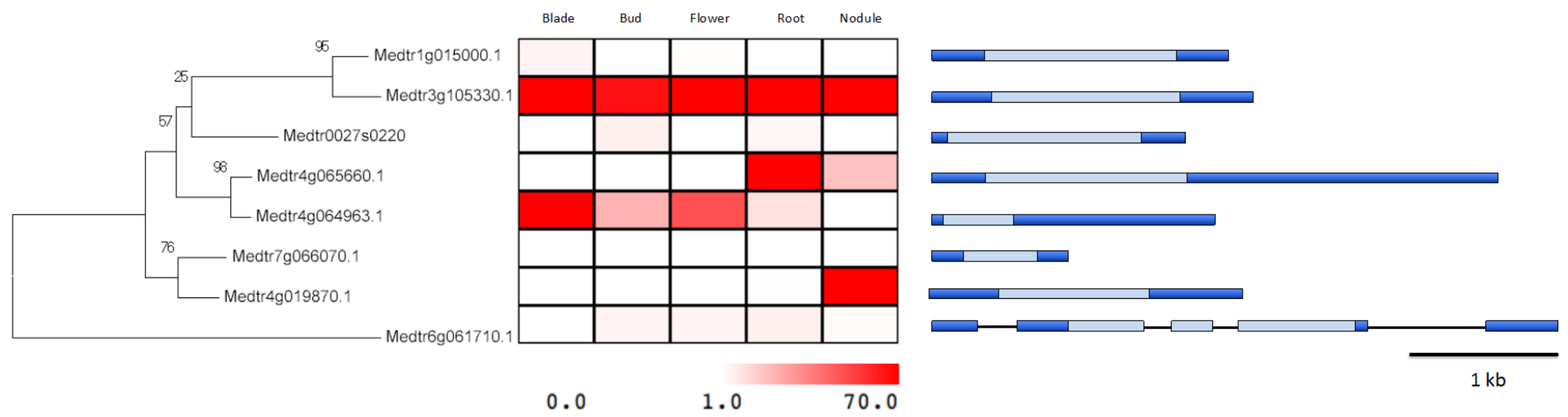

Figure 5.3. Phylogenic tree of the eight Medicago truncatula COPT family members. The tree was constructed using Mega 7 using the Maximum Likelihood method with 1000 bootstraps. Heatmap was constructed using MeV. White is low expression with highest expression shown by red. MtCOPT1 (Medtr7g019870.1) is the only family member to be nodule specific and show high expression in the nodule. Scale is shown below the heatmap. Gene architecture is shown for the 8 Medicago truncatula family members of the Ctr family of transporters (TCDB 1.A.56). Exons are shown in light blue, UTR regions are shown as darker blue and introns are shown as black lines linking exons or sections of UTR. 
Of the eight Medicago Ctr family members, only four showed expression in organs of the mature plant growing under optimal conditions, in which plants were fertilized with $1 / 2 \mathrm{X} B \& \mathrm{D}$ solution (Broughton and Dilworth, 1971), which contains $0.2 \mu \mathrm{M} \mathrm{Cu}^{2+}$ (Figure 5.3). Under these conditions, just one Ctr gene was nodule specific, indicating it may play an essential function of transporting $\mathrm{Cu}^{2+}$ to participate in the symbiotic nitrogen fixation process. It is possible, however, that under lower $\mathrm{Cu}^{2+}$ conditions, significant changes in transcription may occur. The phylogenetic analysis based on protein sequence corroborates the distinctions found in gene architecture. All but one of the Ctr genes in Medicago have no introns. Indeed, Medtr6g061710 has a distinct predicted exon-intron structure, including both UTRs split into two exons.

Based on their gene expression, Medtr3g105330.1 and Medtr4g065660.1 may encompass $\mathrm{Cu}$ uptake and xylem loading systems in the root under normal $\mathrm{Cu}^{2+}$ supply levels. The nodulespecific expression of Medtr7g019870.1 suggests it to be a delivery system into the nodules, perhaps into infected cells carrying out active symbiotic nitrogen fixation. 


\section{Gene architecture of COPT genes and predicted transmembrane domains are representative}

of the Ctr family

Congruent with the other functionally characterized members of this family (Sancenon et al., 2003; Sancenon et al., 2004; Jung et al., 2012), MtCOPT1 contains three TMDs with a fully consistent $\mathrm{MX}_{3} \mathrm{MX}_{12} \mathrm{GX}_{3} \mathrm{G}$ motif (Figure 5.4B), as predicted by the topology analysis programs TMHMM (Figure 5.5A) (Sonnhammer et al., 1998; Krogh et al., 2001) and Protter (Omasits et al., 2014) (Figure 5.5B). (Both programs also predicted an extracellular N-terminus and an intracellular C-terminus. As expected, the MtCOPT1 hydrophilic N-terminal tail also contains the conserved methionine residues present in members of this family (Figure 5.5B).

A

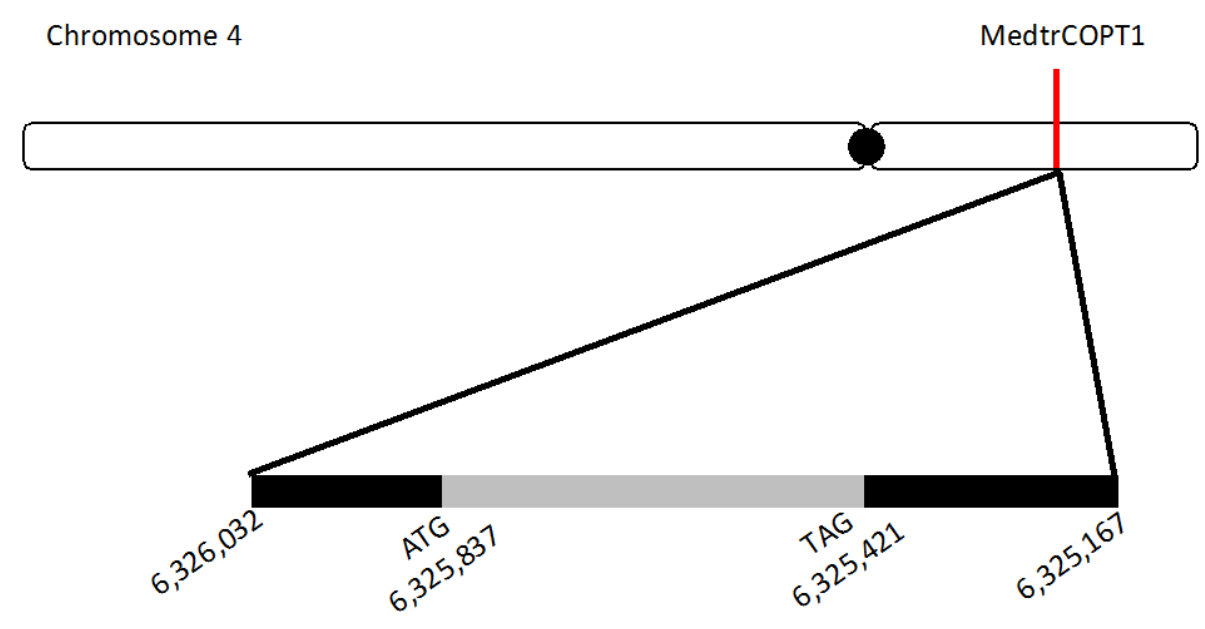

Medtr4g019870

B

\section{MKMIHMMKEDMKMHMNLYWGKDAIILFPGWPNQSLGMYILALS FVFFLALVVEFLPNKSTIKQGTNHIKGGLIQAIIYFFRISFLYLVMLAVMS FNIGIFIAAVVGHTIGFFLVKSHDIFAANKEQNRESAMTIDDI}

Figure 5.4. Predicted gene architecture and protein sequence of the nodule-specific MtCOPT1 transporter gene Medtr4g019870. (A) MtCOPT1 is found on the p arm of chromosome 4 of Medicago truncatula. This gene has one predicted exon (gray bar) and no introns. Untranslated regions (UTRs) are shown in black on the 5' and 3' ends of the exon. Chromosomal coordinates of start and stop codons and limits of each UTR (IMGAG annotation v.4.1) are indicated. (B) Protein sequence of Medtr4g019870.1 is shown with the three transmembrane domains underlined and conserved amino acids of the $\mathrm{MX}_{3} \mathrm{MX}_{12} \mathrm{GX}_{3} \mathrm{G}$ motif shown in red. 
A

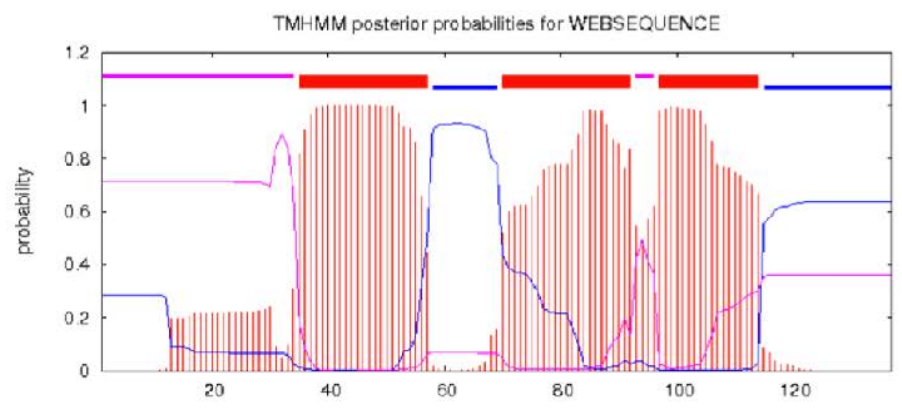

B

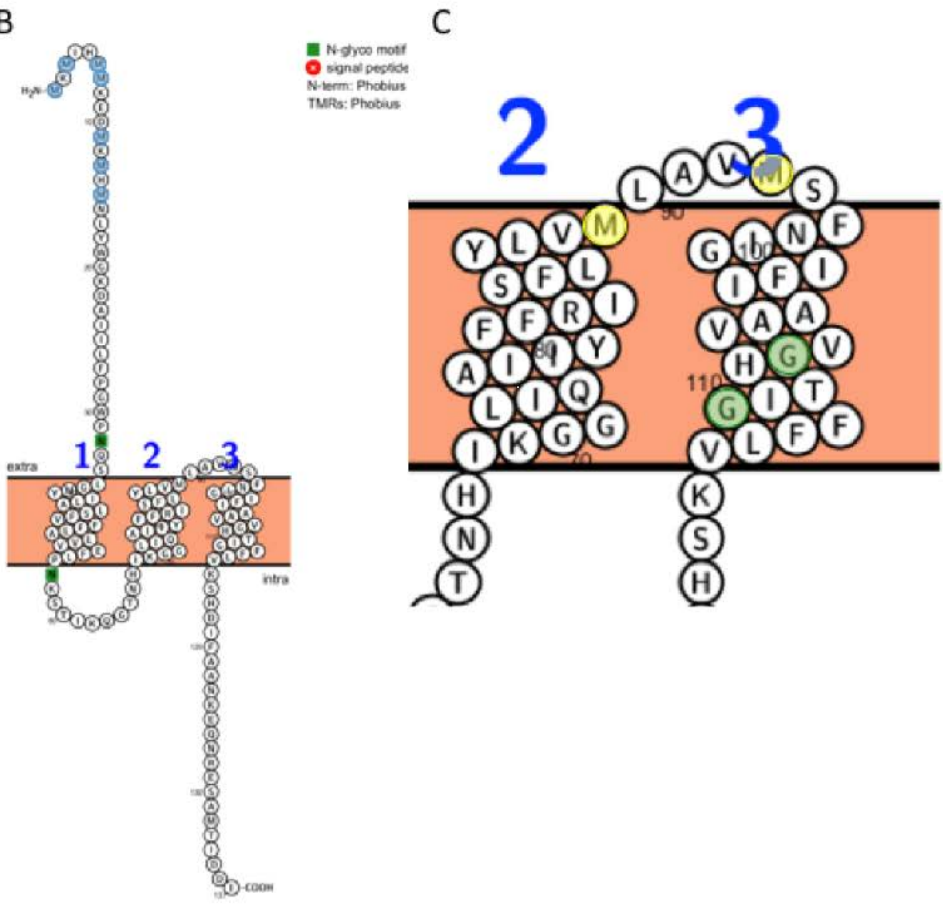

Figure 5.5. Membrane topology of MtCOPT1 (Medtr4g019870.1). (A) The three transmembrane $\alpha$ helices characteristic of the Ctr family were predicted using TMHMM v.2 (Sonnhammer et al., 1998; Krogh et al., 2001). (B) Predicted transmembrane domains of MtCOPT1 protein using the Protter program (Omasits et al., 2014). The expected positions of the terminal regions of the protein, extracellular Nterminus and intracellular C-terminus were confirmed by both topology programs. The conserved methionine residues in the $\mathrm{N}$-terminal tail is highlighted in blue. (C) The conserved $\mathrm{MX}_{3} \mathrm{MX}_{12} \mathrm{GX}_{3} \mathrm{G}(\mathrm{Pfam}$ PF04145) identified in the MtCOPT1 protein. The conserved methionine residues of the $\mathrm{MX}_{3} \mathrm{M}$ motif spanning from the second to third transmembrane domains is shown as yellow circles and the conserved glycine residues of the $\mathrm{GX}_{3} \mathrm{G}$ in the third transmembrane domain is shown as green circles. 
Protein modification of MtCOPT1 was prospected using the Medicago Protein Compendium (Marx et al., 2016). Two amino acid residues were identified as phosphorylated in the C-terminus from protein sequencing results in the database. S130 can be phosphorylated alone or in company with T133 (Figure 5.6). The implications of these protein modifications and the kinases involved remain to be determined.

A

MKMIHMMKEDMKMHMNLYWGKDAIILFPGWPNQSLGMYILALSFVFFLALVVE FLPNKSTIKQGTNHIKGGLIQAIIYFFRISFLYLVMLAVMSFNIGIFIAAVVGHTIGFFLV KSSHDIFAANKEQNRESAMTIDDI

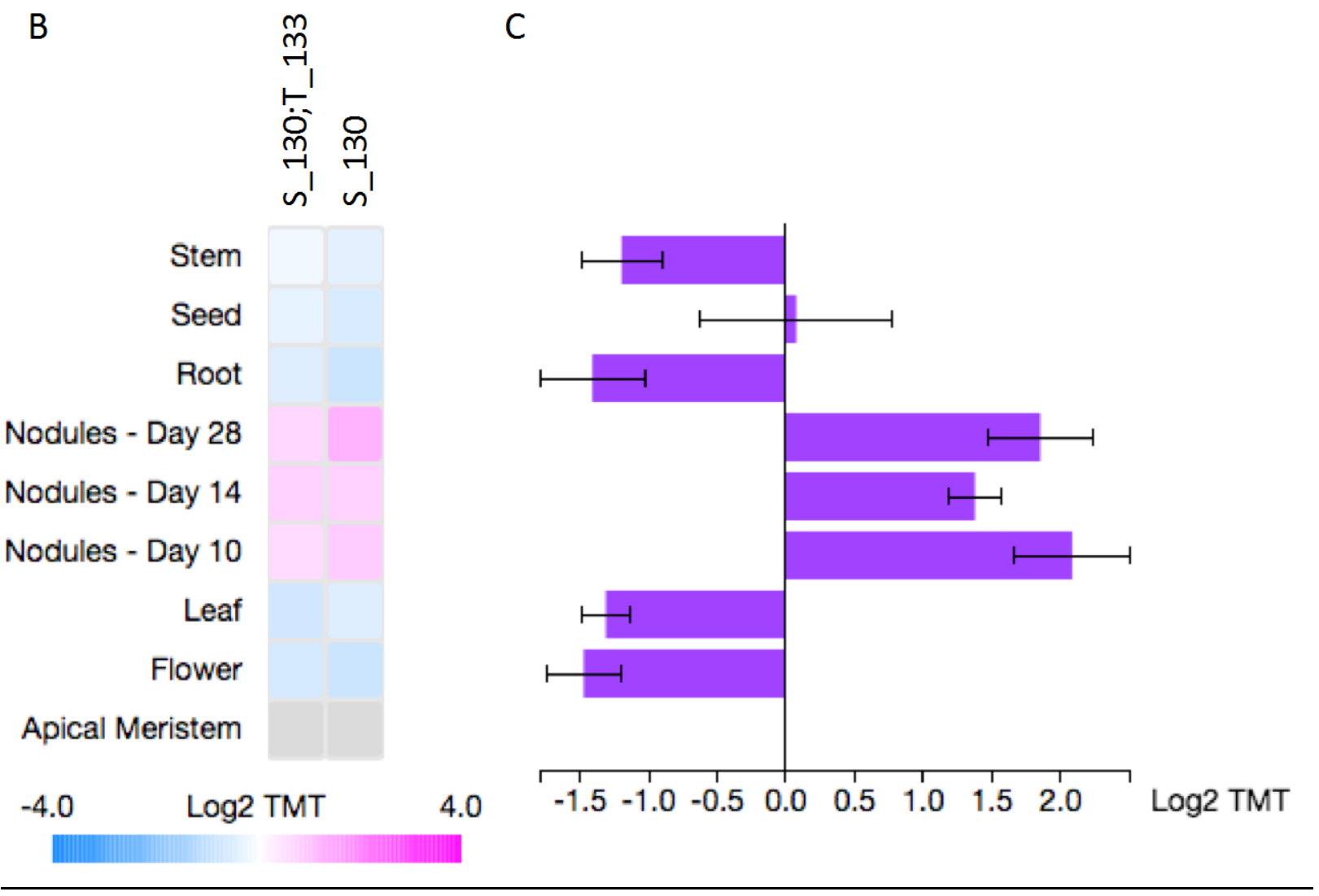

Figure 5.6. Protein sequencing analysis of MtCOPT1 in the Medicago Protein Compendium (http://compendium.medicago.wisc.edu). (A) Protein features related to the three transmembrane domains (underlined), the Ctr conserved domain ( $\mathrm{MX}_{3} \mathrm{MX}_{12} \mathrm{GX}_{3} \mathrm{G}$, in red), the phosphorylated serine and threonine residues (in blue). The protein sequencing data currently offers 54\% coverage for MtCOPT1. (B, C) Expression profiles for the two identified MtCOPT1 phosphorylation isoforms relative to apical meristem. TMT: Tandem Mass Tag. 


\section{MtCOPT1 expression is highest in the nodule interzone}

Expression of MtCOPT1 was first examined using information from the Medicago truncatula Gene Expression Atlas (Benedito et al., 2008; He et al., 2009). Expression of MtCOPT1 is nodule specific (Figure 5.3). Within zones of the mature nodule, MtCOPT1 expression is highest when the nodule cells have been infected and the bacteria have begun to differentiate into fully functional bacteroids within the nodule and afterwards (Figure 5.7A). The interzone has peak expression followed by the fixation zone (Figure 5.7B). As nodules develop, expression is first seen at 10 days post inoculation (dpi) and becomes steady through $28 \mathrm{dpi}$ (Figure 5.7A and 5.8B). The addition of nitrate, an inhibitor of symbiotic nitrogen fixation, led to MtCOPT1 downregulation (Figure 5.7B). MtCOPT1 expression is only seen after $10 \mathrm{dpi}$ and required bacteroid differentiation (Figure 5.8A), suggesting a symbiotic function in mature nodules.

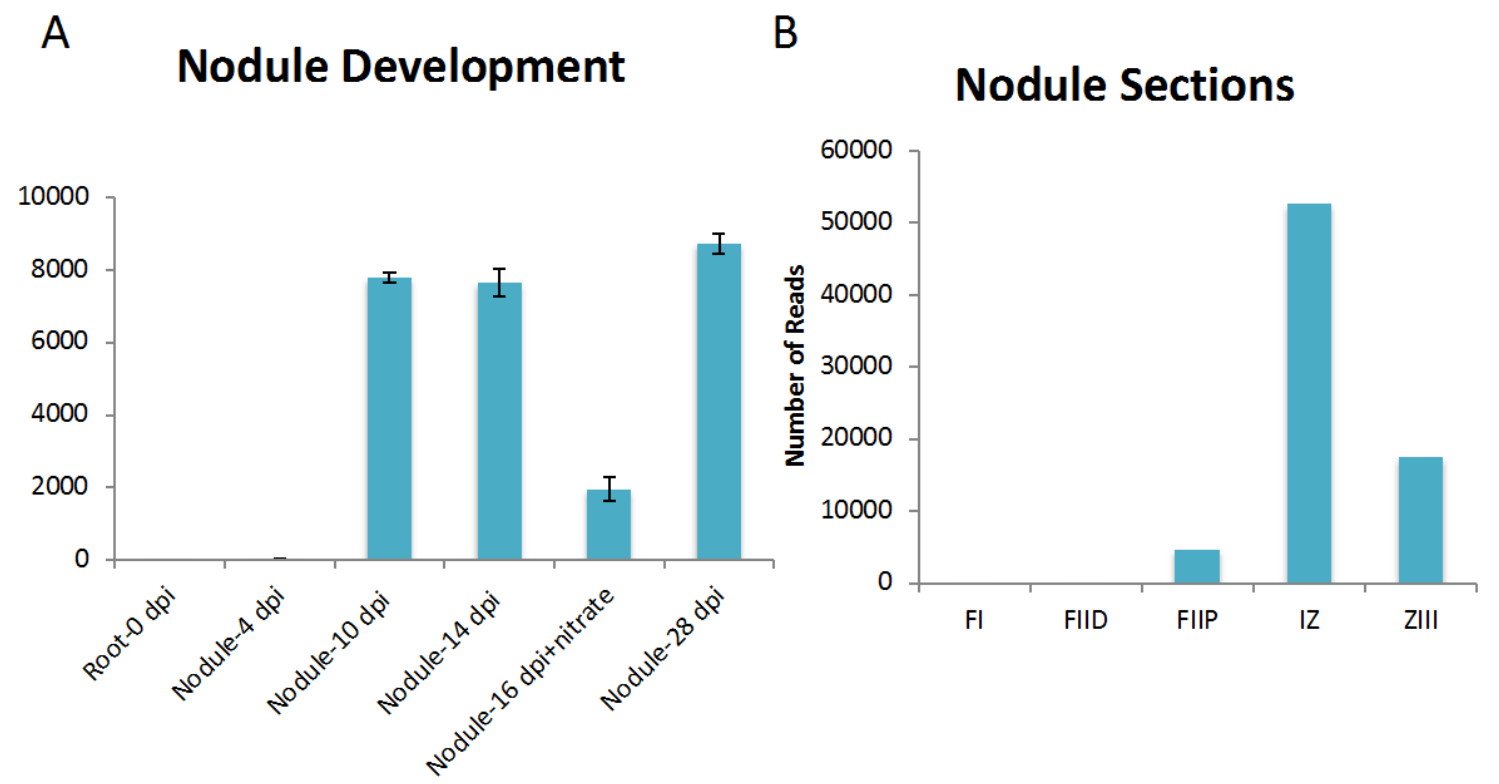

Figure 5.7. Transcriptional profile of the MtCOPT1 gene (Medtr4g019870.1). (A) During nodule development, MtCOPT1 expression starts at ten days post inoculation. Data from Medicago Gene Atlas (https://mtgea.noble.org/v3/; Benedito et al., 2008, He et al., 2009). (B) RNA-seq laser-capture microdissection (LCM) data (Roux et al., 2014) shows highest expression in the inter and nitrogen fixation zones. 


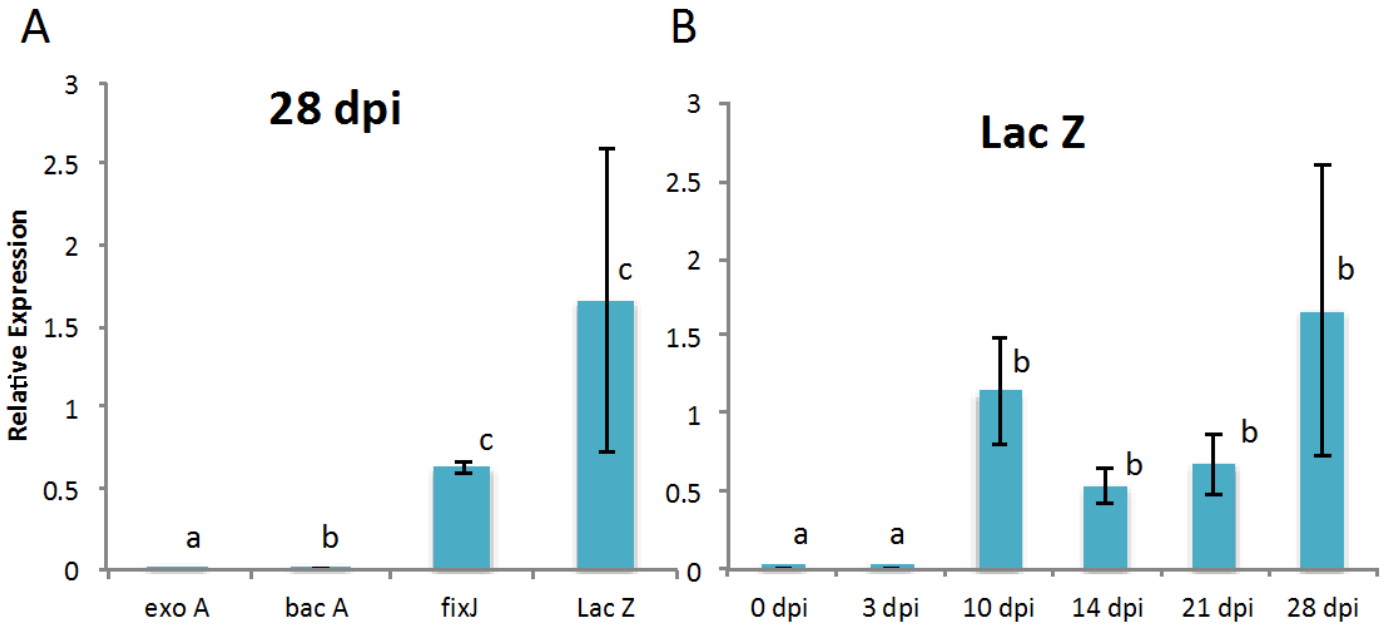

Figure 5.8. RT-qPCR of MtCOPT1 in root systems of Medicago truncatula ecotype 'R108' inoculated with Sm1021 rhizobia. (A) MtCOPT1 expression at 28 dpi nodulating roots inoculated with rhizobial strains exoA, bacA, fixJ, or a functional strain containing LacZ relative to uninoculated root. (B) Time-course of MtCOPT1 expression in root systems inoculated with the functional rhizobial strain.

\section{Yeast import assays show substrate affinity for copper}

Copper import assays were performed with the Saccharomyces cerevisiae mutant strain DTY272 (ctr1 $\Delta$ ctr3 $\Delta$. ctr1 $\Delta$ ctr3 $\Delta$ ), which shows $\mathrm{Cu}^{2+}$ uptake impairment and allows testing of import by genetic complementation.

To test whether MtCOPT1 is a $\mathrm{Cu}^{2+}$ importer, we expressed this gene in the mutant yeast strain on agar media containing increasing concentrations of $\mathrm{CuSO}_{4}$. Very little growth was observed without any $\mathrm{Cu}^{2+}$ supplementation (Figure 5.9). Growth on $0.1 \mathrm{mM} \mathrm{CuSO}_{4}$ and was steady through $8 \mathrm{mM}$ (Figure 5.9). Toxicity levels started at $16 \mathrm{mM} \mathrm{CuSO}_{4}$ growth decreases and no growth was observed at $32 \mathrm{mM} \mathrm{CuSO}_{4}$. Deficiency is overcome at $0.1 \mathrm{mM}$. MtCOPT1 induced better growth than either the DTY272 yeast strain alone, or the DTY272 transformed with the empty vector at both deficiency levels and at toxicity levels. At deficiency levels (0.01 mM), better growth was seen with pDR196-GW-MtCOPT1 compared to both the original mutant yeast strain or the line complemented with the empty vector, indicating import of $\mathrm{Cu}^{2+}$ across the plasma membrane. It was expected that the import of $\mathrm{Cu}^{2+}$ increased survival of cells at deficiency levels, but it was not expected it to confer an advantage at toxicity levels. 


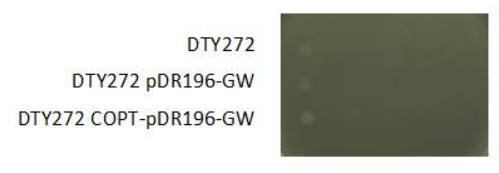

$\mathrm{OmM}$

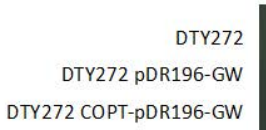

DTY272 COPT-pDR196-GW

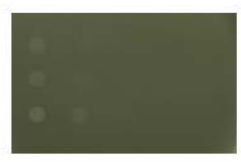

$0.01 \mathrm{mM}$

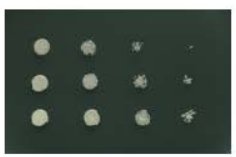

$8 \mathrm{mM}$

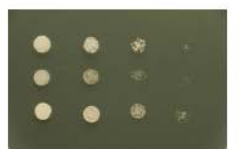

$0.1 \mathrm{mM}$

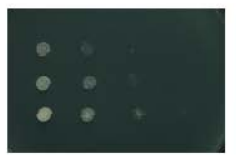

$16 \mathrm{mM}$

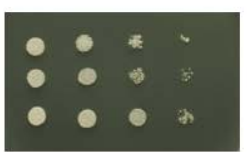

$1 \mathrm{mM}$

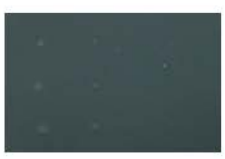

$32 \mathrm{mM} \mathrm{CuSO}_{4}$

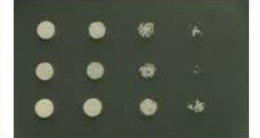

$2 \mathrm{mM}$

Figure 5.9. Copper import assays. YPEG media $+\mathrm{CuSO}_{4}(0,0.01,0.1,1,2,4,8,16,32 \mathrm{mM} \mathrm{CuSO} 4)$. Yeast was grown to $\mathrm{OD}_{660}=1.0$. Cells were washed three times in sterile water and readjusted to $\mathrm{OD}_{600}=1.0$. 10 -fold dilutions of $5 \mathrm{uL}$ drops were pipetted onto YPEG $+\mathrm{CuSO}_{4}$. Plates were grown at $28^{\circ} \mathrm{C}$ and photographed at 3 days. Top row is DTY272, second row is DTY272 empty vector (pDR196-GW), third row is DTY272 COPT in pDR196-GW. S. cerevisiae DTY272 ctr14ctr34 mutant was a gift from Dr. Dennis Thiele from Duke University.

\section{Gene Network shows correlation with nodule specific cysteine rich peptides}

A gene network based on gene expression of the Medicago transcriptome and centered on MtCOPT1 was generated. Fifty-one genes correlated with a stringent threshold ( $\rho \geq 0.90)$. Among them, nineteen Nodule-specific Cysteine-Rich (NCR) secreted proteins showed first-order associations with MtCOPT1. Three genes coding for leghemoglobin, a protein essential for the nitrogen fixation process, were also found strongly associated with MtCOPT1 (Supplemental Table S1). These results point out to a symbiotic role of MtCOPT1 during nitrogen fixation. The identification of common transcription factors as well as cis-elements in promoters of correlated genes in this network may reveal how symbiotic genes coordinate gene expression to allow symbiotic nitrogen fixation to occur in infected cells of the nodule after bacteroid differentiation. 


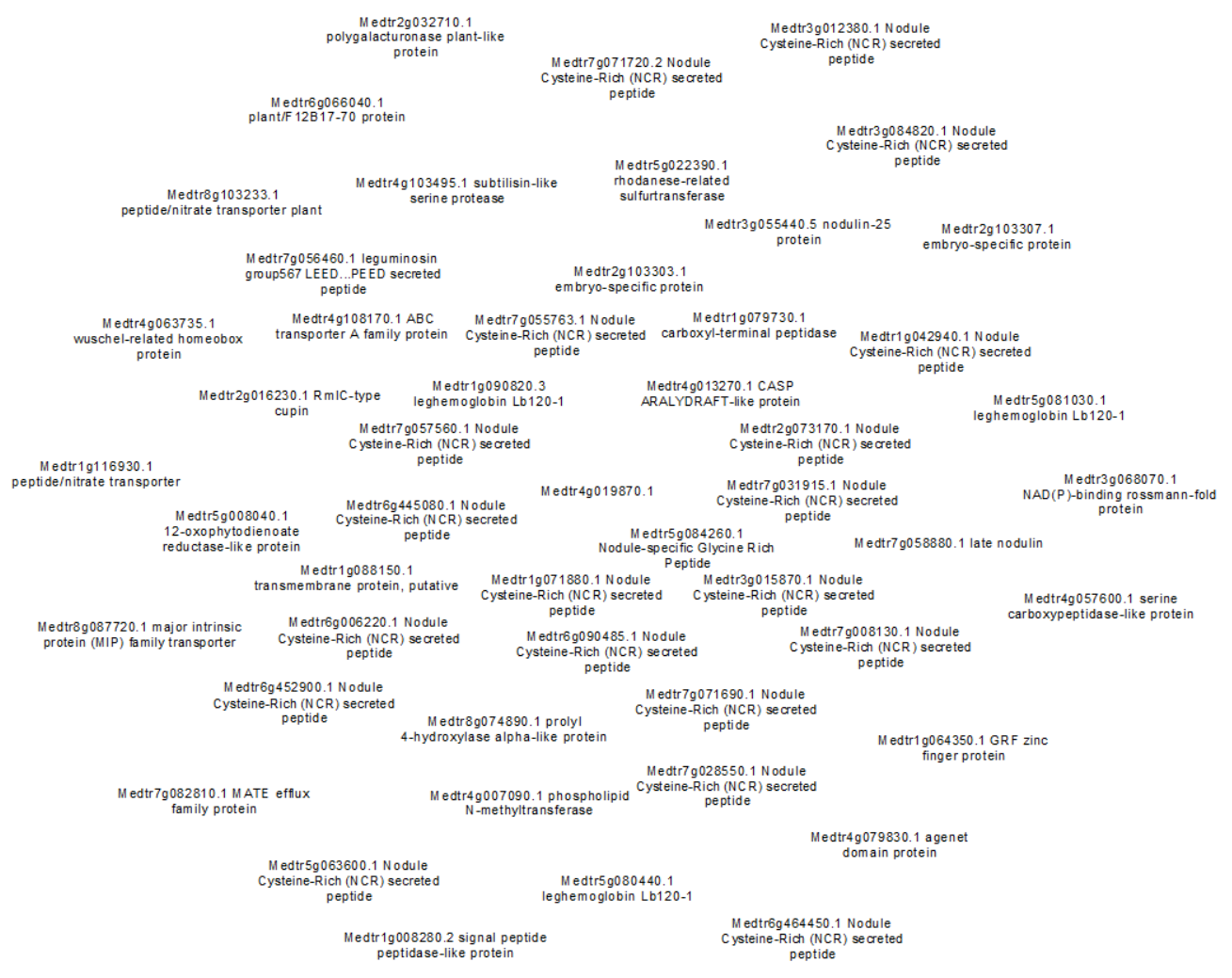

Figure 5.10. Gene network centered on MtCOPT1 gene (yellow node). First-order gene associations were determined using Pearson Coefficient Correlation $(\rho \geq 0.90)$. Visualization was generated in Cytoscape (Shannon et al., 2003). The highest correlation found was $\rho=0.94$. Supplemental Table S1 in the appendix shows the expression matrix and individual correlation values for the 51 genes in this network.

\section{CONCLUSION}

Despite the ubiquitous importance of $\mathrm{Cu}^{2+}$ in plant physiology, and especially in ROS detoxification in cells with high intensity of aerobic respiration activity, such as in nodule cells, little attention had been placed in identifying $\mathrm{Cu}^{2+}$ import systems in legume nodules. We identified a nodule-specific $\mathrm{Cu}^{2+}$ transporter with import activity that is expressed after bacteroid differentiation and continues its expression during active nitrogen fixation.

NOTE: Recently, Senovilla et al. (2018) found MtCOPT1 to localize to the plasma membrane of cells in the differentiation, interzone and early fixation zones and hypothesized MtCOPT1 imports $\mathrm{Cu}^{2+}$ from the apoplast to the cytosol to feed the metabolic processes of symbiotic nitrogen fixation. Their results confirm our findings and precluded the continuation of this work due to the lack of novelty for publication in a peer-reviewed journal. 


\section{MATERIALS AND METHODS}

Phylogenetic analyses and membrane topology prediction: Phylogenetic trees were produced using MEGA v.7 (Molecular Evolutionary Genetics Analysis) software (Tamura et al., 2011; Tamura et al., 2012). Sequences were aligned by Muscle (Edgar, 2004) and the Maximum Likelihood method used the JTT matrix-based model (Jones et al., 1992). The tree with the highest log likelihood is shown. The analysis involved 29 amino acid sequences. All positions containing gaps and missing data were eliminated. Phylogenetic analyses were conducted in MEGA7 (Felsenstein 1985; Kumar et al., 2015). Medicago truncatula sequences were obtained from http://bioinfo3.noble.org/getseq/. TMHMM (http://www.cbs.dtu.dk/services/TMHMM-2.0/; Möller et al., 2001) and Protter (wlab.ethz.ch/protter) were used to predict transmembrane domains with protein sequences as input.

Gene expression analyses: Gene expression analysis was assessed from the Affymetrix Medicago GeneChip microarray data deposited at the Samuel Roberts Noble Foundation Medicago truncatula Gene Expression Atlas (http://mtgea.noble.org/v3/; Benedito et al., 2008). Gene expression analyses of membrane transporters in rhizobial mutants was performed on R108 root systems inoculated with fixJ, bacA, exoA, or hemA::LacZ strains of Sinorhizorium meliloti in Sm1021 background. A control group was not inoculated with rhizobia and was provided full nitrogen fertilization. Plant roots were harvested at $0,3,14,21$, and 28 dpi. RNA was extracted with mirVana miRNA Isolation kit (Life Technologies) followed by DNA removal with Turbo DNA-free kit (Applied Biosystems). First strand complementary DNA was synthesized by priming with oligo-dT using the SuperScript III First-Strand Synthesis Super mix (Life Technologies) following the manual instructions. Primers used were: MtCOPT1 forward: 5' CAT TGC TGC TGT TGG TC, MtCOPT1 reverse: 5' CAA TAG TCA TGG CGG ACT CG. Three biological and three technical replicates were run. SYBR green master mix and $5 \mu \mathrm{L}$ reactions were used on Applied Biosystems 7500 Real Time PCR System and 7500 software. All templates were amplified using the same protocol: $50^{\circ} \mathrm{C}$ for 2 minutes; $95^{\circ} \mathrm{C}$ for 10 minutes; 40 cycles of $95^{\circ} \mathrm{C}$ for 15 seconds and $60^{\circ} \mathrm{C}$ for 1 minute. Melt curves were produced following the 40 cycles by heating to $95^{\circ} \mathrm{C}$ for 15 seconds followed by $60^{\circ} \mathrm{C}$ for 15 seconds and $95^{\circ} \mathrm{C}$ for 15 seconds. 7500 Software (Applied Biosystems) gave $\mathrm{C}_{\mathrm{T}}$ threshold cycle values. Excel was used to organize data and calculate geometric means of technical replications and calculate averages and standard errors. Technical outliers were eliminated from analysis.

The housekeeping genes chosen for this experiment were: EF1 $\alpha$ (Medtr6g021800), tubulin (Medtr7g089120), and MSC27 (X98618.1). NormFinder software (Andersen et al., 2004) was used to identify stably expressed housekeeping genes in the experiment and MSC27 was excluded from the calculations.

Copper import assays: Transcript coding regions with stop codons of gene of interest were transferred from the entry vector to the destination vector pDR196-GW via LR recombination, followed by yeast transformation with the LiAc/SS-DNA/PEG transformation procedure (Gietz and Woods, 2002). Yeast transport mutant strains for substrates of interest were selected. For 
influx transport, the wild-type non-transformed yeast strain and the empty vector yeast strains were the positive controls for auxotrophic yeast strains with the plasmid containing the transcripts'

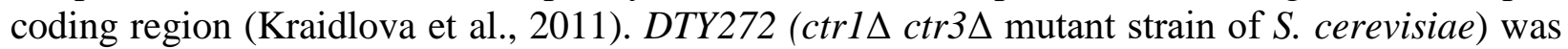
used for import assays. DTY272 yeast strain (control), DTY272 with empty pDR196-GW (control), and DTY272 with COPT in pDR196-GW were grown on YPEG + $\mathrm{CuSO}_{4}(0 \mathrm{mM}, 0.01$ $\mathrm{mM}, 0.1 \mathrm{mM}, 1 \mathrm{mM}, 2 \mathrm{mM}, 4 \mathrm{mM}, 8 \mathrm{mM}, 16 \mathrm{mM}$, and $32 \mathrm{mM} \mathrm{CuSO}_{4}$ ). Five microliter drops of ten-fold dilutions of exponentially growing cells were normalized to $\mathrm{A}_{600}=1.0$ and were spotted on plates and grown at $28^{\circ} \mathrm{C}$ for 3 days. 


\section{REFERENCES}

Abdel-Ghany SE, Pilon M (2008) MicroRNA-mediated Systemic Down-regulation of Copper Protein Expression in Response to Low Copper Availability in Arabidopsis. Journal of Biological Chemistry 283: 15932-15945

Aller SG, Eng ET, De Feo CJ, Unger VM (2004) Eukaryotic CTR copper uptake transporters require two faces of the third transmembrane domain for helix packing, oligomerization, and function. Journal of Biological Chemistry 279: 53435-53441

Aller SG, Unger VM (2006) Projection structure of the human copper transporter CTR1 at 6- $\AA$ resolution reveals a compact trimer with a novel channel-like architecture. Proceedings of the National Academy of Sciences of the United States of America 103: 3627-3632

Andersen CL, Ledet-Jensen J, Ørntoft T (2004) Normalization of real-time quantitative RTPCR data: a model based variance estimation approach to identify genes suited for normalization - applied to bladder- and colon-cancer data-sets. Cancer Research 64: 5245-5250

Andrés-Colás N, Perea-Garcia A, Puig S, Penarrubia L (2010) Deregulated copper transport affects Arabidopsis development especially in the absence of environmental cycles. Plant Physiology 153: 170-184

Beaudoin J, Laliberte J, Labbe S (2006) Functional dissection of Ctr4 and Ctr5 amino-terminal regions reveals motifs with redundant roles in copper transport. Microbiology 152: 209-222

Beaudoin J, Thiele DJ, Labbé S, Puig S (2011) Dissection of the relative contribution of the Schizosaccharomyces pombe Ctr4 and Ctr5 proteins to the copper transport and cell surface delivery functions. Microbiology 157: 1021-1031

Bellemare DR, Shaner L, Morano KA, Beaudoin J, Langlois R, Labbe S (2002) Ctr6, a vacuolar membrane copper transporter in Schizosaccharomyces pombe. Journal of Biological Chemistry 277: 46676-46686

Benedito VA, Li H, Dai X, Wandrey M, He J, Kaundal R, Torres-Jerez I, Gomez SK, Harrison MJ, Tang Y, et al (2010) Genomic inventory and transcriptional analysis of Medicago truncatula transporters. Plant Physiology 152: 1716-1730

Benedito VA, Torres-Jerez I, Murray JD, Andriankaja A, Allen S, Kakar K, Wandrey M, Verdier J, Zuber H, Ott T, et al (2008) A gene expression atlas of the model legume Medicago truncatula. Plant Journal 55: 504-513

Bernal M, Casero D, Singh V, Wilson GT, Grande A, Yang H, Dodani SC, Pellegrini M, Huijser P, Connolly EL, Merchant SS, Krämer U (2012) Transcriptome sequencing identifies SPL7-regulated copper acquisition genes FRO4/FRO5 and the copper dependence of iron homeostasis in Arabidopsis. Plant Cell 24: 738-761 
Burkhead JL, Reynolds KAG, Abdel-Ghany SE, Cohu CM, Pilon M (2009). Copper homeostasis. New Phytologist 182: 799-816

Broughton WJ, Dilworth MJ (1971) Control of leghaemoglobin synthesis in snake beans. Biochemical Journal 125: 1075-1080

Brunori M, Giuffre A, Malatesta F, Sarti P (1998) Investigating the mechanism of electron transfer to the binuclear center in $\mathrm{Cu}$-heme oxidases. Journal of Bioenergetics and Biomembranes 30: $41-45$

Brunori M, Giuffre A, and Sarti P (2005) Cytochrome c oxidase, ligands and electrons. Journal of Inorganic Biochemistry 99: 324-336

Cohu CM, Pilon M (2010) Cell biology of copper. Hell R, Mendel RR, editors. Plant Cell Monographs: Cell Biology of Metals and Nutrients 17: 55-74

Combier JP, Frugier F, de Billy F, Boualem A, El-Yahyaoui F, et al (2006) MtHAP2-1 is a key transcriptional regulator of symbiotic nodule development regulated by microRNA169 in Medicago truncatula. Genes Dev 20: 3084-3088

Combier JP, de Billy F, Gamas P, Niebel A, Rivas S (2008) Trans-regulation of the expression of the transcription factor MtHAP2-1 by a uORF controls root nodule development. Genes \& Development 22: 1549-1559

Culotta VC, Yang M, O'Halloran TV (2006) Activation of superoxide dismutases: putting the metal to the pedal. Biochimica et Biophysica Acta (BBA) - Molecular Cell Research 1763: 747758

Dancis A, Haile D, Yuan DS, Klausner RD (1994a) The Saccharomyces cerevisiae copper transport protein (Ctr1p). Biochemical characterization, regulation by copper, and physiologic role in copper uptake. Journal of Biological Chemistry 269: 25660-25667

Dancis A, Yuan D, Haile D, Askwith C, Eide D, Moehle C, Kaplan J, and Klausner RD (1994b). Molecular characterization of a copper transport protein in S. cerevisiae: an unexpected role for copper in iron transport. Cell 76: 393-402

Del Pozo T, Cambiazo V, González M (2010). Gene expression profiling analysis of copper homeostasis in Arabidopsis thaliana. Biochemical and Biophysical Research Communications 393: 248-252

Edgar RC (2004) MUSCLE: multiple sequence alignment with high accuracy and high throughput. Nucleic Acids Research 32: 1792-1797

Eisses JF, Kaplan JH (2002) Molecular characterization of hCTR1, the human copper uptake protein. Journal of Biological Chemistry 277: 29162-29171 
Eisses JF, Kaplan JH (2005) The mechanism of copper uptake mediated by human CTR1: a mutational analysis. Journal of Biological Chemistry 280: 37159-37168

Felsenstein J (1985) Confidence limits on phylogenies: An approach using the bootstrap. Evolution 39: 783-791

Festa RA and Thiele DJ (2011) Copper: an essential metal in biology. Current Biology 21: 877_ 883

Garcia-Molina A, Andrés-Colás N, Perea-García A, del Valle-Tascón S, Peñarrubia L, Puig S (2011) The intracellular Arabidopsis COPT5 transport protein is required for photosynthetic electron transport under severe copper deficiency. Plant Journal 65: 848-860

Gietz RD, Woods RA (2002) Transformation of yeast by lithium acetate/single-stranded carrier DNA/polyethylene glycol method. Methods of Enzymology 350: 87-96

Guo Y, Smith K, Lee J, Thiele DJ, Petris MJ (2004) Identification of methionine-rich clusters that regulate copper-stimulated endocytosis of the human Ctr1 copper transporter. Journal of Biological Chemistry 279: 17428-17433

Gupta A, Lutsenko S (2009) Human copper transporters: mechanism, role in human diseases and therapeutic potential Future Medicinal Chemistry 1: 1125-1142

Hansch R and Mendel RR (2009) Physiological functions of mineral micronutrients ( $\mathrm{Cu}, \mathrm{Zn}$, $\mathrm{Mn}, \mathrm{Fe}, \mathrm{Ni}, \mathrm{Mo}, \mathrm{B}, \mathrm{Cl})$. Current Opinions in Plant Biology 12: 259-266

Hassett R and Kosman DJ (1995) Evidence for Cu (II) reduction as a component of copper uptake by Saccharomyces cerevisiae. Journal of Biological Chemistry 270: 128-134

He J, Benedito VA, Wang M, Murray JD, Zhao PX, Tang Y, Udvardi MK (2009) The Medicago truncatula gene expression atlas web server. BMC Bioinformatics 10: 441

Ishida S, Lee J, Thiele DJ, Herskowitz I (2002) Uptake of the anticancer drug cisplatin mediated by the copper transporter Ctr1 in yeast and mammals. Proceeding of the National Academy of Sciences of the United States of America 99: 14298-14302

Ioannoni R, Beaudoin J, Mercier A, Labbé S (2010) Copper-Dependent Trafficking of the Ctr4Ctr5 Copper Transporting Complex. PLoS ONE 5: 11964

Jung H, Gayomba SR, Rutzke MA, Craft E, Kochian LV, Vatamaniuk OK (2012) COPT6 is a plasma membrane transporter that functions in copper homeostasis in Arabidopsis and is a novel target of SQUAMOSA promoter-binding protein-like 7. Journal of Biological Chemistry 287: 33252-33267

Jones DT, Taylor WR, Thornton JM. (1992) The rapid generation of mutation data matrices from protein sequences. Computer Applications in the Biosciences 8: 275-282 
Klaumann S, Nickolaus SD, Fürst SH, Starck S, Schneider S, Ekkehard Neuhaus H, Trentmann $\mathbf{O}$ (2011) The tonoplast copper transporter COPT5 acts as an exporter and is required for interorgan allocation of copper in Arabidopsis thaliana. New Phytologist 192: 393-404

Kumar S, Stecher G, Tamura K (2015) MEGA7: Molecular Evolutionary Genetics Analysis version 7.0 for bigger datasets. Molecular Biology and Evolution Molecular Biological Evolution 33: $1870-4$

Kraidlova L, Van Zeebroeck G, Van Dijck P, Sychrova H (2011) The Candida albicans GAP gene family encodes permeases involved in general and specific amino acid uptake and sensing. Eukaryotic Cell 10: 1219-1229

Krogh A, Larsson B, von Heijne G, Sonnhammer ELL (2001) Prediction transmembrane protein topology with a hidden markov model: application to complete genomes. Journal of Molecular Biology 305: 567-580

Lee J, Peña M. M, Nose Y, Thiele DJ (2002) Biochemical characterization of the human copper transporter ctr1. Journal of Biological Chemistry 277: 4380-4387

Li H, Fan R, Li L, Wei B, Li G, Gu L, Wang X, and Zhang X (2014) Identification and characterization of a novel copper transporter gene family TaCT1 in common wheat. Plant, Cell \& Environment 37: 1561-73

Lyons E, Pedersen B, Kane J, Freeling M (2008) The value of nonmodel genomes and an example using SynMap within CoGe to dissect the hexaploidy that predates rosids. Tropical Plant Biology 1: 181-190

Lyons E \& Freeling M (2008) How to usefully compare homologous plant genes and chromosomes as DNA sequences. The Plant Journal 53: 661-673

Marjorette M, Peña O, Puig S, Thiele DJ (2000) Characterization of the Saccharomyces cerevisiae high affinity copper transporter Ctr3. Journal of Biological Chemistry 275: 3324433251

Martins, V, Hanana M, Blumwald E, Gerós H (2012) Copper transport and compartmentation in grape cells. Plant Cell Physiology 53: 1866-1880

Marx H, Minogue CE, Jayaraman D, Richards AL, Kwiecien NW, Siahpirani AF, Rajasek ar S, MaedaJ, Garcia K, Del Valle-Echevarria AR, et al. (2016) A proteomic atlas of the legume Medicago truncatula and its nitrogen-fixing endosymbiont Sinorhizobium meliloti. Nature Biotechnology 34: 1198-1205

Maryon EB, Molloy SA, Kaplan JH (2013) Cellular glutathione plays a key role in copper uptake mediated by human copper transporter 1 American Journal of Physiology - Cell Physiology 304: 768-779 
Mitra RM, Long SR (2004) Plant and bacterial symbiotic mutants define three transcriptionally distinct stages in the development of the Medicago truncatula/Sinorhizobium meliloti symbiosis. Plant Physiology 134: 595-604

Moller S, Croning MD, Apweiler R (2001) Evaluation of methods for the prediction of membrane spanning regions. Bioinformatics 17: 646-53

Moller IM, Jensen PE, Hansson A (2007) Oxidative modifications to cellular components in plants Annual. Review Plant Biology 58:459-481

Mukherjee I, Campbell NH, Ash JS, Connolly EL (2006) Expression profiling of the Arabidopsis ferric chelate reductase (FRO) gene family reveals differential regulation by iron and copper. Planta 223: 1178-90

O’Halloran TV \& Culotta VC (2000) Metallochaperones, an intracellular shuttle service for metal ions. Journal of Biological Chemistry 275: 25057-25060

Omasits U, Ahrens CH, Muller S, Wollscheid B (2014) Protter: interactive protein feature visualization and integration with experimental proteomic data. Bioinformatics 30: 884-886

Overmyer K, Brosche M, Kangasjaryi J (2003) Reactive oxygen species and hormonal control of cell death. Trends in Plant Science 7: 335-342

Patsikka E, Kairavuo M, Sersen F, Aro EM, Tyystjarvi E (2002) Excess copper predisposes photosystem II to photoinhibition, in-vivo by out competing iron and causing decrease in leaf chlorophyll. Plant Physiology 129: 1359-1367

Perea-García A, Garcia-Molina A, Andrés-Colás N, Vera-Sirera F, Pérez-Amador MA, Puig S, Peñarrubia L (2013) Arabidopsis copper transport protein COPT2 participates in the cross talk between iron deficiency responses and low-phosphate signaling. Plant Physiology 162: 180-194

Pham AN, Xing G, Miller CJ, Waite TD (2013) Fenton-like copper redox chemistry revisited: Hydrogen peroxide and superoxide mediation of copper-catalyzed oxidant production. Journal of Catalysis 301: 54- 64

Plante S, Ioannoni R, Beaudoin J, Labbe S (2014) Characterization of Schizosaccharomyces pombe copper transporter proteins in meiotic and sporulating cells. Journal of Biological Chemistry 289: 10168-10181

Portnoy ME, Schmidt PJ, Rogers RS, Culotta VC (2001). Metal transporters that contribute copper to metallochaperones in Saccharomyces cerevisiae. Molecular Genetics and Genomics 265: 873-882

Printz B, Lutts S, Hausman JF, Sergeant K (2016) Copper trafficking in plants and its implication on Cell Wall dynamics. Frontiers Plant Science 7: 601 
Puig S, Andres-Colas N, Garcia-Molina A, Penarrubia L (2007) Copper and iron homeostasis in Arabidopsis: response to metal deficiencies, interactions and biotechnological applications. Plant Cell Environment 30: 271-290

Puig S, Thiele DJ (2002) Molecular mechanisms of copper uptake and distribution. Current Opinions Chemical Biology 6: 171-180

Puig S, Lee J, Lau M, Thiele D (2002) Biochemical and genetic analysis of yeast and human high affinity copper transporters suggest a conserved mechanism for copper uptake. Journal of Biological Chemistry 277: 26021-26030

Redinbo MR, Yeates TO, Merchant S (1994) Plastocyanin: structural and functional analysis Journal of Bioenergetics and Biomembranes 26:49-66

Roux B, Rodde N, Jardinaud MF, Timmers T, Sauviac L, Cottret L, Carrère S, Sallet E, Courcelle E, Moreau S, Debellé F, Capela D, de Carvalho-Niebel F, Gouzy J, Bruand C, Gamas P (2014) An integrated analysis of plant and bacterial gene expression in symbiotic root nodules using laser-capture microdissection coupled to RNA sequencing. Plant Journal 77: 817837

Sancenón V, Puig S, Mira H, Thiele DJ, Peñarrubia L (2003) Identification of a copper transporter family in Arabidopsis thaliana. Plant Molecular Biology 51: 577-587

Sancenón V, Puig S, Mateu-Andrés I, Dorcey E, Thiele DJ, Peñarrubia L (2004) The Arabidopsis copper transporter COPT1 functions in root elongation and pollen development. Journal of Biological Chemistry 279: 15348-15355

Senovilla M, Castro-Rodriguez R, Abreu I, Escudero V, Kryvoruchko IS, Udvardi M, Imperial J, Gonzalez-Guerrero M (2018) Medicago truncatula copper transporter1 (MtCOPT1) delivers copper for symbiotic nitrogen fixation. New Phytologist 218: 696-709

Shannon P, Markiel A, Ozier O, Baliga NS, Wang JT, Ramage D, Amin N, Schwikowski B, Ideker T (2003) Cytoscape: a software environment for integrated models of biomolecular interaction networks. Genome Research 13: 2498-504

Smit P, Limpens E, Geurts R, Fedorova E, Dolgikh E, Gough C, Bisseling T (2007) Medicago LYK3, an entry receptor in rhizobial nodulation factor signaling. Plant Physiology 145: 183-191

Song X, Sun S, Zhang W, Yin Z (2004) A method for the synthesis of spherical copper nanoparticles in the organic phase. Journal of Colloid and Interface Science 273: 463-469

Sonnhammer ELL, von Heijne G, Krogh A (1998) A hidden Markov model for predicting transmembrane helices in protein sequences. Proceeding of the ISMB 6: 175-182 
Svistoonoff S, Benabdoun FM, Nambiar-Veetil M, Imanishi L, Vaissayre V, Cesari S, et al (2013) The Independent Acquisition of Plant Root Nitrogen-Fixing Symbiosis in Fabids Recruited the Same Genetic Pathway for Nodule Organogenesis. PLoS ONE 8(5): 64515

Tainer JA, Getzoff ED, Beem KM, Richardson JS, Richardson DC (1983) Structure and mechanism of copper, zinc superoxide dismutase. Nature 306:284-290

Tamura K, Peterson D, Peterson N, Stecher G, Nei M, Kumar S (2011) MEGA5: molecular evolutionary genetics analysis using maximum likelihood, evolutionary distance, and maximum parsimony methods. Molecular Biology Evolution 28:2731-2739

Tamura K, Battistuzzi FU, Billing-Ross P, Murillo O, Filipski A, Kumar S (2012) Estimating divergence times in large molecular phylogenies. Proceedings of the National Academy of Science United States of America 109: 19333-19338

van den Berghe PVE, Folmer DE, Malingré HE, van Beurden E, Klomp AEM, van de Sluis B, Merkx M, Berger R, Klomp LWJ (2007) Human copper transporter 2 is localized in late endosomes and lysosomes and facilitates cellular copper uptake. Journal of Biochemistry 407: 4959

van Heeswijk WC, Westerhoff HV, Boogerd FC (2013) Nitrogen assimilation in Escherichia coli: putting molecular data into a systems perspective. Microbiology and Molecular Biology Review 77: 628-695

Vinardell JM, Fedorova E, Cebolla A, Kevei Z, Horvath G, Kelemen Z, Tarayre S, Roudier F, Mergaert P, Kondorosi A, et al (2003) Endoreduplication mediated by the anaphasepromoting complex activator CCS52A is required for symbiotic cell differentiation in Medicago truncatula nodules. Plant Cell 15: 2093-2105

Waters BM, Chu HH, Didonato RJ, Roberts LA, Eisley RB, Lahner B, Salt DE, Walker EL (2006) Mutations in Arabidopsis yellow stripe-like1 and yellow stripe-like3 reveal their roles in metal ion homeostasis and loading of metal ions in seeds. Plant Physiology 141, 1446-1458

Wintz H, Fox T, Wu YY, Feng V, Chen W, Chang HS, Zhu T, Vulpe C (2003) Expression profiles of Arabidopsis thaliana in mineral deficiencies reveal novel transporters involved in metal homeostasis. Journal of Biological Chemistry 278: 47644-47653

Young ND, Debellé F, Oldroyd GED, Geurts R, Cannon SB, Udvardi MK, Benedito VA, Mayer KFX, Gouzy J, Schoof H (2011) The Medicago genome provides insight into the evolution of rhizobial symbioses. Nature 480: 520-524

Yuan M, Li X, Xiao J, Wang S (2011) Molecular and functional analyses of COPT/Ctr-type copper transporter-like gene family in rice. BMC Plant Biology 11: 69

Yuan M, Chu Z, Li X, Xu C, Wang S (2010) The bacterial pathogen Xanthomonas oryzae overcomes rice defenses by regulating host copper redistribution. Plant Cell 22: 3164-3176 
Zhou C, Han L, Pislariu C, Nakashima J, Fu C, Jiang Q, et al (2011) From Model to Crop: Functional Analysis of a STAY-GREEN Gene in the Model Legume Medicago truncatula and Effective Use of the Gene for Alfalfa Improvement. Plant Physiology 157: 1483-1496

Zhou Q, Liu Z, Liu Y, Jiang J, Xu R (2016) Relative abundance of chemical forms of Cu(II) and $\mathrm{Cd}(\mathrm{II})$ on soybean roots as influenced by $\mathrm{pH}$, cations and organic acids. Scientific Reports 6: 36373 


\section{APPENDIX}

Supplemental Table S1. First-order correlations $(0.9 \geq \rho \geq 1.0)$ of gene network centered on MtCOPT1. shown in Figure 10. Raw RNA-Seq data (SRA files) from mature organs of the plant (Young et al., 2011) and zones of the mature nodule (Roux et al., 2014) were reanalyzed and normalized to transcripts per million (TPM).

\begin{tabular}{|c|c|c|c|c|c|c|c|c|c|c|c|c|c|c|}
\hline ญ̆ & 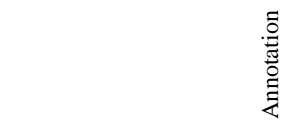 & 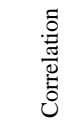 & $\begin{array}{l}\frac{g}{\partial} \\
\frac{1}{\pi} \\
\frac{1}{2}\end{array}$ & $\frac{\frac{\pi}{\pi}}{n}$ & $\stackrel{\mathscr{m}}{\mathscr{m}}$ & $\stackrel{\widetilde{m}}{\mathscr{n}}$ & 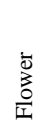 & $\vec{\circ}$ & $\begin{array}{l}\frac{o}{z} \\
\text { z }\end{array}$ & 宝 & 茎 & 气 & $\underline{N}$ & 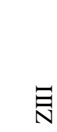 \\
\hline Medtr4g019870.1 & $\begin{array}{c}\text { Ctr family copper } \\
\text { transporter }\end{array}$ & 1 & 0 & 0 & 0 & 0 & 0 & 1 & 201 & 0 & 0 & 46 & 112 & 61 \\
\hline Medtr1g071880.1 & $\begin{array}{l}\text { Nodule Cysteine-Rich } \\
\text { (NCR) secreted peptide }\end{array}$ & 0.94 & 0 & 0 & 0 & 0 & 0 & 0 & 171 & 0 & 0 & 16 & 41 & 31 \\
\hline Medtr5g084260.1 & $\begin{array}{c}\text { Nodule-specific Glycine } \\
\text { Rich Peptide }\end{array}$ & 0.94 & 0 & 0 & 1 & 0 & 0 & 9 & 1983 & 0 & 0 & 46 & 370 & 104 \\
\hline Medtr1g079730.1 & carboxyl-terminal peptidase & 0.93 & 0 & 0 & 2 & 3 & 1 & 1 & 19 & 0 & 0 & 1 & 1 & 2 \\
\hline Medtr1g090820.3 & leghemoglobin Lb120-1 & 0.93 & 0 & 0 & 0 & 0 & 0 & 34 & 3359 & 1 & 8 & 198 & 1003 & 377 \\
\hline Medtr3g015870.1 & $\begin{array}{l}\text { Nodule Cysteine-Rich } \\
\text { (NCR) secreted peptide }\end{array}$ & 0.93 & 0 & 0 & 0 & 0 & 0 & 1 & 577 & 0 & 1 & 70 & 186 & 285 \\
\hline Medtr4g013270.1 & $\begin{array}{l}\text { CASP ARALYDRAFT- } \\
\text { like protein }\end{array}$ & 0.93 & 0 & 0 & 0 & 0 & 0 & 0 & 205 & 0 & 3 & 8 & 19 & 13 \\
\hline Medtr6g006220.1 & $\begin{array}{l}\text { Nodule Cysteine-Rich } \\
\text { (NCR) secreted peptide } \\
\end{array}$ & 0.93 & 0 & 0 & 0 & 0 & 0 & 0 & 67 & 0 & 0 & 13 & 38 & 19 \\
\hline Medtr6g445080.1 & $\begin{array}{l}\text { Nodule Cysteine-Rich } \\
\text { (NCR) secreted peptide }\end{array}$ & 0.93 & 0 & 0 & 0 & 0 & 0 & 12 & 8000 & 1 & 2 & 137 & 623 & 501 \\
\hline Medtr6g090485.1 & $\begin{array}{l}\text { Nodule Cysteine-Rich } \\
\text { (NCR) secreted peptide }\end{array}$ & 0.93 & 0 & 0 & 0 & 0 & 0 & 0 & 316 & 0 & 0 & 116 & 250 & 130 \\
\hline Medtr7g031915.1 & $\begin{array}{l}\text { Nodule Cysteine-Rich } \\
\text { (NCR) secreted peptide }\end{array}$ & 0.93 & 0 & 0 & 0 & 0 & 0 & 0 & 295 & 0 & 0 & 33 & 97 & 65 \\
\hline Medtr7g055763.1 & $\begin{array}{l}\text { Nodule Cysteine-Rich } \\
\text { (NCR) secreted peptide }\end{array}$ & 0.93 & 0 & 0 & 0 & 0 & 0 & 0 & 56 & 0 & 0 & 20 & 73 & 28 \\
\hline Medtr7g057560.1 & $\begin{array}{l}\text { Nodule Cysteine-Rich } \\
\text { (NCR) secreted peptide }\end{array}$ & 0.93 & 0 & 0 & 0 & 0 & 0 & 0 & 56 & 0 & 0 & 20 & 73 & 28 \\
\hline Medtr1g088150.1 & $\begin{array}{c}\text { transmembrane protein, } \\
\text { putative }\end{array}$ & 0.92 & 0 & 0 & 0 & 0 & 0 & 0 & 17 & 0 & 0 & 1 & 3 & 3 \\
\hline Medtr2g073170.1 & $\begin{array}{l}\text { Nodule Cysteine-Rich } \\
\text { (NCR) secreted peptide }\end{array}$ & 0.92 & 0 & 0 & 0 & 0 & 0 & 0 & 541 & 0 & 1 & 280 & 809 & 645 \\
\hline Medtr2g103303.1 & embryo-specific protein & 0.92 & 0 & 0 & 0 & 0 & 0 & 1 & 632 & 1 & 11 & 13 & 21 & 24 \\
\hline Medtr4g108170.1 & $\begin{array}{l}\text { ABC transporter A family } \\
\text { protein } \\
\end{array}$ & 0.92 & 0 & 0 & 0 & 1 & 0 & 0 & 21 & 0 & 0 & 1 & 1 & 1 \\
\hline Medtr7g071690.1 & $\begin{array}{l}\text { Nodule Cysteine-Rich } \\
\text { (NCR) secreted peptide }\end{array}$ & 0.92 & 0 & 0 & 0 & 0 & 0 & 4 & 714 & 0 & 1 & 286 & 848 & 98 \\
\hline Medtr8g074890.1 & $\begin{array}{l}\text { prolyl 4-hydroxylase alpha- } \\
\text { like protein } \\
\end{array}$ & 0.92 & 0 & 0 & 0 & 0 & 0 & 0 & 17 & 0 & 0 & 2 & 4 & 2 \\
\hline Medtr1g042940.1 & $\begin{array}{l}\text { Nodule Cysteine-Rich } \\
\text { (NCR) secreted peptide }\end{array}$ & 0.91 & 0 & 0 & 0 & 0 & 0 & 3 & 1058 & 2 & 10 & 804 & 1439 & 1231 \\
\hline Medtr2g016230.1 & RmlC-type cupin & 0.91 & 0 & 1 & 5 & 2 & 4 & 2 & 40 & 0 & 0 & 3 & 6 & 5 \\
\hline Medtr3g055440.5 & nodulin- 25 protein & 0.91 & 0 & 0 & 0 & 0 & 0 & 0 & 0 & 0 & 0 & 0 & 0 & 0 \\
\hline Medtr4g007090.1 & $\begin{array}{l}\text { phospholipid N- } \\
\text { methyltransferase }\end{array}$ & 0.91 & 0 & 0 & 0 & 0 & 0 & 1 & 53 & 1 & 6 & 8 & 12 & 11 \\
\hline
\end{tabular}




\begin{tabular}{|c|c|c|c|c|c|c|c|c|c|c|c|c|c|c|}
\hline Medtr4g103495.1 & $\begin{array}{c}\text { subtilisin-like serine } \\
\text { protease }\end{array}$ & 0.91 & 0 & 0 & 0 & 0 & 0 & 0 & 1 & 0 & 0 & 0 & 0 & 0 \\
\hline Medtr5g008040.1 & $\begin{array}{l}12 \text {-oxophytodienoate } \\
\text { reductase-like protein }\end{array}$ & 0.91 & 0 & 0 & 0 & 0 & 0 & 0 & 54 & 0 & 0 & 7 & 10 & 1 \\
\hline Medtr5g022390.1 & $\begin{array}{c}\text { rhodanese-related } \\
\text { sulfurtransferase }\end{array}$ & 0.91 & 0 & 0 & 0 & 0 & 1 & 136 & 401 & 0 & 0 & 24 & 66 & 39 \\
\hline Medtr6g452900.1 & $\begin{array}{l}\text { Nodule Cysteine-Rich } \\
\text { (NCR) secreted peptide }\end{array}$ & 0.91 & 0 & 0 & 0 & 0 & 0 & 0 & 229 & 0 & 1 & 152 & 445 & 262 \\
\hline Medtr7g008130.1 & $\begin{array}{l}\text { Nodule Cysteine-Rich } \\
\text { (NCR) secreted peptide }\end{array}$ & 0.91 & 0 & 0 & 0 & 0 & 0 & 0 & 40 & 0 & 0 & 10 & 25 & 20 \\
\hline Medtr7g028550.1 & $\begin{array}{l}\text { Nodule Cysteine-Rich } \\
\text { (NCR) secreted peptide }\end{array}$ & 0.91 & 0 & 0 & 0 & 0 & 0 & 0 & 40 & 0 & 0 & 15 & 27 & 17 \\
\hline Medtr7g056460.1 & $\begin{array}{l}\text { leguminosin group567 } \\
\text { LEED...PEED secreted } \\
\text { peptide }\end{array}$ & 0.91 & 0 & 0 & 0 & 0 & 0 & 0 & 10 & 0 & 0 & 3 & 9 & 7 \\
\hline Medtr7g058880.1 & late nodulin & 0.91 & 0 & 0 & 0 & 0 & 0 & 0 & 304 & 1 & 12 & 29 & 82 & 66 \\
\hline Medtr1g008280.2 & $\begin{array}{l}\text { signal peptide peptidase- } \\
\text { like protein }\end{array}$ & 0.9 & 0 & 10 & 21 & 26 & 11 & 29 & 127 & 1 & 4 & 14 & 21 & 9 \\
\hline Medtr1g064350.1 & GRF zinc finger protein & 0.9 & 0 & 0 & 0 & 0 & 0 & 0 & 219 & 0 & 3 & 15 & 66 & 26 \\
\hline Medtr1g116930.1 & peptide/nitrate transporter & 0.9 & 0 & 0 & 0 & 0 & 0 & 0 & 30 & 0 & 1 & 1 & 2 & 3 \\
\hline Medtr2g032710.1 & $\begin{array}{l}\text { polygalacturonase plant- } \\
\text { like protein }\end{array}$ & 0.9 & 0 & 3 & 6 & 6 & 5 & 1 & 13 & 0 & 0 & 1 & 1 & 0 \\
\hline Medtr2g103307.1 & embryo-specific protein & 0.9 & 0 & 0 & 0 & 0 & 0 & 0 & 547 & 0 & 0 & 9 & 19 & 14 \\
\hline Medtr3g012380.1 & $\begin{array}{c}\text { Nodule Cysteine-Rich } \\
\text { (NCR) secreted peptide }\end{array}$ & 0.9 & 0 & 0 & 0 & 0 & 0 & 20 & 1529 & 0 & 2 & 340 & 1038 & 652 \\
\hline Medtr3g068070.1 & $\begin{array}{l}\text { NAD(P)-binding rossmann- } \\
\text { fold protein }\end{array}$ & 0.9 & 0 & 0 & 0 & 0 & 0 & 0 & 26 & 0 & 0 & 3 & 5 & 1 \\
\hline Medtr3g084820.1 & $\begin{array}{l}\text { Nodule Cysteine-Rich } \\
\text { (NCR) secreted peptide }\end{array}$ & 0.9 & 0 & 1 & 0 & 0 & 0 & 19 & 3461 & 0 & 1 & 273 & 1026 & 566 \\
\hline Medtr4g057600.1 & $\begin{array}{l}\text { serine carboxypeptidase- } \\
\text { like protein }\end{array}$ & 0.9 & 0 & 0 & 0 & 0 & 0 & 0 & 16 & 0 & 1 & 1 & 2 & 2 \\
\hline Medtr4g063735.1 & $\begin{array}{l}\text { wuschel-related homeobox } \\
\text { protein } \\
\end{array}$ & 0.9 & 0 & 0 & 0 & 0 & 0 & 0 & 23 & 0 & 0 & 2 & 8 & 5 \\
\hline Medtr4g079830.1 & agenet domain protein & 0.9 & 0 & 0 & 0 & 0 & 0 & 2 & 35 & 0 & 0 & 5 & 17 & 8 \\
\hline Medtr5g063600.1 & $\begin{array}{l}\text { Nodule Cysteine-Rich } \\
\text { (NCR) secreted peptide }\end{array}$ & 0.9 & 0 & 0 & 0 & 0 & 0 & 2 & 560 & 0 & 1 & 103 & 216 & 114 \\
\hline Medtr5g080440.1 & leghemoglobin Lb120-1 & 0.9 & 0 & 0 & 0 & 0 & 0 & 3 & 3209 & 0 & 4 & 309 & 1105 & 364 \\
\hline Medtr5g081030.1 & leghemoglobin Lb120-1 & 0.9 & 0 & 1 & 1 & 0 & 0 & 16 & 9753 & 2 & 34 & 245 & 1113 & 471 \\
\hline Medtr6g464450.1 & $\begin{array}{l}\text { Nodule Cysteine-Rich } \\
\text { (NCR) secreted peptide }\end{array}$ & 0.9 & 0 & 0 & 0 & 0 & 0 & 0 & 272 & 0 & 0 & 45 & 114 & 69 \\
\hline Medtr6g066040.1 & plant/F12B17-70 protein & 0.9 & 0 & 0 & 0 & 0 & 0 & 0 & 26 & 0 & 0 & 7 & 12 & 2 \\
\hline Medtr7g071720.2 & $\begin{array}{l}\text { Nodule Cysteine-Rich } \\
\text { (NCR) secreted peptide }\end{array}$ & 0.9 & 0 & 0 & 0 & 0 & 0 & 0 & 280 & 0 & 0 & 59 & 159 & 86 \\
\hline Medtr7g082810.1 & $\begin{array}{l}\text { MATE efflux family } \\
\text { protein } \\
\end{array}$ & 0.9 & 0 & 0 & 0 & 0 & 0 & 1 & 38 & 0 & 0 & 2 & 4 & 8 \\
\hline Medtr8g087720.1 & $\begin{array}{l}\text { major intrinsic protein } \\
\text { (MIP) family transporter }\end{array}$ & 0.9 & 0 & 0 & 3 & 3 & 0 & 5 & 137 & 0 & 4 & 7 & 8 & 15 \\
\hline Medtr8g103233.1 & $\begin{array}{l}\text { peptide/nitrate transporter } \\
\text { plant }\end{array}$ & 0.9 & 0 & 0 & 1 & 1 & 0 & 3 & 27 & 1 & 5 & 2 & 3 & 4 \\
\hline
\end{tabular}




\title{
Chapter 6
}

\section{Introducing additional nodule specific membrane transporters as potential essential participants in symbiotic nitrogen fixation in Medicago truncatula}

\begin{abstract}
Successful symbiotic nitrogen fixation relies heavily on the movement of essential substrates to allow reactions to occur within the infected cells of nodules. Membrane transporters play a key role in moving molecules between symbionts to assist in protection during high energy production within the cell and to provide essential cofactors to enable enzyme activity. Two potential membrane transporter families were investigated. The Oligopeptide Transporter (OPT) family is classified in the Transporter Classification Database as 2.A.67. Members of the family have been shown to transport peptides from 3-8 amino acids in length and are capable of transporting glutathione. Family members typically have 12-15 transmembrane domains (TMDs) and are 600-900 amino acids in length. Medicago truncatula has 11 OPT family members identified in the genome. One, Medtr7g092230.1 (MtOPT1) is expressed exclusively in the nodule. Expression begins early in the developing nodule and can be seen at 4 days post inoculation with expression seen in all zones except the meristem, indicating importance throughout the developing nodule process. Rhizobial mutant analysis revealed only infection by rhizobia is essential for gene expression and not bacterial differentiation or nitrogen fixation. The Vacuolar Iron Transporter (VIT) family belongs to the Transporter Classification Database 2.A.89 family. Family members have been identified in plants and yeast. Members of the vacuolar iron transporter family have been shown to transport $\mathrm{Fe}^{2+}$ and $\mathrm{Mn}^{2+}$. The Medicago truncatula genome codes for six VIT transporters. One of those members, Medtr4g094335.1, herein called MtSEN1, is highly and exclusively expressed in the nodule. RT-qPCR analysis with mutant rhizobia found MtSEN1 requires rhizobial infection for expression and upregulated expression is seen in nodules 3 days post inoculation, where most likely, in preparation for nitrogen fixation, iron is being transported for use as a cofactor in nitrogenase and leghemoglobin. Iron, glutathione, and homoglutathione are found in nodules and transporters belonging to families known for transport of those molecules
\end{abstract}


are probable transporters. Therefore, nodule specific expression of these two putative membrane transporters could potentially play an essential role in supporting symbiotic nitrogen fixation.

\section{INTRODUCTION}

\section{The Oligopeptide transporter (OPT) and Vacuolar Iron transporter (VIT) families}

In plants, glutathione (GSH, $\gamma$-L-glutamyl-L-cysteinylglycine) is the primary form of mobilized organic sulfur (Lubkowitz, 2011). As a scavenger of reactive oxygen species (ROS), glutathione and homoglutathione are thought to provide defense against stresses especially during the high consumption of ATP during cell differentiation and nitrogen fixation, when electrons can be lost and damage the cell (Pasternak et al., 2014). Additionally, glutathione is the most abundant non-protein thiol in almost all prokaryotic and eukaryotic cells (Bourbouloux et al., 2000). AtOPT6 from Arabidopsis thaliana was found to transport glutathione derivatives (Cagnac et al., 2004) and Opt1p from the fungus Candida albicans is a high-affinity glutathione transporter (Koh et al., 2002).

The OPT family of transporters (TCDB 2.A.67) is also known to have affinity to peptides of three to five residues in prokaryotes, yeast, and plants, potentially useful to help protect from ROS, created during the energy intensive process of symbiotic nitrogen fixation (Becana et al., 2010). (Homo)glutathione transported to infected cells of nodules could protect against damage. (Homo)glutathione, unique to the Leguminosae family, is composed of three amino acid residues and has been recognized as an important modulator of the efficiency of the nitrogen fixation process in legumes (Macnicol, 1987; El Msehli et al., 2011; Colville et al., 2015). OPT transporters are found exclusively in prokaryotes, plants, and fungi. The OPT family is divided into two distant clades, the OligoPeptide Transporters and the Yellow Stripe-Like proteins with affinity for secondary amino acids bound to metals (Lubkowitz, 2011). Given the number of organisms for whom genomes have already been sequenced, it is unlikely OPT genes will be found in eukaryotes other than the aforementioned domains of life (Lubkowitz, 2006). This well characterized family includes members that transport oligopeptides of 3-8 amino acid residues in length (Gomolplitinant and Saier Jr., 2011). Among the 9 OPT genes in Arabidopsis thaliana, OPT1, 4, 5, 6, and 7 were demonstrated to transport the pentapeptide KLLLG, while OPT4 also transports 
the tetrapeptides KLGL and KLLG (Koh et el., 2002). The OPT family is one of three families responsible for peptide transport in plants. The other two are the Peptide Transporter (PTR) and the ATP-Binding Cassette (ABC) transporter superfamilies (Stacey et al., 2002). Some OPT members have also been shown to transport metal ions. Thlaspi caerulescens OPT3 transports $\mathrm{Fe}^{2+}, \mathrm{Zn}^{2+}, \mathrm{Cd}^{2+}$ and $\mathrm{Cu}^{2+}$ (Hu et al., 2012).

In Arabidopsis thaliana, VIT1 has been shown to transport $\mathrm{Fe}^{2+}$ into the vacuole of seeds (Kim et al., 2006; Roschzttardtz et al., 2009). In Lotus japonicas, the VIT1 homolog SEN1 is required for symbiotic nitrogen fixation and bacteroid differentiation, but its subcellular localization was not determined (Hakoyama et al., 2012). The Saccharomyces cerevisiae homolog CCC1 is a transporter of iron and manganese and localizes to the tonoplast and golgi (Lapinskas et al., 1996). Wheat vacuolar transporter TaVIT2 has also been shown to transport iron and manganese and localizes to the vacuolar membrane (Connorton et al., 2017). The VIT family of transporters (TCDB 2.A.89) have been shown to transport $\mathrm{Fe}^{2+}$ in plants.

Iron is an essential micronutrient for humans and more than a billion people suffer from anemia due to iron deficiency (WHO, 2008). Pulses and seeds are great sources of iron, and biofortification can be accomplished through transgenic crops or traditional breeding practices. Iron is the fourth most abundant element in the earth's crust, but it is the third most limiting nutrient of plant growth with over a third of the world's soils considered to be iron deficient (Grotz and Guerinot, 2006). Iron demand is increased during symbiotic nitrogen fixation as it is required in the synthesis of iron containing proteins, including leghemoglobin in the plant and nitrogenase and cytochromes of the electron transport chain within bacteroids (Seefeldt, 1994; Seefeldt et al., 2009).

\section{RESULTS AND DISCUSSION}

The transporter prediction program TransportTP was utilized to determine the number of family members in the OPT family ( $\mathrm{Li}$ et al., 2009). In the Medicago genome, there are 11 identified OPT genes. Expression of Medicago OPT family members were analyzed to determine organ expression. The Medicago truncatula MtOPT1, Medtr7g092230.1, was found to have high nodule specific expression (Figure 6.1C), unlike its two closely related genes on chromosome 7. Medtr7g092240.1 shows expression in the flower and Medtr7g093350.1 shows expression in the 
nodule but at lower levels than MtOPT1 (Figure 6.1C). The three closely related genes have varying gene architecture (Figure 6.1B). MtOPT1 has 4 predicted exons and three predicted introns and lacks predicted UTRs (Figure 6.1D).

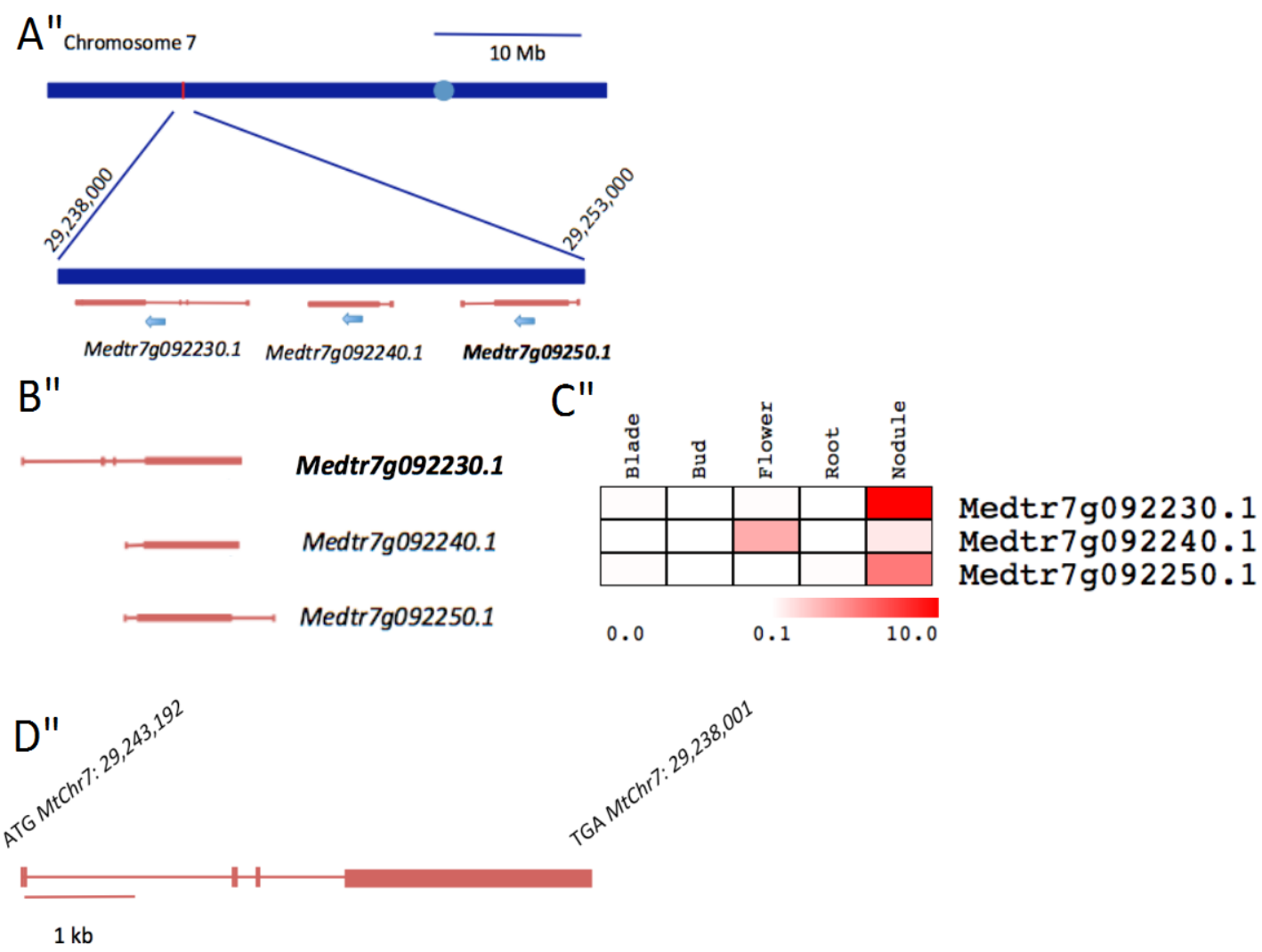

Figure 6.1. MtOPT1 and closely related genes' chromosomal location, gene architecture, and organ expression. (A) Map of chromosome 7 with expanded view of adjoining OPT genes, followed by predicted gene architecture of OPT. (B) Gene architecture of adjoining Medicago genes. All three have one large exon and are in the same orientation. (C) RNA-Seq heatmap of mature organs of same three genes (Young et al., 2011) using MultiExperiment Viewer (MeV.tm4.org; Howe et al., 2011). (D) MtOPT1 (Medtr7g092230.1) has four predicted exons (red boxes) and three introns (red lines). The chromosome 7 coordinates for start and stop codons are shown. Remarkably, the MtOPT1 gene model has no predicted UTRs.

Medicago truncatula MtOPT1 is closely related to AtOPT9 from Arabidopsis, which has not been fully characterized. Also related are the Candida albicans Opt1p, as well as Schizosaccharomyces pombe Pgt1, which are both glutathione transporters (Thakur et al., 2008). A homolog of Medtr7g092230.1 in Saccharomyces cerevisiae was characterized as a peptide 
uptake system (Hauser et al., 2000). Notice the clustering of YSL, or yellow stripe 1, proteins on a separate clade (Figure 6.2).

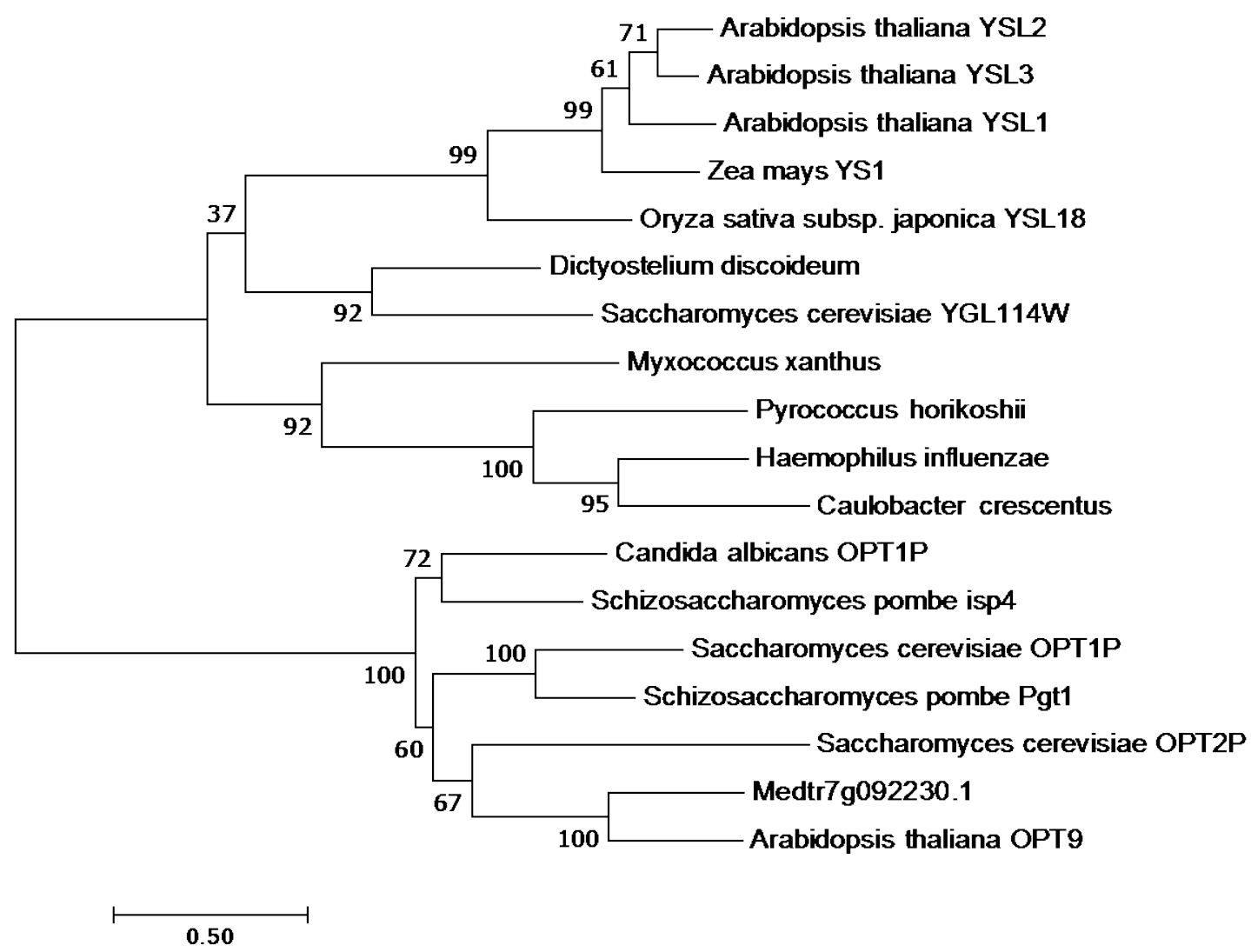

Figure 6.2. Molecular Phylogenetic analysis by Maximum Likelihood method of Medtr7g092230.1 and all eukaryotic OPT homologs of the Transporter Classification Database (www.TCDB.org; Kumar et al., 2016).

The most closely related proteins to MtOPT1 (Medtr7g092230.1) in the Medicago genome are Medtr7g092240.1 and Medtr7g092250.1 (Figure 6.3). Medtr7g092230.1 and Medtr7g092240.1 share 91\% identity at the protein level. However, Medtr7g092240.1 shows high expression in flowers and a basal constitutive activity, including in roots and nodules, while the other closely related protein, Medtr7g092250.1, shows high expression in nodules and basal expression elsewhere in the plant. It is tempting to suggest that this positional situation was created by asymmetrical recombinations at some point in the evolution of legumes and that one of the duplicates evolved through neofunctionalization towards nodule development and the nitrogen symbiosis. 
However, Figure 6.3 shows that the branch that holds MtOPT1 encompasses 6 legume transporters (including the three closely related proteins aforementioned) and neighbors an Arabidopsis branch holding two Arabidopsis orthologs, AtOPT1 and AtOPT5. AtOPT1 is highly expressed in flower with less expression in leaf and stem, while AtOPT5 is expressed primarily in flowers (Koh et al., 2002). AtOPT9 is expressed in pollen and microspores (Bock et al., 2006). Medtr7g092230.1 also shows high expression in flowers with basal expression elsewhere.

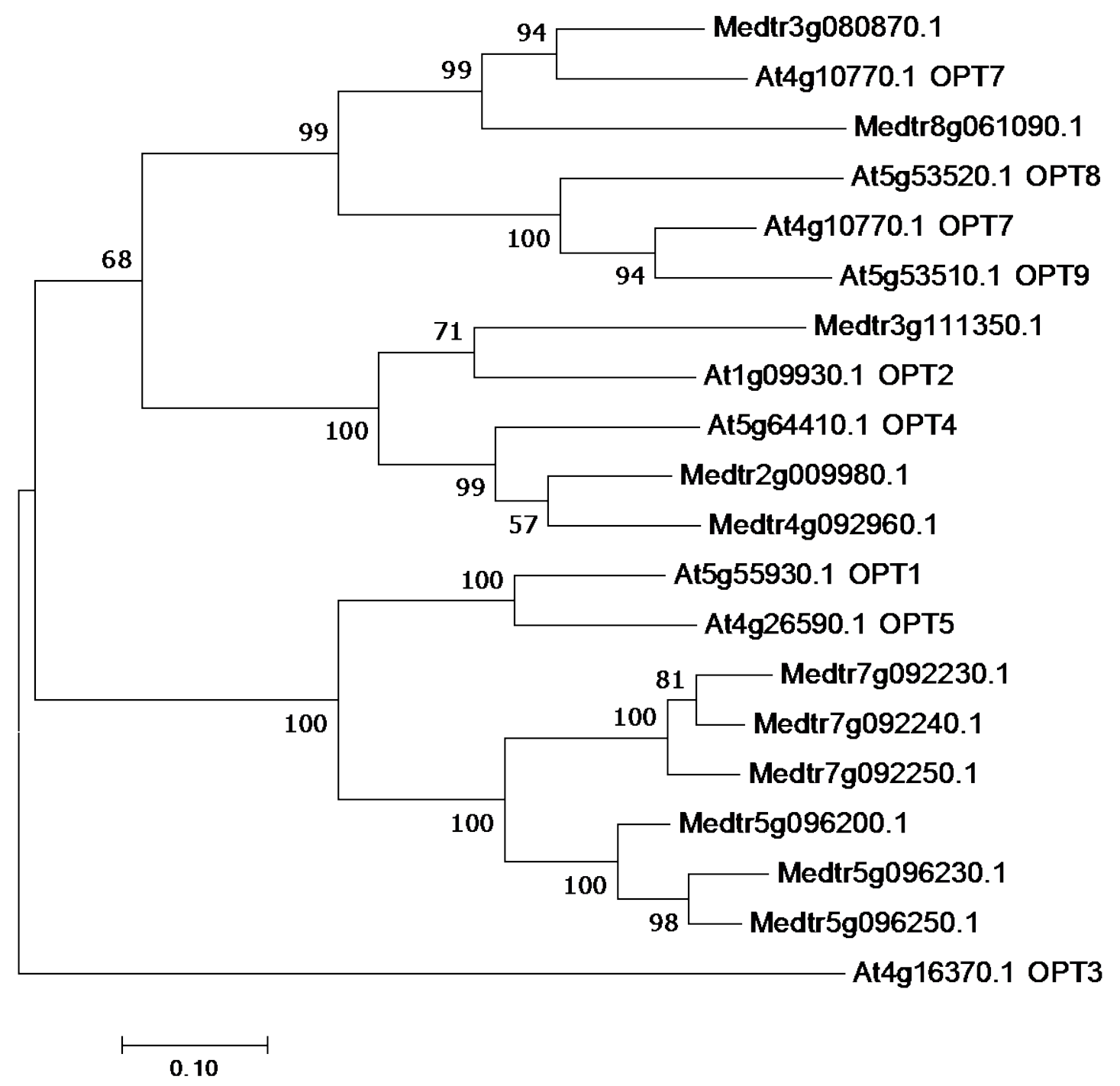

Figure 6.3. Molecular Phylogenetic analysis by Maximum Likelihood method of the complete OPT gene family in Medicago truncatula and Arabidopsis thaliana genomes constructed in MEGA7 (Felsenstein 1985; Kumar et al., 2015). Notice that the two closest Medicago homologs to Medtr7g092230.1 are localized next to it on the tree. 
A protein alignment of the three OPT clustered on chromosome 7 (Medtr7g092230.1, Medtr7g092240.1, and Medtr7g092250.1) was constructed to examine the thirteen transmembrane domains of the transporter (Figure 6.4). Two OPT domains highly conserved in the OPT family are present in all three members (Figure 6.4).

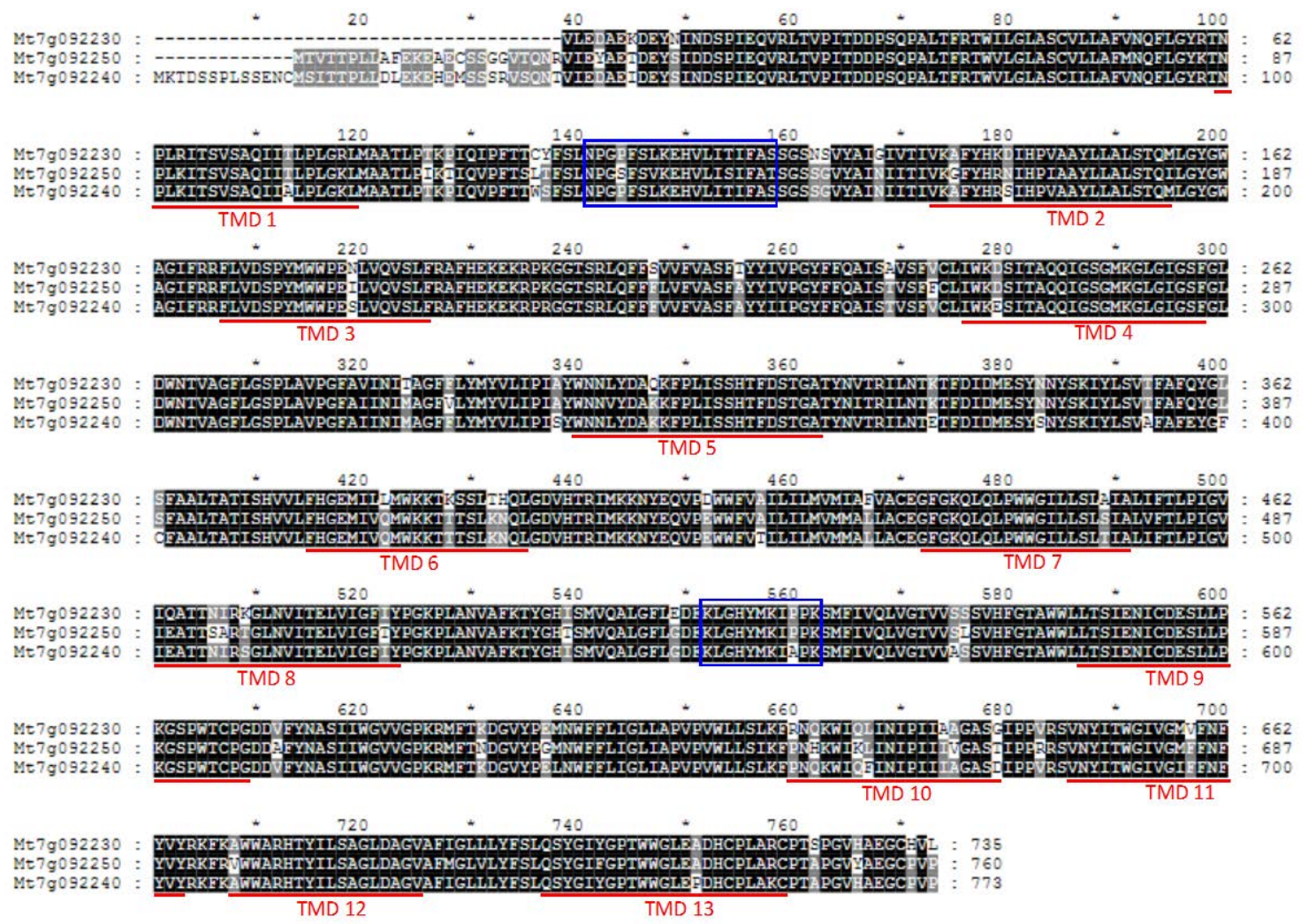

Figure 6.4. Protein alignment of Medtr7g092230.1, Medtr7g092240.1, and Medtr7g092250.1 with thirteen transmembrane domains shown below the sequences (red lines). Blue boxes show NPG and KIPPR motifs (Pfam domain: PF02669), respectively, which are conserved domains of the OPT family.

TMHMM software (http://www.cbs.dtu.dk/services/TMHMM/) revealed thirteen putative transmembrane domains for family member Medtr7g092240.1. Indeed, OPT family proteins typically have 12 to 15 transmembrane $\alpha$-helical spanners (TMS). MtOPT1 analysis reveals 13 predicted transmembrane domains with a C-terminus facing outside of the cell. Transmembrane domains were predicted using two prediction programs, both TMHMM and Protter predicted 13 transmembrane domains with intracellular $\mathrm{N}$-terminal domains and extracellular C-terminal domains (Sonnhammer et al., 1998; Krogh et al., 2001; Omasits et al., 2014) (Figure 6.5A and 6.5B). 
A

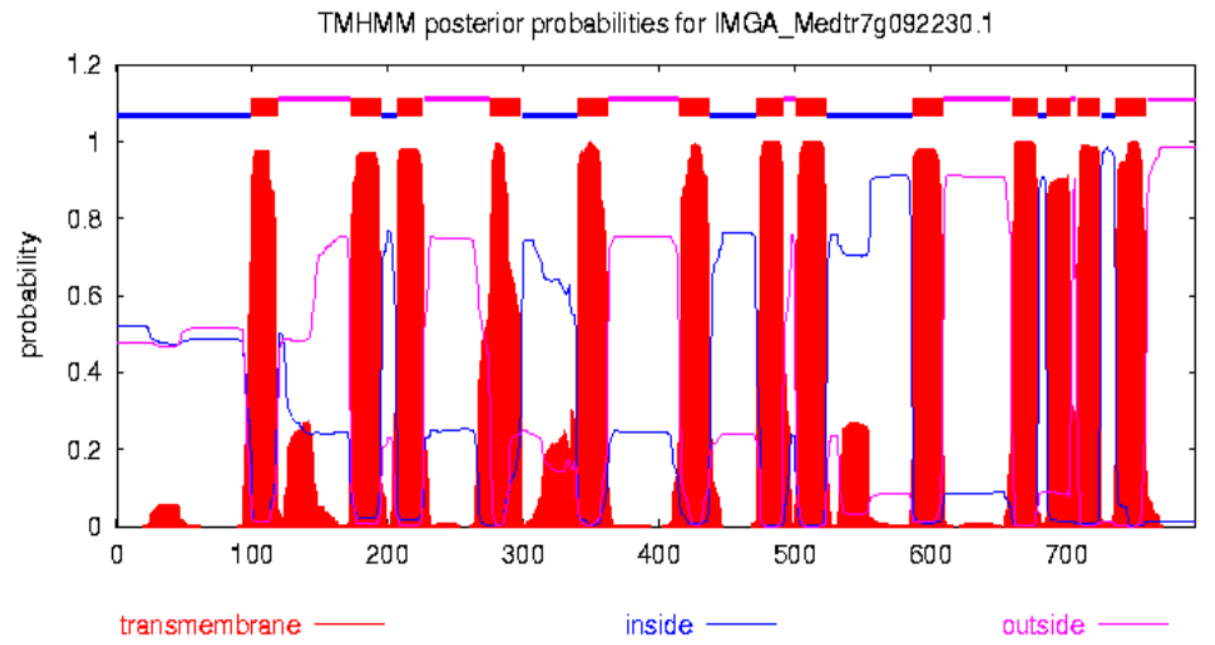

B

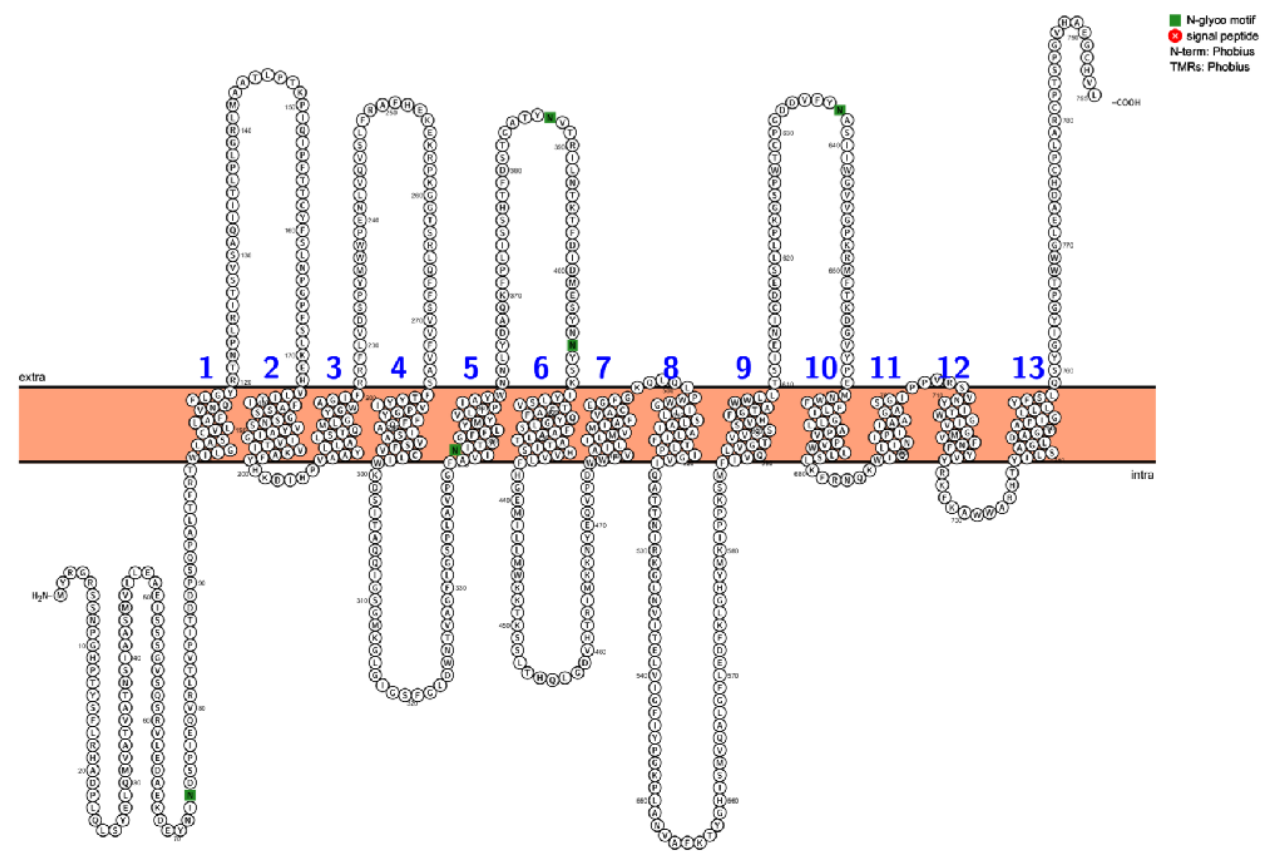

Figure 6.5. Membrane topology of MtOPT1 (Medtr7g092230.1). (A) Thirteen predicted transmembrane $\alpha$-helices were found using TMHMM v.2 (http://www.cbs.dtu.dk/services/TMHMM-2.0/; Sonnhammer et al., 1998; Krogh et al., 2001). (B) Thirteen TMDs was also predicted by Protter. Model was created using the Protter website to predict the protein's secondary structure within the membrane (http://wlab.ethz.ch/protter; Omasits et al., 2014).

\section{Real time analysis shows rhizobial infection is essential for MtOPT1 expression}

RT-qPCR analysis was conducted on Medicago truncatula ecotype 'R108' inoculated with Sm1021 rhizobia and rhizobial mutants that do not proceed past certain developmental stages. exoA 
rhizobia cannot infect plants, bacA rhizobia are unable to differentiate, and fixJ rhizobia are unable to fix nitrogen (Mitra and Long, 2004; Griffitts and Long, 2008). MtOPT1 requires infection for expression, but does not require bacteroid differentiation or nitrogen fixation (Figure 6.6A). Over a time course with LacZ rhizobia, expression is not seen at 0 dpi or $3 \mathrm{dpi}$, but is seen from $14 \mathrm{dpi}$ through mature, nitrogen fixing nodules at $28 \mathrm{dpi}$ indicating expression is important only after the initial infection and invasion of rhizobia which would include bacteroid differentiation and nitrogen fixation (Figure 6.6B).
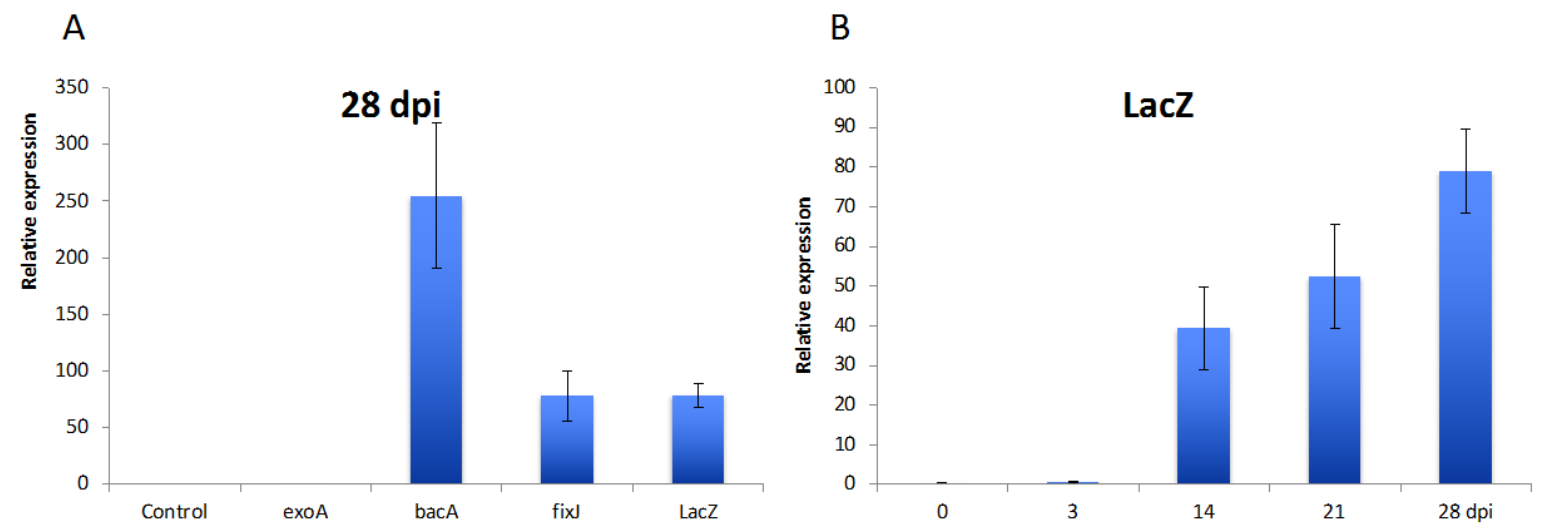

Figure 6.6. RT-qPCR analysis of MtOPT1 in root systems of Medicago truncatula ecotype 'R108' inoculated with Sm1021 rhizobia. (A) MtOPT1 expression at 28 dpi nodulating roots inoculated with rhizobial strains exoA, bacA, fixJ, or a functional strain containing LacZ. (B) Time-course of MtOPT1 expression in root systems inoculated with the functional rhizobial strain.

The MtOPT1 transporter may be involved in the transport of antioxidants essential to protect from Reactive Oxygen Species (ROS) during early development of nodules and infection and differentiation of bacteroids during symbiotic nitrogen fixation.

\section{Iron and the Vacuolar Iron Transporter Family}

The transporter prediction program TransportTP was utilized to determine the number of family members in the VIT family (Li et al., 2009). In the Medicago genome, there are 6 identified VIT genes. Expression of Medicago VIT family members were analyzed to determine organ expression. One of those members, Medtr4g094335.1, herein called MtSEN1, is highly and exclusively expressed in the nodule. MtSEN1 has a nodule specific expression fashion (Figure 
6.7A). MtSEN1 expression is high during early nodule development starting at 4 days post inoculation (Figure 6.7B). Expression occurs in all zones of the mature nodule, with higher expression in the distal part of the interzone, just below the nodule meristem, but it's expression remains high throughout nodule development, including in the nitrogen fixation zone (Figure 6.7C). Early expression in the meristematic zone of the nodule suggests involvement in symbiosome/bacteroid differentiation and nitrogen fixation.
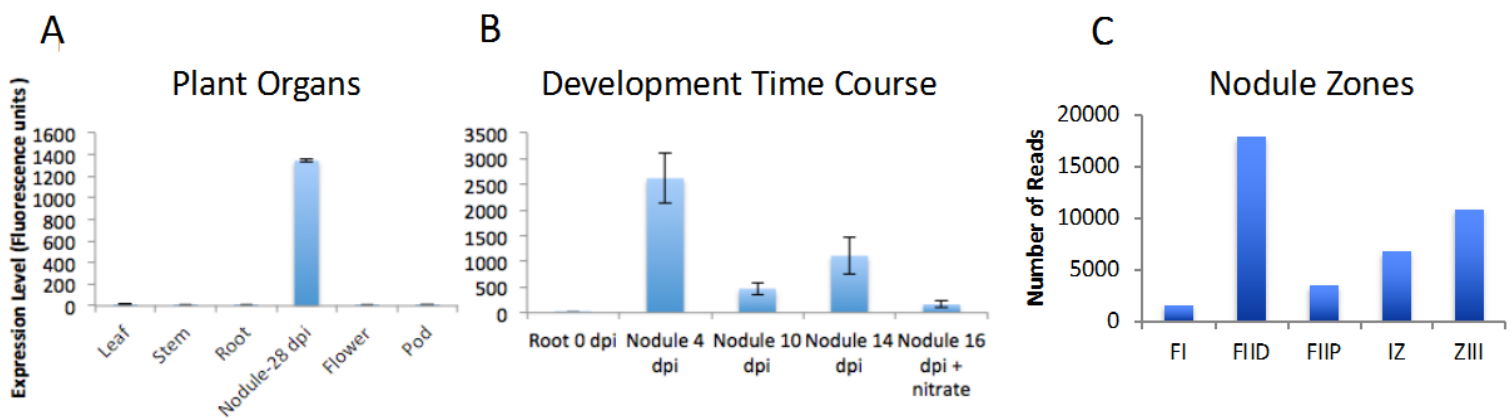

Figure 6.7. Expression profile of MtSEN1 gene. (A) Expression in mature plant organs, (B) during nodule development and (C) in zones of mature nodule. Data from the Medicago Gene Atlas (http://bioinfo.noble.org/gene-atlas; Benedito et al., 2008; He et al., 2009) and Roux et al. (2014).

MtSEN1 is on chromosome 4. The gene is predicted to have a single exon and no introns. Chromosomal coordinates of untranslated regions (UTRs) are shown in relation to start and stop codons (Figure 6.8).

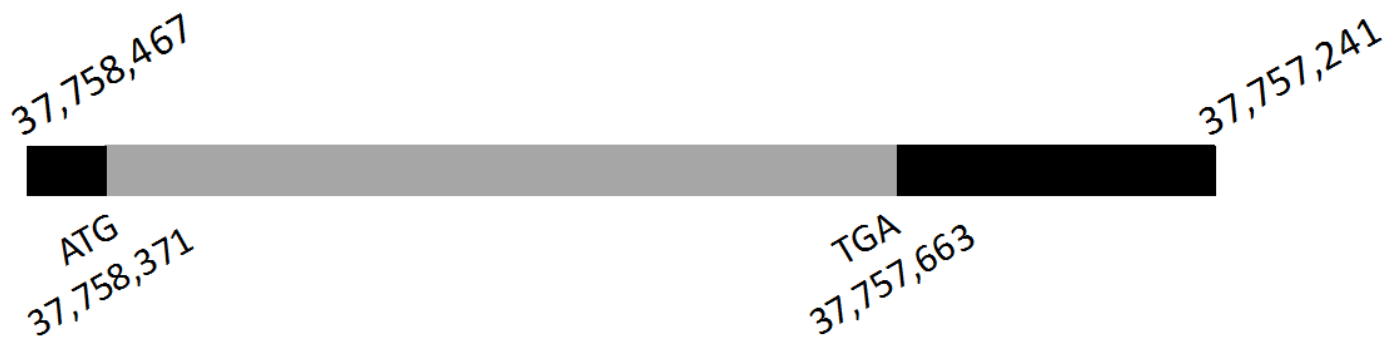

Figure 6.8. Gene structure of MtSEN1. The MtSEN1 gene has one exon shown in gray and no introns. 5' and 3' untranslated regions (UTRs) can be seen as black boxes. MtSEN1 is located on chromosome 4 of the Medicago genome.

The VIT family of transporters commonly have 5 TMDs as is seen in members from the fungus Ustilago maydis to Arabidopsis thaliana VIT1 (Kim et al., 2006). Although the TMHMM 
software predicts four TMDs, it can be seen in the prediction model that there is potentially a fifth transmembrane domain that did not quite reach the cutoff value to be counted as a transmembrane domain (Möller et al., 2001). However, the Protter program predicts that region as a fifth transmembrane domain (TMD) (Figure 6.9B) (Omasits et al., 2014). 


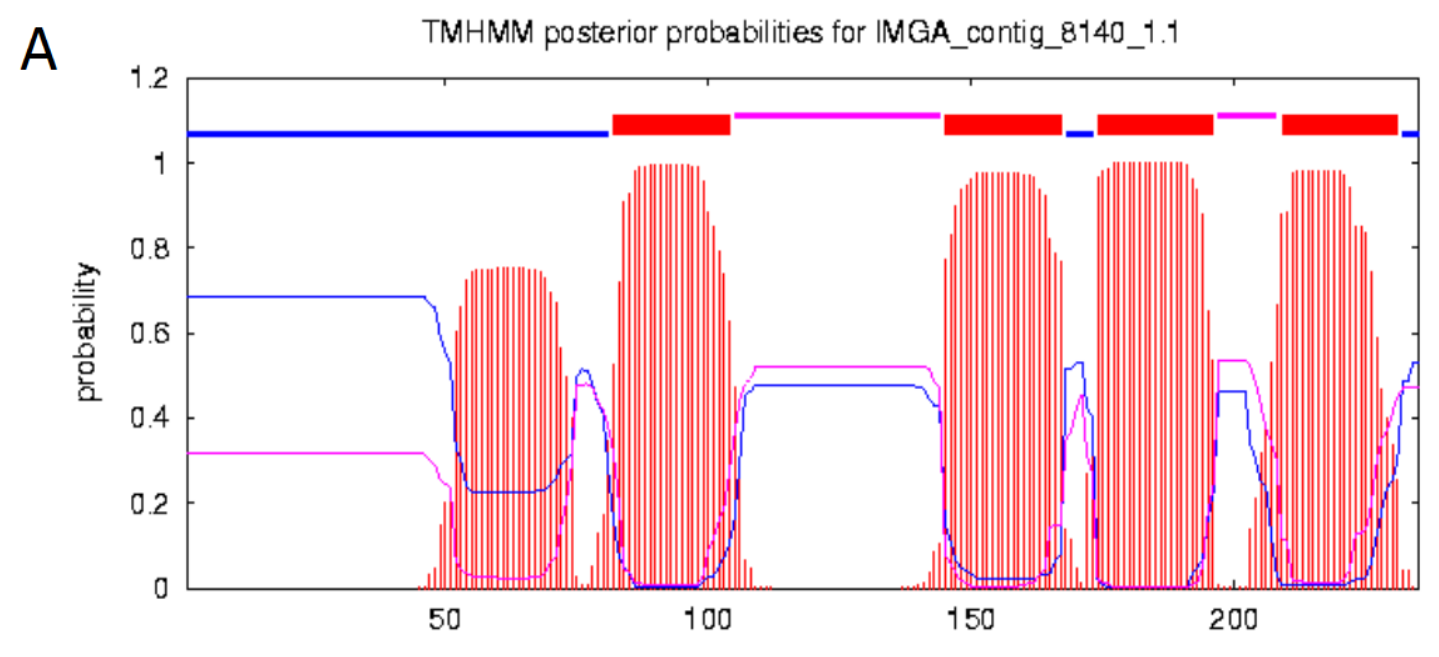

B

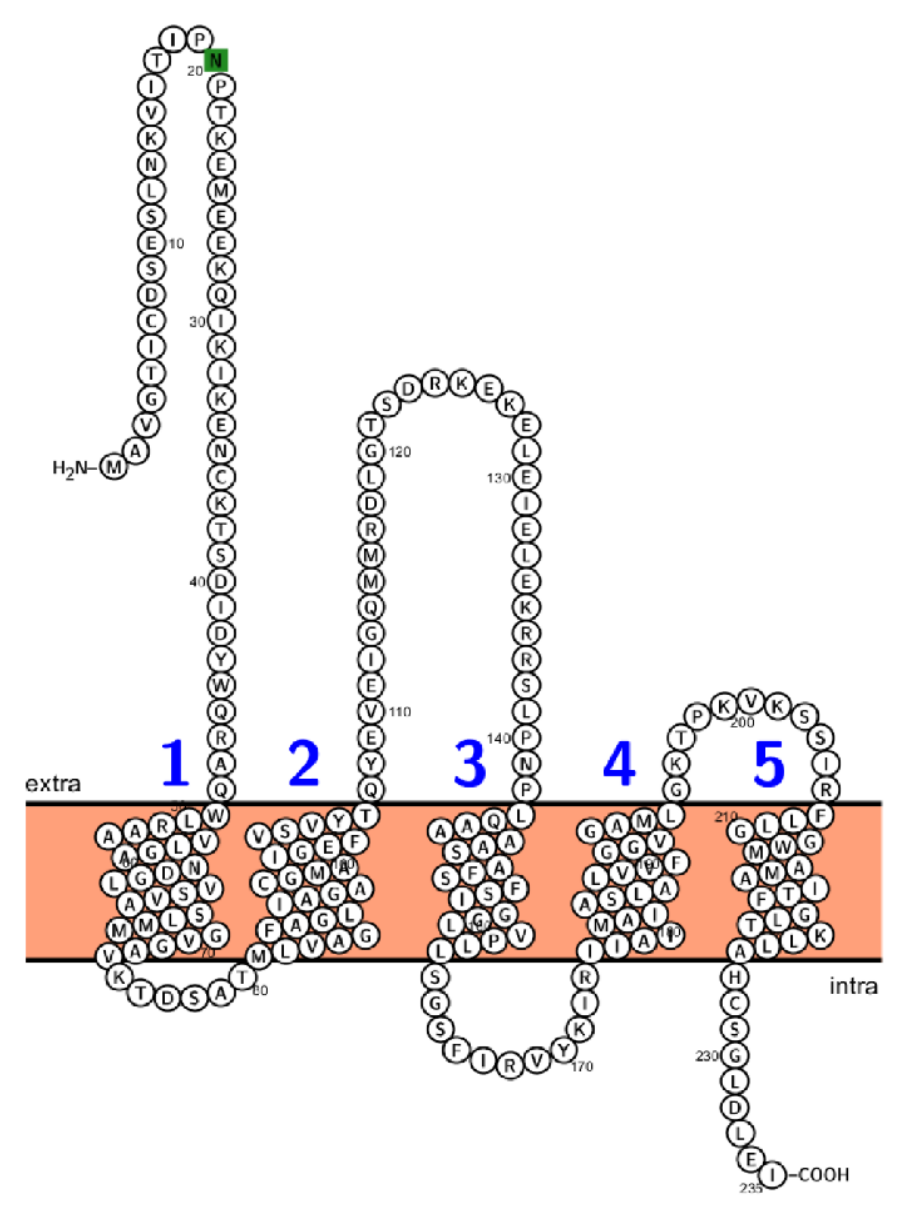

Figure 6.9. Membrane topology of MtSEN1. (A) Four predicted transmembrane helices are predicted by TMHMM. Both N- and C- terminus tails are predicted to intracellular. Figure generated using TMHMM v.2 (http://www.cbs.dtu.dk/services/TMHMM-2.0/). (B) Although TMHMM only predicts 4 transmembrane domains, Protter predicts five transmembrane domains from the protein sequence. The $\mathrm{N}$ terminus tail is predicted to be extracellular and the C-terminus tail is predicted to be intracellular. Model was created using the Protter website to predict the protein's secondary structure within the membrane (http://wlab.ethz.ch/protter; Omasits et al., 2014). 
MtSEN1 (Medtr4g094335.1) is closely related to Medtr2g008110.1, AtVITH2.1, AtVITH1, AtVITH2, AtVITH3, and AtVITH4 (Figure 6.10).

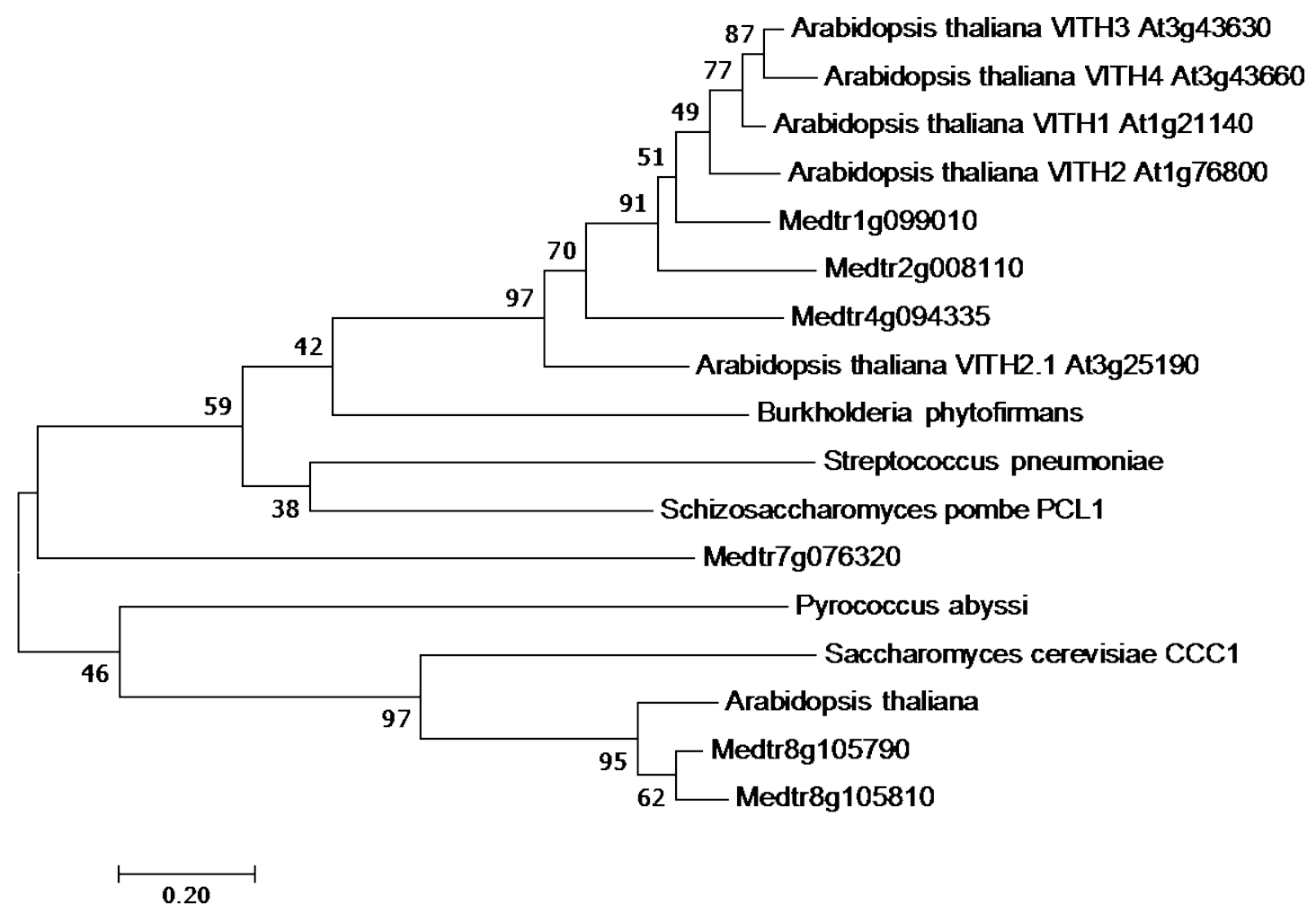

Figure 6.10. Molecular Phylogenetic analysis by Maximum Likelihood method of MtSEN1, Medicago truncatula family members and Arabidopsis and homologs constructed in MEGA7 (Felsenstein 1985; Kumar et al., 2016).

Mutant S. meliloti rhizobial strains were used to determine which nodule development events were necessary for gene expression. exoA is a rhizobial mutant that cannot infect the plant, bacA cannot differentiate bacteroids, and fixJ cannot fix nitrogen (Mitra and Long, 2004; Griffitts and Long, 2008). Infection by S. meliloti rhizobia is necessary for expression of MtSEN1, but bacterial differentiation and nitrogen fixation are not essential to expression (Figure 6.11A). Expression of MtSEN1 is seen after the 3-day post inoculation mark and expression is high from 10 dpi to 28 dpi (Figure 6.11B) indicating involvement in differentiating bacteria and nitrogen fixation. Overall, MtSEN1 is highly expressed early in nodule development with peak expression 
during rhizobial infection of cells suggesting function related to processes prior to supporting fully functional, nitrogen fixing bacteroids.
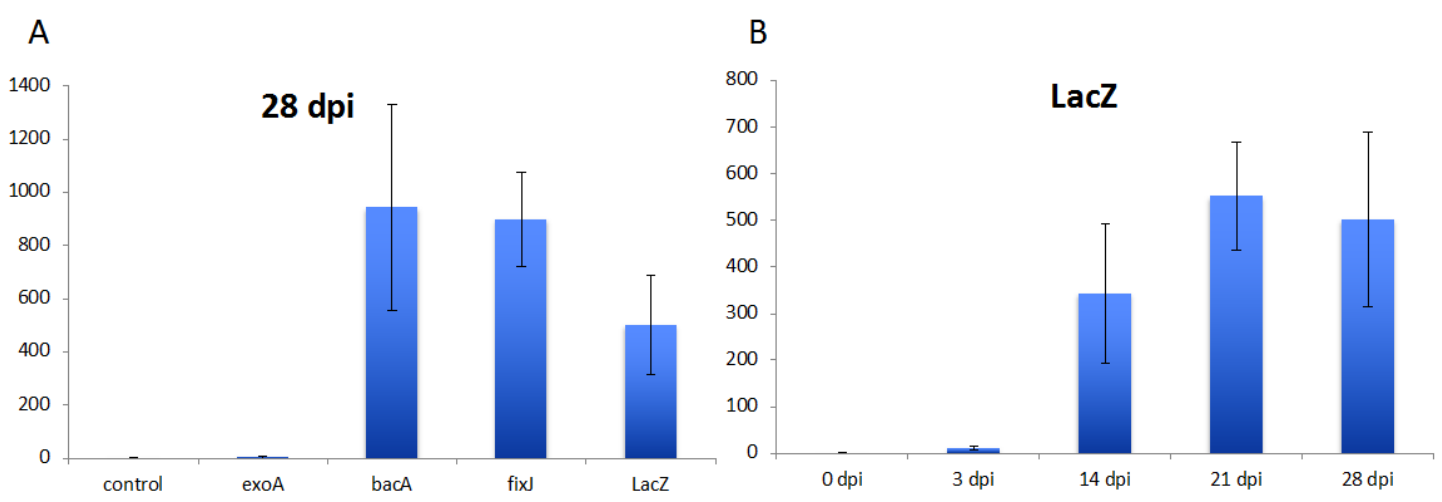

Figure 6.11. RT-qPCR of MtSEN1 in root systems of Medicago truncatula ecotype 'R108' inoculated with Sm1021 rhizobia. (A) MtSen1 expression at 28 dpi nodulating roots inoculated with rhizobial strains exoA, bacA, fixJ, or a functional strain containing LacZ. (B) Time-course of MtSEN1 expression in root systems inoculated with the functional rhizobial strain.

\section{CONCLUSION}

Together, MtOPT1 and MtSEN1 are putative nodule specific transporters predicted to have involvement in symbiotic nitrogen fixation through the transport of small oligopeptides ranging from three to eight amino acids in length, or glutathione or homoglutathione via MtOPT1 or iron via MtSEN1. Future studies to functionally characterize MtOPT1 and MtSEN1 would include transport affinity substrate assays, subcellular localization, and CRISPR experiments to determine knockout phenotype and potentially could reveal key players in symbiotic nitrogen fixation.

\section{MATERIALS AND METHODS}

Phyogenetic analysis and membrane topology predictions: The evolutionary history was inferred by using the Maximum Likelihood method based on the JTT matrix-based model (Jones et al., 1992). The tree with the highest log likelihood is shown. The percentage of trees in which the associated taxa clustered together is shown next to the branches. Initial tree(s) for the heuristic search were obtained automatically by applying the Maximum Parsimony method. The tree is drawn to scale, with branch lengths measured in the number of substitutions per site. The analysis involved 20 amino acid sequences. All positions containing gaps and missing data were eliminated. Evolutionary analyses were conducted in MEGA7 (Kumar et al., 2016). TMHMM (http://www.cbs.dtu.dk/services/TMHMM-2.0/; Möller et al., 2001) and Protter 
(wlab.ethz.ch/protter) were used to predict transmembrane domains with protein sequences as input.

Gene expression analyses: Gene expression analysis was assessed from the Affymetrix Medicago GeneChip microarray data deposited at the Samuel Roberts Noble Foundation Medicago truncatula Gene Expression Atlas (http://mtgea.noble.org/v3/; Benedito et al., 2008). Gene expression analyses of membrane transporters in rhizobial mutants was performed on R108 root systems inoculated with fixJ, bacA, exoA, or hemA::LacZ strains of Sinorhizorium meliloti in Sm1021 background. A control group was not inoculated with rhizobia and was provided full nitrogen fertilization. Plant roots were harvested at $0,3,14,21$, and 28 dpi. RNA was extracted with mirVana miRNA Isolation kit (Life Technologies) followed by DNA removal with Turbo DNA-free kit (Applied Biosystems). First strand complementary DNA was synthesized by priming with oligo-dT using the SuperScript III First-Strand Synthesis Super mix (Life Technologies) following the manual instructions. Primers used were: MtOPT1 forward: 5'ACCTGTTCCAGTGTGGCTTC, MtOPT1 reverse: 5'ACCTGCGGCGATAATAGG, MtSEN1 forward: 5' TTAGGAGCAGCATTGGTAAGG, MtSEN1 reverse: 5' CCAACCACCACTCTAACACAAGA. Three biological and three technical replicates were run. SYBR green master mix and $5 \mu \mathrm{L}$ reactions were used on Applied Biosystems 7500 Real Time PCR System and 7500 software. All templates were amplified using the same protocol: $50^{\circ} \mathrm{C}$ for 2 minutes; $95^{\circ} \mathrm{C}$ for 10 minutes; 40 cycles of $95^{\circ} \mathrm{C}$ for 15 seconds and $60^{\circ} \mathrm{C}$ for 1 minute. Melt curves were produced following the 40 cycles by heating to $95^{\circ} \mathrm{C}$ for 15 seconds followed by $60^{\circ} \mathrm{C}$ for 15 seconds and $95^{\circ} \mathrm{C}$ for 15 seconds. 7500 Software (Applied Biosystems) gave $\mathrm{C}_{\mathrm{T}}$ threshold cycle values. Excel was used to organize data and calculate geometric means of technical replications and calculate averages and standard errors. Technical outliers were eliminated from analysis.

The housekeeping genes chosen for this experiment were: EF1 $\alpha$ (Medtr6g021800), tubulin (Medtr7g089120), and MSC27 (X98618.1). NormFinder software (Andersen et al., 2004) was used to identify stably expressed housekeeping genes in the experiment and MSC27 was excluded from the calculations. 


\section{REFERENCES}

Andersen CL, Ledet-Jensen J, Ørntoft T (2004) Normalization of real-time quantitative RTPCR data: a model based variance estimation approach to identify genes suited for normalization - applied to bladder- and colon-cancer data-sets. Cancer Research 64: 5245-5250

Becana M, Matamoros MA, Udvardi M, Dalton DA (2010) Recent insights into antioxidant defenses of legume root nodules. New Phytologist 188: 960-976

Benedito VA, Li H, Dai X, Wandrey M, He J, Kaundal R, Torres-Jerez I, Gomez SK, Harrison MJ, Tang Y, et al (2010) Genomic inventory and transcriptional analysis of Medicago truncatula transporters. Plant Physiology 152: 1716-1730

Benedito VA, Torres-Jerez I, Murray JD, Andriankaja A, Allen S, Kakar K, Wandrey M, Verdier J, Zuber H, Ott T, et al (2008) A gene expression atlas of the model legume Medicago truncatula. Plant Journal 55: 504-513

Bock KW, Honys D, Ward JM, Padmanaban S, Nawrocki EP, Hirschi KD, Twell D, Sze H (2006) Integrating membrane transport with male gametophyte development and function through transcriptomics. Plant Physiology 140: 1151-1168

Bourbouloux A, Shahi P, Chakladar A, Delrot S, Bachhawat AK (2000) Hgt1p, a high affinity glutathione transporter from the yeast Saccharomyces cerevisiae. Journal of Biological Chemistry 275: 13259-13265

Cagnac O, Bourbouloux A, Chakrabarty D, Zhang MY, Delrot S (2004) AtOPT6 transports glutathione derivatives and is induced by primisulfuron. Plant Physiology 135: 1378-1387

Colville L, Sáez CMB, Lewis GP, Kranner I (2015) The distribution of glutathione and homoglutathione in leaf, root and seed tissue of 73 species across the three sub-families of the Leguminosae. Phytochemistry 115: 175-183

Connorton, JM, Jones, ER, Rodriguez-Ramiro I, Fairweather-Tait S, Uauy C, Balk J (2017) Vacuolar iron transporter TaVIT2 transports Fe and Mn and is effective for biofortification. Plant Physiology 174: 2434-2444

El Msehli S, Lambert A, Baldacci-Cresp F, Hopkins J, Boncompagni E, Smiti SA, Hérouart D, Frendo P (2011) Crucial role of (homo)glutathione in nitrogen fixation in Medicago truncatula nodules. New Phytologist 192: 496-506

Felsenstein J (1985) Confidence limits on phylogenies: An approach using the bootstrap. Evolution 39: 783-791

Frendo P, Harrison J, Norman C, et al (2005) Glutathione and homoglutathione play a critical role in the nodulation process of Medicago truncatula. Molecular Plant Microbe Interactions 18: 254-259 
Gomolplitinant KM, Saier MH (2011) Evolution of the oligopeptide transporter family. Journal of Membrane Biology 240: 89-110

Griffitts JS and Long SR (2008) A symbiotic mutant of Sinorhizobium meliloti reveals a novel genetic pathway involving succinoglycan biosynthetic functions. Molecular Microbiology 67: $1292-1230$

Grotz N, Guerinot ML (2006) Molecular aspects of $\mathrm{Cu}$, Fe and $\mathrm{Zn}$ homeostasis in plants. Biochim. Biophys. Acta Mol. Cell Res. 1763 595-608

Hakoyama T, Niimi K, Yamamoto T, Isobe S, Sato S, et al (2012) The integral membrane protein SEN1 is required for symbiotic nitrogen fixation in Lotus japonicus nodules. Plant Cell Physiology 53: 225-236

Hauser M, Donhardt AM, Barnes D, Naider F, Becker JM (2000) Enkephalins are transported by a novel eukaryotic peptide uptake system. Journal of Biological Chemistry 275: 3037-3041

He J, Benedito VA, Wang M, Murray JD, Zhao PX, Tang Y, Udvardi MK (2009) The Medicago truncatula gene expression atlas web server. BMC Bioinformatics 10: 441

Howe EA, Sinha R, Schlauch D, Quackenbush J (2011) RNA-Seq analysis in MeV. Bioinformatics 27: 3209-3210

Hu YT, Ming F, Chen WW, Yan JY, Xu ZY, Li GX, et al (2012) TcOPT3, a member of oligopeptide transporters from the hyperaccumulator Thlaspi caerulescens, is a novel $\mathrm{Fe} / \mathrm{Zn} / \mathrm{Cd} / \mathrm{Cu}$ transporter. PloS one 7: 38535

Jones DT, Taylor WR, and Thornton JM (1992) The rapid generation of mutation data matrices from protein sequences. Computer Applications in the Biosciences 8: 275-282

Kaiser BN, Gridley KL, Brady JN, Phillips T, Tyerman SD (2005) The role of molybdenum in agricultural plant production. Annals of Botany 96: 745-754

Kim SA, Punshon T, Lanzirotti A, Li L, Alonso JM, Ecker JR, Kaplan J, Guerinot ML (2006) Localization of iron in Arabidopsis seed requires the vacuolar membrane transporter VIT1. Science 314: 1295-1298

Koh S, Wiles AM, Sharp JS, Naider FR, Becker JM, Stacey G (2002) An oligopeptide transporter gene family in Arabidopsis. Plant Physiology 128: 21-29

Kumar S, Stecher G, Tamura K (2016) MEGA7: Molecular Evolutionary Genetics Analysis version 7.0 for bigger datasets. Molecular Biology and Evolution 33:1870-1874

Krogh A, Larsson B, von Heijne G, Sonnhammer ELL (2001) Prediction transmembrane protein topology with a hidden markov model: application to complete genomes. Journal of 
Molecular Biology 305: 567-580

Krusell L, Krause K, Ott T, Desbrosses G, Krämer U, Sato S, Nakamura Y, Tabata S, James EK, Sandal N, et al (2005) The sulfate transporter SST1 is crucial for symbiotic nitrogen fixation in Lotus japonicus root nodules. Plant Cell 17: 1625-1636

Lapinskas PJ, Lin SJ, Culotta VC (1996) The role of the Saccharomyces cerevisiae CCC1 gene in the homeostasis of manganese ions. Molecular Microbiology 21: 519-528

Li H, Benedito VA, Udvardi MK, Zhao PX (2009) TransportTP: A two-phase classification approach for membrane transporter prediction and characterization. BMC Bioinformatics 10: 418

Lubkowitz M (2006) The OPT family functions in long-distance peptide and metal transport in plants. Genetic Engineering 27: 35-55

Lubkowitz M (2011) The oligopeptide transporters: a small gene family with a diverse group of substrates and functions? Molecular Plant 4: 407-415

Macnicol PK (1987) Homoglutathione and glutathione synthetases of legume seedlings: partial purification and substrate specificity. Plant Science 53: 229-235

Mitra RM, Long SR (2004) Plant and bacterial symbiotic mutants define three transcriptionally distinct stages in the development of the Medicago truncatula/Sinorhizobium meliloti symbiosis. Plant Physiology 134: 595-604

Möller S, Croning MD, Apweiler R (2001) Evaluation of methods for the prediction of membrane spanning regions. Bioinformatics 17: 646-653

Omasits U, Ahrens CH, Muller S, Wollscheid B (2014) Protter: interactive protein feature visualization and integration with experimental proteomic data. Bioinformatics 30: 884-886

Pasternak T, Asard H, Potters G, Jansen MAK (2014) The thiol compounds glutathione and homoglutathione differentially affect cell development in alfalfa (Medicago sativa L.). Plant Physiology and Biochemistry 74: 16-23

Roux B, Rodde N, Jardinaud MF, Timmers T, Sauviac L, Cottret L, Carrère S, Sallet E, Courcelle E, Moreau S, Debellé F, Capela D, de Carvalho-Niebel F, Gouzy J, Bruand C, Gamas P (2014), An integrated analysis of plant and bacterial gene expression in symbiotic root nodules using laser-capture microdissection coupled to RNA sequencing. Plant Journal 77: 817837

Roschzttardtz H, Conéjéro G, Curie C, Mari S (2009) Identification of the endodermal vacuole as the iron storage compartment in the Arabidopsis embryo. Plant Physiology 151: 1329-1338 
Seefeldt LC (1994) Docking of nitrogenase iron- and molybdenum-iron proteins for electron transfer and MgATP hydrolysis: the role of arginine 140 and lysine 143 of the Azotobacter vinelandii iron protein. Protein Science 3: 2073-2081

Seefeldt LC, Hoffman BM, Dean DR (2009) Mechanism of Mo-dependent nitrogenase. Annual Review of Biochemistry 78:701-722

Sonnhammer ELL, von Heijne G, and Krogh A (1998) A hidden Markov model for predicting transmembrane helices in protein sequences. In J. Glasgow, T. Littlejohn, F. Major, R. Lathrop, D. Sankoff, and C. Sensen, editors, Proceedings of the Sixth International Conference on Intelligent Systems for Molecular Biology 175-182

Stacey G, Koh S, Granger C, Becker JM (2002) Peptide transport in plants. Trends in Plant Science 7:257-263

TCDB.org Transporter Classification Database. 2005-2012. Saier Lab Group.

$<$ http://tcdb.org $>$.

Thakur A, Kaur J, Bachhawat AK (2008) Pgt1, a glutathione transporter from the fission yeast Schizosaccharomyces pombe. FEMS Yeast Research 8: 916-929

Young ND, Debellé F, Oldroyd GED, Geurts R, Cannon SB, Udvardi MK, Benedito VA, Mayer KFX, Gouzy J, Schoof H, et al (2011) The Medicago genome provides insight into the evolution of rhizobial symbioses. Nature 480: 520-524 


\section{Chapter 7}

\section{GENERAL CONCLUSIONS}

Membrane transporters are essential to move substrates between organelles within cells and from cell to cell within plants. As reviewed in Chapter 2, membrane transporters support symbiotic nitrogen fixation during the relationship between plants and rhizobia which introduces another level of nutritional flux not seen in plants unable to form a symbiosis. Although there are more than 2,000 putative membrane transporters in the Medicago truncatula genome, relatively few have been characterized, and the genetic identity of transporters central to the nitrogen fixation process have not fully been elucidated. An analysis to identify putative functional transporters of the APC superfamily of transporters in Medicago truncatula playing roles in the symbiotic nitrogen fixation process is presented (Chapter 3). This research also aimed to functionally characterize transporters involved in amino acid and copper transport during symbiotic nitrogen fixation (Chapters 4 and 5). We examined nodule specific transporters to define substrates, examine knockdown expression, and delineate patterns of expression.

In Chapter 3, I classified APC superfamily members through manual curation of confidence levels for expected transporter functionality by comparing to functionally characterized family members within the Transporter Classification Database, Swiss-Prot annotation, Gene Ontology, and expected Pfam domains. Additionally, for APC superfamily members, I compiled information relating to gene expression in plant organs as well as in nodule zones leading to the identification of candidate gene coding for amino acid transporters within nodules supporting symbiotic nitrogen fixation.

In Chapter 4, I set out to functionally characterize MtAPC1 (Medtr8g089360.1). In silico analysis expression patterns were analyzed to begin analysis of the gene. In situ analysis showed expression in infected cells in the nitrogen fixation zone. Yeast import assays were performed to test affinity to 16 amino acids and it was concluded that Mt APC1 was not an importer as previously thought. Real time analysis of RNAi showed reduced expression of MtAPC1 expression with no visible phenotype, potentially due to gene redundancy.

In Chapter 5, MtCOPT1 (Medtr4g019870.1) was functionally characterized through in silico analysis to determine expression patterns of the gene. RT-qPCR analysis in our lab confirmed expression patterns with highest expression at 10 days post inoculation consistent with 
involvement in nitrogen fixation. Protein modifications, by phosphorylation of serine and threonine residues in the C-terminus were identified, but the potential functional effects of such modifications remain to be determined. Yeast import assays of MtCOPT1 showed affinity to copper.

In Chapter 6, I preliminarily analyzed two nodule specific transporters, MtOPT1 (Medtr7g092230.1) and MtSEN1 (Medtr4g094335.1), to evaluate potential function in relation to symbiotic nitrogen fixation. In silico analysis revealed early expression at 4 days post inoculation with expression seen in the invasion zone and sustained through the nitrogen fixation zone for MtOPT1 and expression in the infection zone and also sustained through the nitrogen fixation zone in MtSEN1 (Medtr4g094335.1) suggesting roles during symbiotic nitrogen fixation. These results will foster future research to identify the exact roles they play in nodule development and the symbiosis.

In summary, this dissertation contributes to the identification and classification of putative APC Superfamily membrane transporters. It provides insights and gives direction for membrane transporters that would be of interest to further study for functional characterization. In addition, this dissertation contributed to functional characterization of nodule specific membrane transporters of amino acids and copper, with the identification of nodule-specific putative transporters with potential affinities to iron and oligopeptides. 
